Florida International University FIU Digital Commons

1994

\title{
Vent alignments in San Francisco volcanic field, Arizona : statistical analysis and assessment of structural controls
}

Zhuoning Chen

Florida International University

DOI: $10.25148 /$ etd.FI14060186

Follow this and additional works at: https://digitalcommons.fiu.edu/etd

Part of the Geology Commons

\section{Recommended Citation}

Chen, Zhuoning, "Vent alignments in San Francisco volcanic field, Arizona : statistical analysis and assessment of structural controls" (1994). FIU Electronic Theses and Dissertations. 2154.

https://digitalcommons.fiu.edu/etd/2154

This work is brought to you for free and open access by the University Graduate School at FIU Digital Commons. It has been accepted for inclusion in FIU Electronic Theses and Dissertations by an authorized administrator of FIU Digital Commons. For more information, please contact dcc@fiu.edu. 


\section{FLORIDA INTERNATIONAL UNIVERSITY \\ Miami, Florida}

VENT ALIGNMENTS IN SAN FRANCISCO VOLCANIC FIELD, ARIZONA: STATISTICAL ANALYSIS AND ASSESSMENT OF STRUCTURAL CONTROLS

A thesis submitted in partial satisfaction of the requirements for the degree of

MASTER OF SCIENCE

IN

GEOLOGY

by

Zhuoning Chen

1994 
To: Arthur W. Herriott

College of Arts and Sciences

This thesis, written by Zhuoning Chen, and entitled Vent Alignments In San Francisco Volcanic Field, Arizona: Statistical Analysis And Assessment Of Structural Controls, having been approved in respect to style and intellectual content, is referred to you for judgement.

We have read this thesis and recommend that it be approved.

Charles Connor

Dean Whitman

Neptune Srimal

Grenville Draper, Major Professor

Date of Defense: February 24, 1994

The thesis of Zhuoning Chen is approved.

Dean Arthur W. Herriott

College of Arts and Sciences

Dr. Richard L. Campbell

Dean of Graduate Studies

Florida International University, 1994 


\section{ACKNOWLEDGMENTS}

I would like to acknowledge Dr. Grenville Draper and Dr. Charles Connor for their inspiring guidance and valuable suggestions during the preparation of this thesis work, without their expertise and comments I would never have completed this work.

I wish also to thank my thesis committee member Dr. Dean Whitman and Dr. Neptune Srimal for their many helpful suggestions in the preparation of this text.

Finally, I would like to thank to everybody in the Geology Department for their assistance in the past two years. 


\section{ABSTRACT OF THE THESIS \\ VENT ALIGNMENTS IN SAN FRANCISCO VOLCANIC FIELD, ARIZONA: STATISTICAL ANALYSIS AND ASSESSMENT OF STRUCTURAL CONTROLS \\ by \\ Zhuoning Chen \\ Florida International University, 1994 \\ Miami, Florida \\ Dr. Grenville Draper, Major Professor}

Using cluster analysis, a total of 605 vents in San Francisco Volcanic Field are studied over an area of approximately $5000 \mathrm{~km}^{2}$. Application of alignment analysis techniques, including the twopoint azimuth analysis and Hough transform analysis, demonstrates that cinder cones are aligned along common orientations within larger clusters. These alignments consist of 9-10 cinder cones, are 20-38 km long, and are regional features. The vent alignments indicate the presence of geological features along which magma ascended more readily than elsewhere. The NE-trending Mesa Butte and Oak Creek Canyon-Doney fault systems seem to control the intermediate to silicic centers which are on the intersection of these fault systems with Cataract Creek fault system and affect the development of cinder cone alignments. Geological maps and geophysical surveys indicate that most vent alignments are parallel or subparallel to these large scale fault systems. This suggests that vent alignment patterns are controlled by regional structures. 


\section{TABLE OF CONTENTS}

PAGE

\section{ABSTRACT}

CHAPTER ONE. INTRODUCTION.................................................................

Distribution Of Volcanic Centers In Cinder Cone Fields........................1 Investigation Of Vent Distribution In The San Francisco Volcanic

Field (SFVF).

CHAPTER TWO. CHARACTERISTICS AND GEOLOGIC SETTING

IN SAN FRANCISCO VOLCANIC FIELD......................................................14

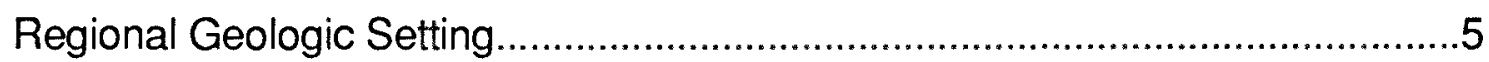

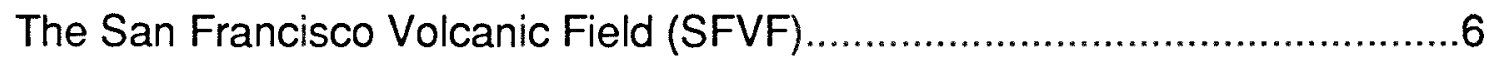

Regional Geology And Fault Systems.......................................................11

CHAPTER THREE. STATISTICAL ANALYSIS OF CINDER CONE

DISTRIBUTION AND ALIGNMENTS IN SFVF.......................................15-40

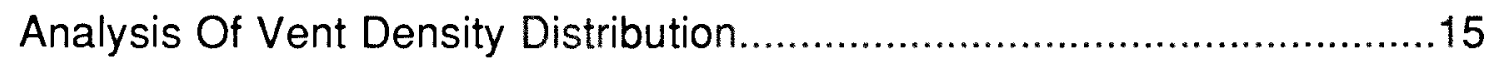

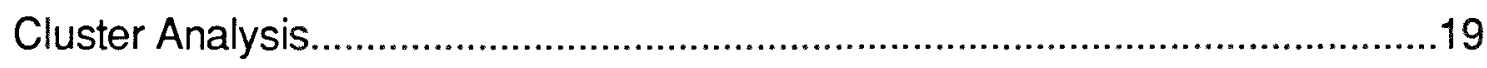

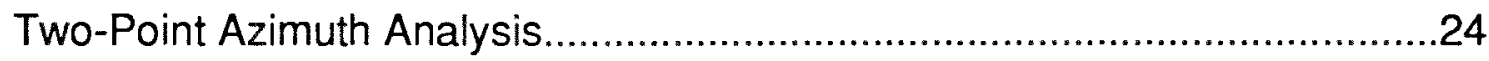

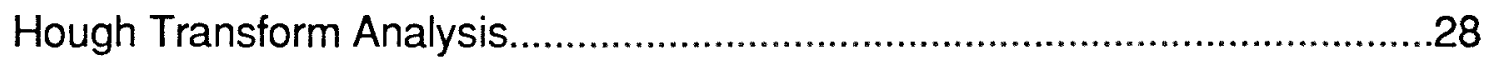

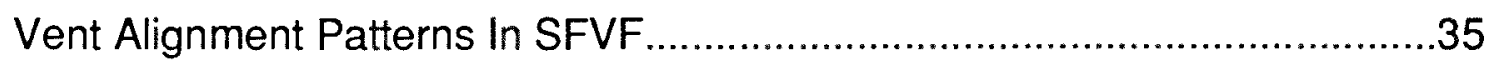

CHAPTER FOUR. PRELIMINARY GEOPHYSICAL STUDIES ........................41-62

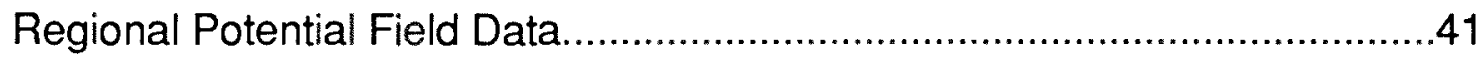

Spider Web Ranch Geophysical Surveys.....................................................48

CHAPTER FIVE. DISCUSSION AND CONCLUSION....................................63-71

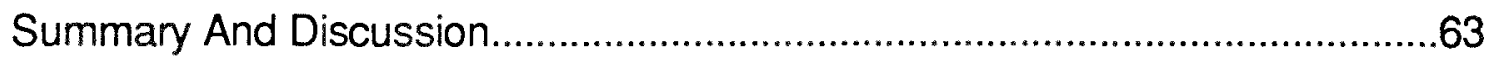


Magma Emplacement In The San Francisco Volcanic Field................66

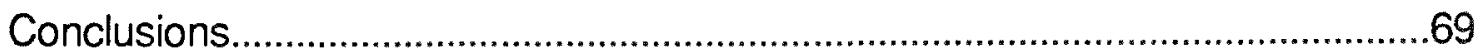

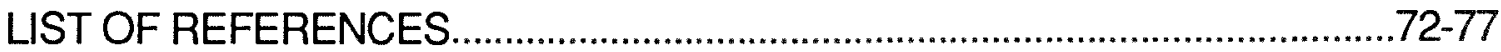

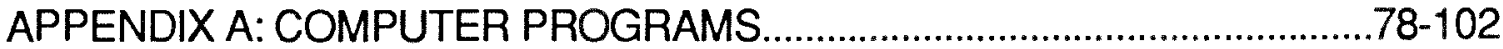

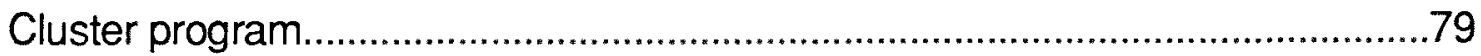

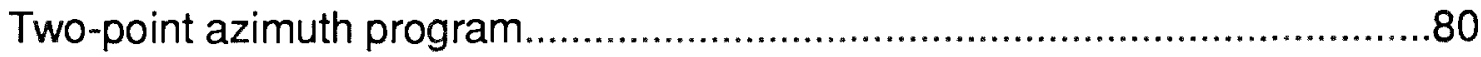

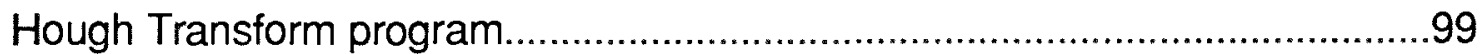

APPENDIX B: GEOPHYSICAL SURVEY DATA ..................................103-131

The formula for the reduction to the Bouguer anomaly...................104

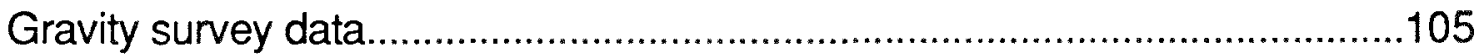

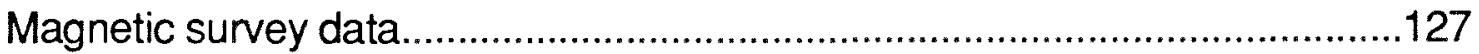




\section{LIST OF FIGURES AND TABLES}

\section{Page}

Fig. 2.1: Location of San Francisco volcanic field.....................................

Fig. 2.2: Map of the location of all 605 vents in SFVF............................

Fig. 2.3: San Francisco Volcanic Field, Arizona.........................................10

Fig. 2.4: Principal structural features in the field.................................13

Fig. 3.1: Map of density distribution of cinder cones (grid spacing

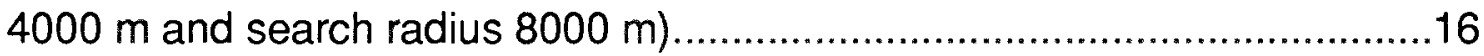

Fig. 3.2: Map of density distribution of cinder cones (grid spacing $2000 \mathrm{~m}$ and search radius $4000 \mathrm{~m}$ ). 18

Fig. 3.3: Map of the change in the number of vent clusters with changing search radius(interval $250 \mathrm{~m}$ )

Fig. 3.4: Vents plotted by cluster memberships (search radius $7000 \mathrm{~m}$ ) using uniform kernel density fusion cluster analysis .23

Fig. 3.5: The diagram of intersegment azimuths and the azimuthal distribution of two-point azimuth method 26

Fig. 3.6: Two-point azimuth analysis shows preferred azimuthal direction for cluster 3 .

Fig. 3.7: Hough transform method illustrate for three nearly collinear points. 30

Fig. 3.8: Hough transform alignments on cluster 3

Fig. 3.9: Hough transform alignments on cluster $3 \ldots \ldots \ldots \ldots \ldots \ldots \ldots \ldots \ldots \ldots \ldots \ldots . . .33$

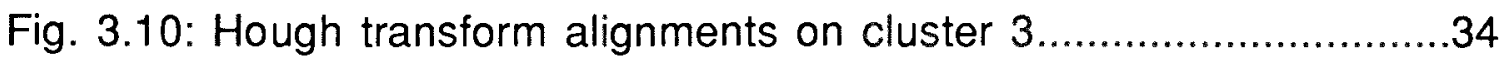

Fig. 3.11: Vent alignment patterns in SFVF(search radius $7000 \mathrm{~m}$ )..36 
Fig. 3.12: Vent alignment patterns in SFVF(search radius $6500 \mathrm{~m}$ )..38

Fig. 4.1: Gravity residual anomalies in SFVF.

Fig. 4.2: Aeromagnetic residual anomalies in SFVF. 44

Fig. 4.3: Map of directionally filtered gravity anomalies......................46

Fig. 4.4: Geological map of Spider Web Ranch area.................................49

Fig. 4.5: Bouguer anomaly of gravity survey profiles

(Line \#10000, Line \#4000, Line \#3000, and Line \#5000).................51

Fig. 4.5 (continued): Bouguer anomaly of gravity survey profiles

(Line \#7000 and Line \#2000). .52

Fig. 4.5 (continued): Bouguer anomaly of gravity survey profiles (Line \#1000 and Line \#9000). 53

Fig. 4.6: Plane map of gravity anomalies and geological features......55

Fig. 4.7: Scatter plot of Free air anomalies and elevation.....................56

Fig. 4.8: The anomaly of magnetic profiles (Line \#10000,

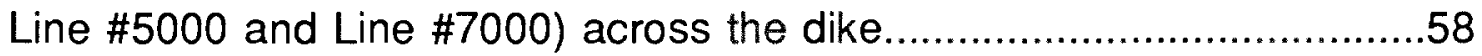

Fig. 4.9: The magnetic anomaly of Line $\# 10000$ in expanded scale....59

Fig. 4.10: Bouguer anomaly of gravity survey profiles

(Line \#8000 and Line \#6000) near vent 6811A. 61

Fig. 4.11: The anomaly of magnetic profiles (Line \#8000 and

Line \#6000) near vent 6811A..... .62

Fig. 5.1: Structural features in the SFVF. .67

Fig. 5.2: Neotectonic stress orientations in the Arizona.......................70

Table. 3.1: Stable clusters over range of search radius........................24

Table. 3.2: Summary of the alignment analysis.........................................37 


\section{CHAPTER ONE}

\section{INTRODUCTION}

\section{DISTRIBUTION OF VOLCANIC CENTERS IN CINDER CONE FIELDS}

Although cinder cone fields are a common volcanic feature, the reasons why they form, instead of a single large shield volcano, remains a controversial topic. There are two main hypotheses that explain the origin of cinder cone fields.

The first hypothesis suggests that cinder cone fields form because the areas in question have a relatively low magma supply rate (Fedotov, 1981; Hasenake and Carmichael, 1985). In this situation, it is claimed that magma conduits in the crust are not maintained and individual magma batches ascend along varied pathways to the surface, rather than in a single conduit. With decreasing magma supply rate, large shield volcanoes become intermediate size centers and then "areally" distributed small volcanic centers (Fedotov, 1981).

On the other hand, many authors think that the areally distributed volcanism of cinder cones fields may be the result of structural discontinuities of the crust, and that magma emplacement is controlled by pre-existing fractures and faults (Nakamura, 1977; Nakamura et al., 1979; Thompson and Zoback, 1979). Close association between regional structural features and vent alignments have been suggested for many 
cinder cone fields within the Basin and Range Province and the Colorado Plateau (Kear, 1964; Settle, 1979; Delaney et al., 1986; Connor et al., 1992). In these regions, vents are apparently aligned along, or parallel to, fault trends. While the mechanics of the phenomena remains unknown, this behavior suggests that shallow crustal structural features are an important factor in the genesis of cinder cone fields.

In this study, statistical analysis of vent alignments and geophysical studies are employed to evaluate the importance of crustal structures in controlling the location of vents in the San Francisco Volcanic Field of northern Arizona. The SEVF was chosen because of the relatively simple structure of underlying geological substrate - a thick sequence of flat lying Paleozoic and Mezozoic rocks which overlie Pre-Cambrian metamorphic rocks.

\section{INVESTIGATION OF VENT DISTRIBUTION IN THE SAN FRANCISCO VOLCANIC FIELD}

Volcanism in the SFVF appears to be spatially associated with several major fault systems, but the dense vent distribution makes the recognition of specific alignments a difficult task.

This investigation explores some major problems in the SFVE, which include:

(1). How are cinder cone alignments formed? 
(2). What percentage of the cones are part of the alignments?

(3). How long are these alignments?

(4). What is the role of major fault systems in forming the alignments? and

(5). What is the precise relation between surface expressions of regional structures and vent alignments?

To answer these questions, and give insights into the relationship between regional structures and vent alignment, several statistical methods have been employed: cluster analysis, two-point azimuth analysis and Hough Transform analysis.

As in other cinder cone fields, volcanic centers in the SFVF, show a tendency to cluster (Carr, 1976; Heming, 1980; Walker, 1981; Connor et al., 1989). Using this analysis, it is possible to identify and map clusters in the distribution of cinder cones in the SFVF. Such maps provide quantitative information about the cinder cone distribution and may provide information on the processes governing magma ascent beneath the volcanic field.

Within the identified clusters, statistical analyses are used to classify vent alignments on the basis of their length, number of vents, orientation and their statistical significance. The results of this statistical analysis of vent distribution (Chapter 3) are compared to structural data and geophysical data collected in the field (Chapter 4). In 
addition, geological, gravity and magnetic data are used to delineate specific structures associated with individual vents. Finally, the significance of the volcanic alignments and possible mechanisms of cinder cone emplacement within the field are discussed. 


\section{CHAPTER TWO}

\section{CHARACTERISTICS AND GEOLOGIC SETTING \\ IN SAN FRANCISCO VOLCANIC FIELD}

\section{REGIONAL GEOLOGICAL SETTING}

The Colorado Plateau is a broadly elevated region in the southern part of the Western Interior of the United states that has exceptional exposures of upper Paleozoic, Mesozoic, and Cenozoic rocks. The quality of exposures is a result of regional uplift in the middle and late Tertiary (Peterson et al., 1989) that caused rapid erosion and subsequent deep canyon incision in a semi-arid to arid climate. The structure of the plateau consists of broad basins, uplifts, and platforms locally bordered by monoclines. Although elevated in Tertiary time, the plateau region was a distinct crustal block by the beginning of Mesozoic time (Raisz, 1939). Upper Paleozoic to Cenozoic strata contain a record of marine and continental deposition complicated in varying degrees by the interplay between sea-level changes and tectonism, both within the plateau region and in bordering regions (Peterson et al., 1989).

Cinder cone volcanism was widespread in the southern part of the Colorado Plateau physiographic province during the late Tertiary and throughout much of the Quaternary (Wolfe et al., 1983). Almost all of this volcanism was 
concentrated within seven volcanic fields located near the margins of the plateau (Fig. 2.1).

Geophysical models of the Colorado Plateau/Basin and Range transition show a significant decrease in depth to the mantle from approximately $40 \mathrm{~km}$ in the interior of the plateau to $22 \mathrm{~km}$ in the Basin and Range (Brumbaugh, 1987). The Mogollon Rim forms the physiographic boundary between the Colorado Plateau and the Transition zone (the zone between the Colorado Plateau and the Basin and Range).

\section{THE SAN FRANCISCO VOLCANIC FIELD}

The San Francisco volcanic field is located in northcentral Arizona (Fig. 2.1), just north of the Transition Zone and the Mogollon Rim. It is one of several (dominantly basaltic) volcanic fields of Late Cenozoic age situated near the southern Colorado plateau (Tanaka et al., 1986). The field extends $120 \mathrm{~km}$ east-west and about $80 \mathrm{~km}$ north-south and consists of 605 vents distributed over an area of approximately $5000 \mathrm{~km}^{2}$ (Fig. 2.2). Vents are predominantly basaltic cinder cones of Plio-Quaternary age. Three hundred and forty two of these vents are between 0.75-5 million years old, 263 vents are less than 750,000 years old and about 20 of these vents are less than 40,000 years old (Tanaka et al., 1986). Nearly all of the area has been mapped by the U.S. Geological survey at a scale of 1:50,000 (Moore et al., 1987) . 


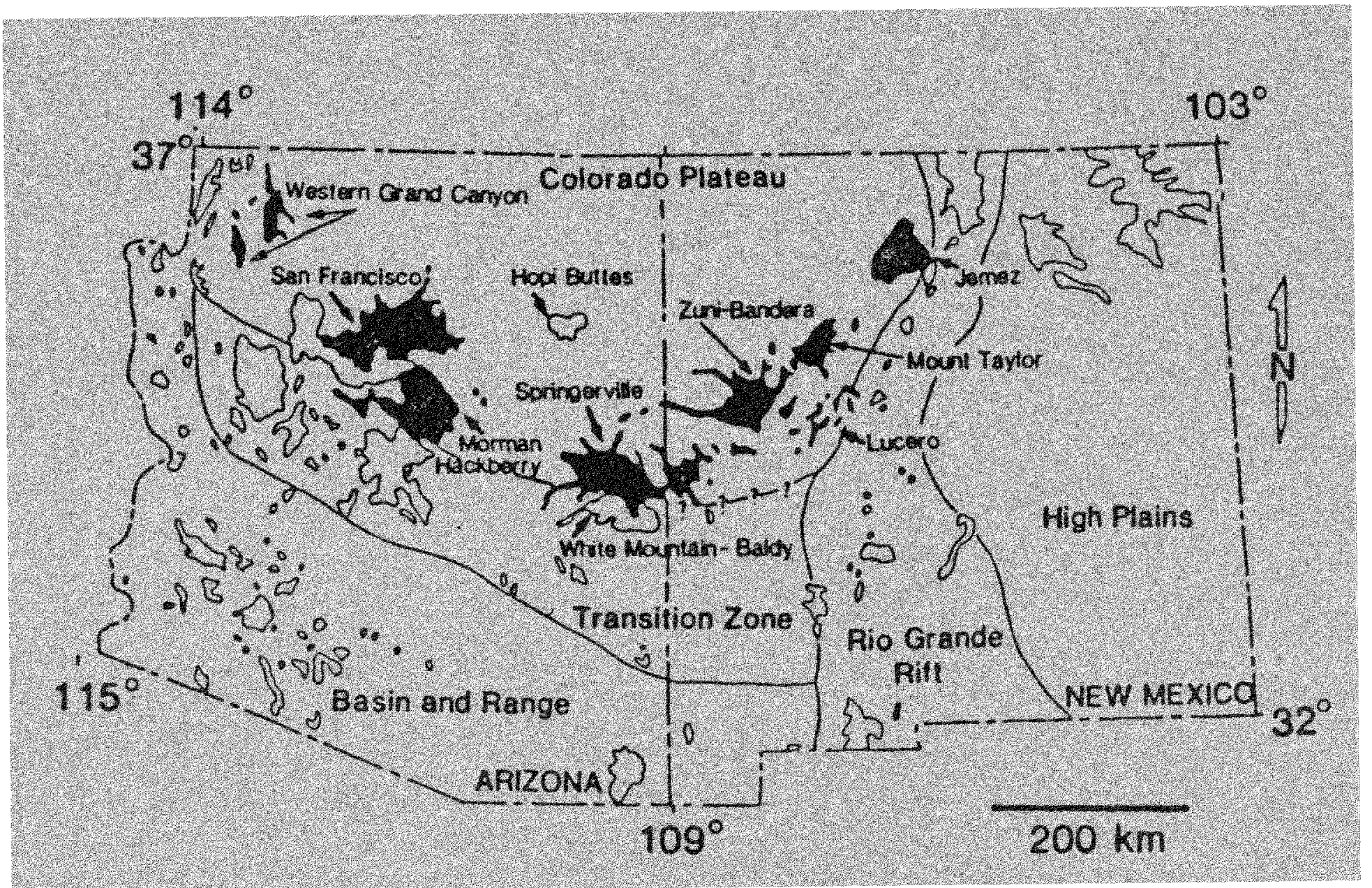

Fig. 2.1: Location of late Cenozoic basaltic volcanic fields in the Colorado Plateau and Transition Zone region. Shaded areas indicate volcanic fields less than 5 million years old and outlined areas show volcanic fields 5 to 16 million years old (from Wolfe et al., 1983). 


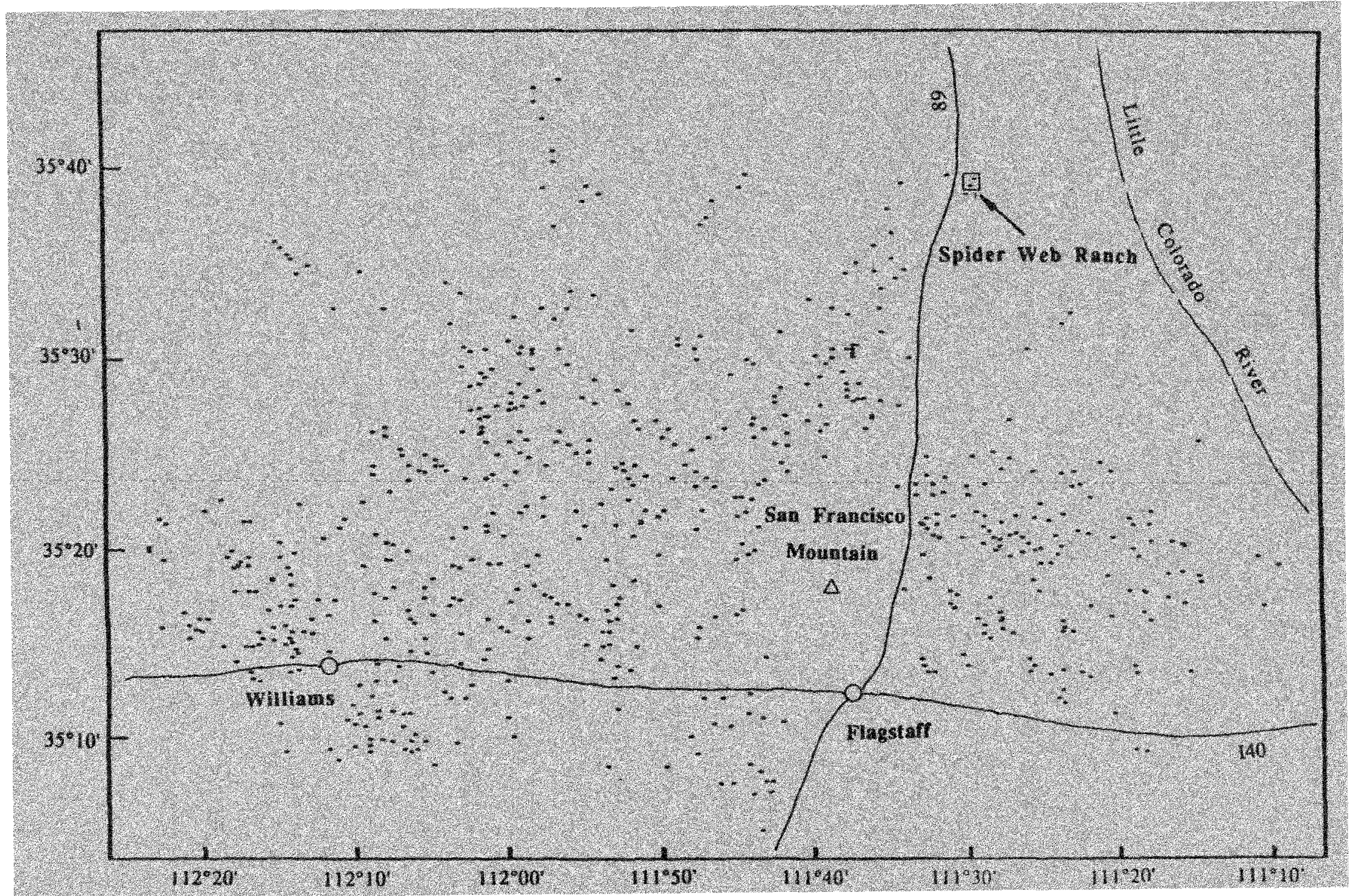

Fig. 2.2: Map of the location of all 605 vents in the San Francisco Volcanic Field. Asterisk represents the location of cinder cone vents (from Wolfe and others, 1987). 
The SEVF rests on Miocene volcanic rocks and erosional surfaces of low relief on permian and Triassic sedimentary rocks (Wolfe and others, 1983). In contrast to other volcanic fields along the margin of the Colorado plateau, such as the Springerville Volcanic Field (Fig. 2.1; Condit et al., 1989; Ulrich et al., 1989), large silicic centers are present in the SFVE (Wolfe et al., 1987a,b). Post-Miocene basaltic volcanism was broadly contemporaneous with the silicic and intermediate volcanism that formed Bill Williams Mountain, Sitgreaves Mountain, Kendrick Peak, San Erancisco Mountain, O'Leary Peak and several isolated domes (Fig. 2.3; Tanaka et al., 1986).

The San Erancisco Volcanic Field contains rocks which range from basalt to rhyolite in composition. All have erupted through Precambrian basement rocks and approximately one kilometer of overlying, nearly horizontal paleozoic and Mesozoic sedimentary rocks (Wolfe et al., 1987). About 500 $\mathrm{km}^{3}$ volcanic rocks cover the $5000 \mathrm{~km}^{2}$ of Paleozoic and Mesozoic rocks of the Colorado Plateau in Northern Arizona (Wolfe et al., 1987). Flows of basalt, basaltic andesite and a lesser amount of andesite, benmoreite and dacite were extruded from numerous individual vents, each of which erupted briefly and then became inactive (Wolfe et al., 1987). Such vents are widely distributed and their flows cover much of the area. 


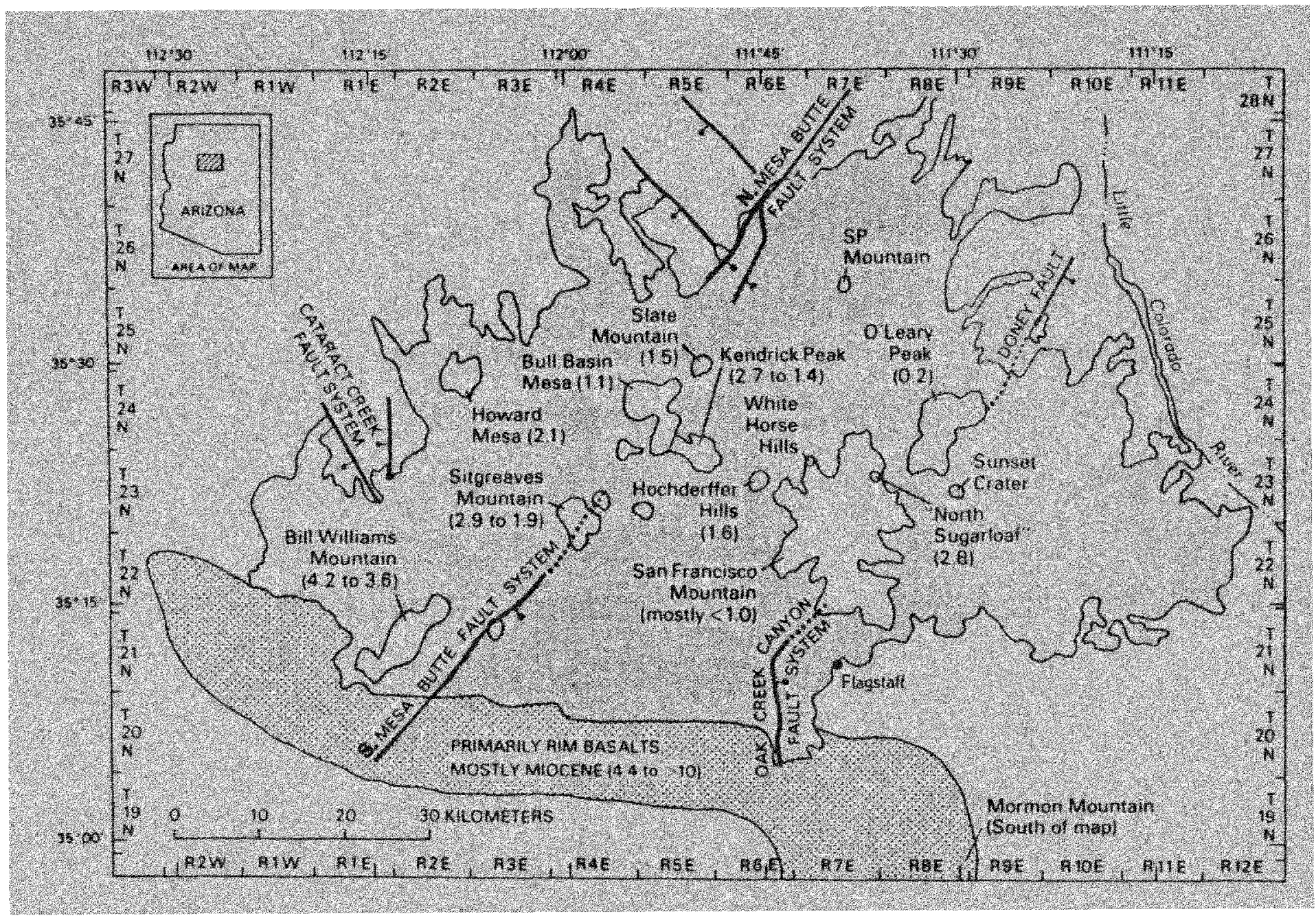

Fig. 2.3: San Francisco Volcanic Field, Arizona(after Tanaka and others, 1986). Gray pattern, Pliocene and Pleistocene volcanic rocks; silicic centers within volcanic field are white. Numbers in parentheses indicate ages in millions of years. Faults dotted where concealed; bar and ball on downthrown side. 
Previous investigators, (eg. Tanaka et al., 1986) identified a regional, west-to-east migration of volcanism in the field, and suggested that this was a result of the westward movement of the North American Plate relative to a sub-lithospheric mantle magma source. The $\mathrm{K}$-Ar ages of the silicic centers in the field also suggest a northeastward, Pre-Matayama migration of volcanism, parallel to the Mesa Butte fault.

\section{REGIONAL GEOLOGY AND FAULT SYSTEMS}

Regional studies in the Flagstaff - Grand Canyon region (Ulrich et al., 1994; Breed et al., 1986), indicate that the study area is underlain by more than $1100 \mathrm{~m}$ (3500 ft) of essentially flat lying Paleozoic to Lower Mesozoic sedimentary rocks, which unconformably overlay tilted PreCambrian sedimentary and metamorphic rocks. In the study area itself, the only units that crop out are the Lower Permian Kaibab Formation which is unconformably overlain by the lower to ?middle Triassic Moenkopi Formation. The Kaibab Formation consists of yellowish gray dolomitic limestones, sandstones and siltstones. The Moenkopi Formation on the other hand consists of red-brown colored mudstones, siltstones and sandstones.

Several regional fault systems cut the Paleozoicl Mesozoic sedimentary rock sequence and locally affect volcanic rocks of the San Francisco volcanic field as well. 
The Mesa-Butte, Oak Creek Canyon and Doney fault systems (Eigs. 2.3 and 2.4) are the most prominent of these and have experienced normal slip in the Quaternary (Condit, 1978; Shoemaker et al., 1978).

The Mesa Butte fault system is a major structural feature trending northeast across the area. It is partly covered by volcanic rocks and entirely buried in the central part (Fig. 2.3). Several large silicic volcanic centers, including Bill Williams, Sitgreaves and Kendrick Peaks, are situated on or near the Mesa Butte system.

The faults recognized in the system can be grouped into a northeastern segment and a southwestern segment. The Mesa Butte fault is the principal member of the northeastern segment of the fault system and can be recognized at the surface for a distance of about $15 \mathrm{~km}$. The maximum observed displacement in this segment is about $100 \mathrm{~m}$ (Shoemaker et al., 1978). A branch fault, the Cedar Ranch fault (Fig. 2.4), joins the Mesa-Butte fault near Mesa Butte and can be traced southwestward about $15 \mathrm{~km}$ where it disappears beneath younger lavas. Faults belonging to the southwestern segment of the Mesa Butte fault system can be traced for $16 \mathrm{~km}$ and the maximum displacement of the exposed rocks is about $150 \mathrm{~m}$ (Shoemaker et al., 1978). The fault disappears to the northeast beneath a field of Pleistocene age lava flows.

In the eastern part of the field, the oak Creek Canyon system extends north from Oak creek Canyon through Elagstaff 


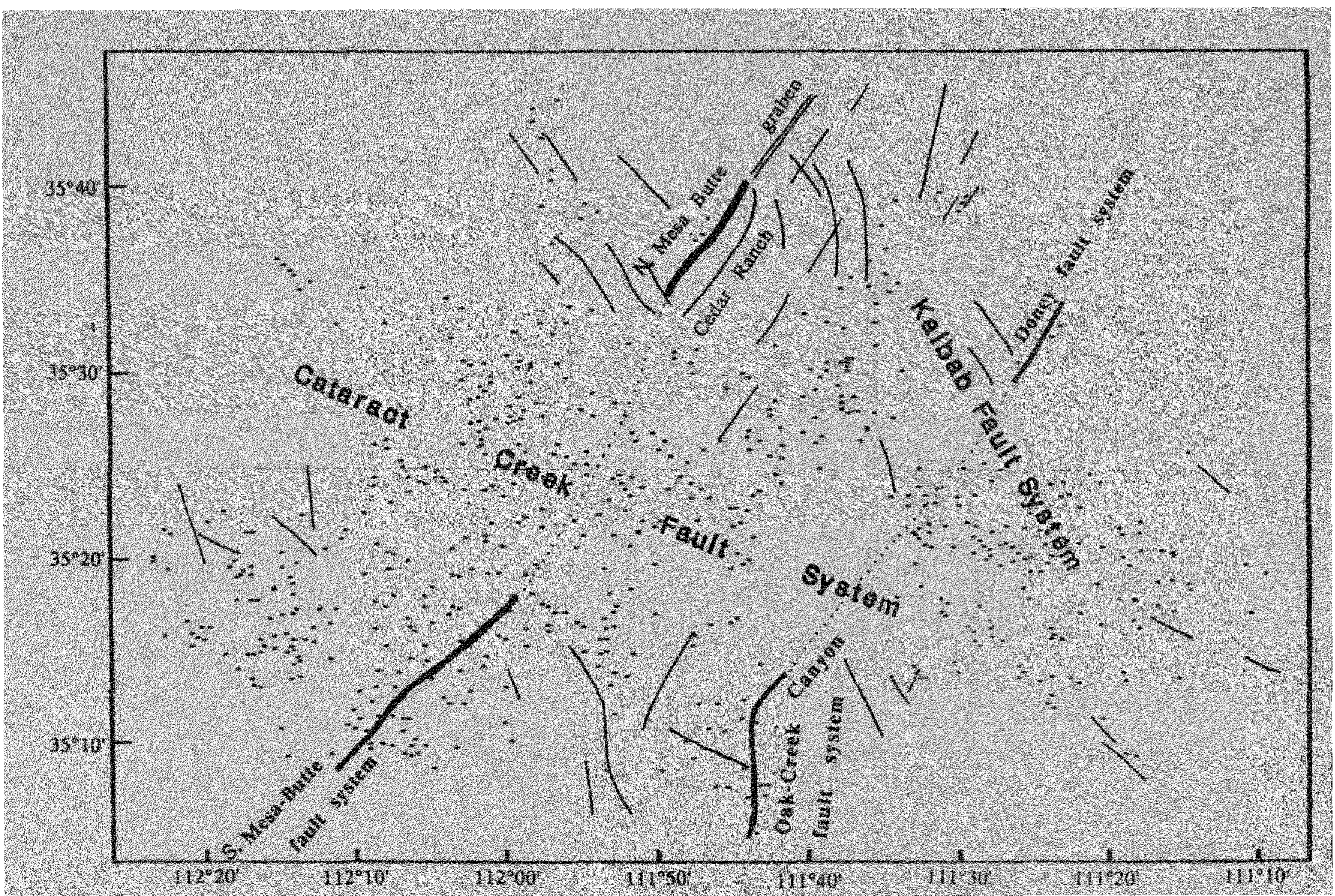

Fig. 2.4: Principal structural features (Wolfe et al., 1987) in the SFVF. Thick lines are major fault systems and thin lines are other faults. (asterisk represents the location of cinder cone vents) 
(Fig. 2.4), dips east at a high angle and displays down-tothe-east displacement (Ulrich et al., 1984). To the north of Flagstaff, the Oak Creek Canyon fault system is concealed by Quaternary and Pliocene volcanic rocks of the San Francisco volcanic field and the large stratovolcano of San Francisco Mountain which lies astride the system. The Doney fault may be a northeastern extension of the oak creek Canyon fault system (Fig. 2.4). Similarly oriented structures exposed in the Grand Canyon have been interpreted as having originated during Precambrian time and subsequently reactivated during Mesozoic and Cenozoic time (Shoemaker and others, 1978).

other systems of faults, such as the Cataract Creek and Kaibab systems, trend northwest through the field. Each system is a relatively broad zone in which the individual faults are short and tend to be parallel or subparallel with the overall trend of the zone (Shoemaker et al., 1978). Northwest-trending normal faults of small throw are conspicuous within the northwestern part and southeastern part of the field (Fig. 2.4). 


\section{CHAPTER THREE}

\section{STATISTICAL ANALYSIS OF CINDER CONE DISTRIBUTION AND ALIGNMENTS IN SAN FRANCISCO VOLCANIC FIELD}

Six hundred and five separate and distinct volcanic centers were identified in the study area (Fig. 2.2). The majority are cinder cones with associated lava flows. In this Chapter, a statistical analysis of the cinder cone distribution is presented. I begin with a discussion of cinder cone density distribution, and then present a quantitative statistical analysis of vent clustering and vent alignment.

\section{ANALYSIS OF VENT DENSITY DISTRIBUTION}

A map of the density distribution of cinder cones in the SFVF was constructed by overlaying the study area with a grid whose spacing was $4000 \mathrm{~m}$ and then the number of cinder cones in search radius $8000 \mathrm{~m}$ were counted about each grid point. The grid point values were contoured with the commercially available MS-DOS application SURFER using a minimum curvature algorithm (Briggs, 1974) with a contour interval of 10 vents/100 $\mathrm{km}^{2}$. The resulting contour map (Fig. 3.1) shows that vents are most densely concentrated in the western part of the field and the contours are elongate in a NE orientation, approximately parallel with the southern segment 


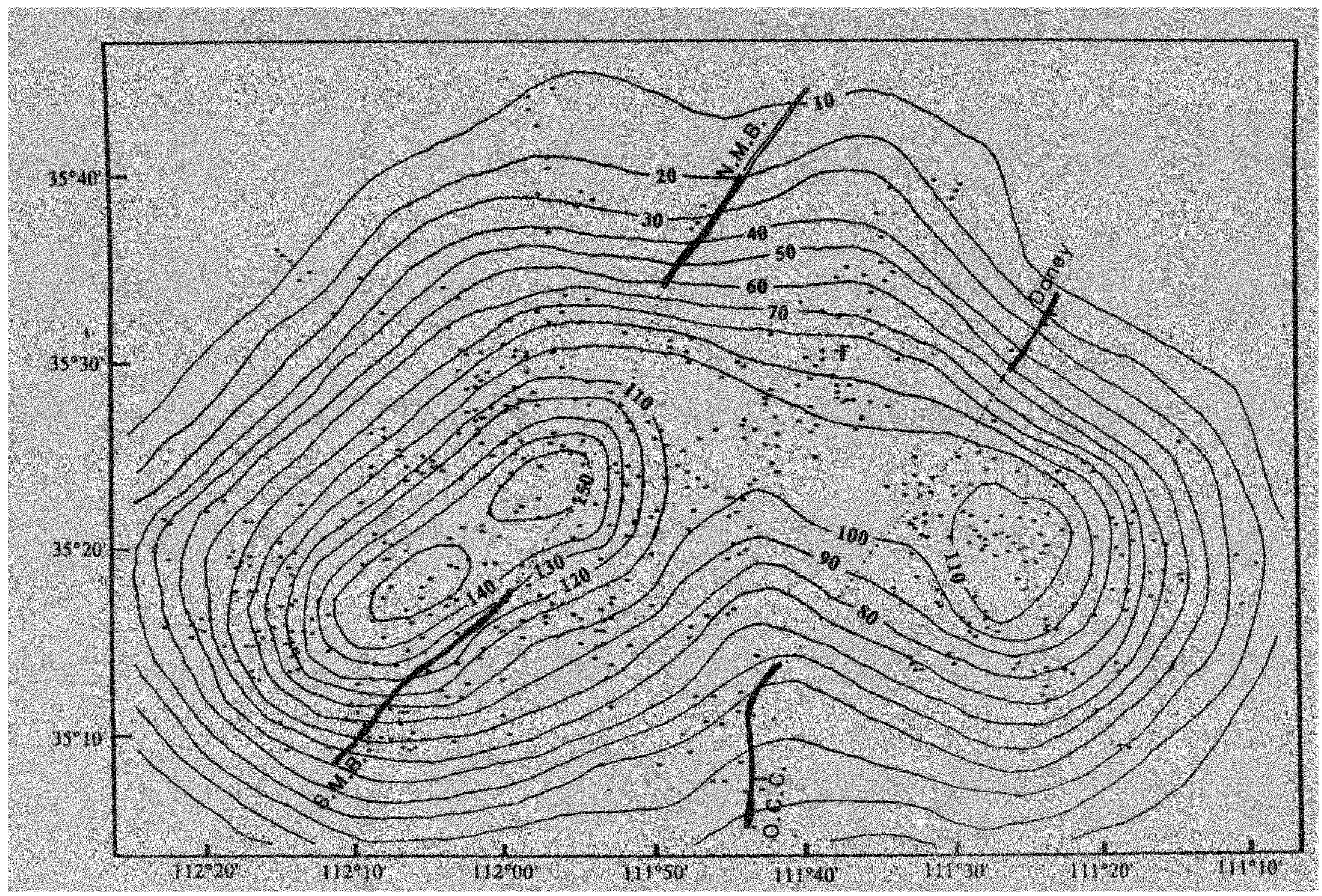

Fig. 3.1: Map of the density distribution of cinder cones in the San Francisco Volcanic Field (grid spacing $4000 \mathrm{~m}$ and search radius $8000 \mathrm{~m}$ ). Contour interval is 10 vents $/ 100 \mathrm{~km}^{2}$. Dark lines are major fault systems. 
of the Mesa-Butte fault system. This distribution suggests that the Mesa-Butte fault zone may play an important role in controlling the regional vent distribution. The concentration of vents is also high in the eastern part of the field, adjacent to the Oak Creek Canyon - Doney fault system, also suggesting that a fault system may influence vent distribution.

The results of density mapping are strongly influenced by grid spacing and search radius. The appearance, therefore, of the density contour map will change if a different grid spacing and search radius are used. For a smaller grid spacing and search radius $(2000 \mathrm{~m}$ and $4000 \mathrm{~m}$ respectively), the density map forms $4-5$ distinct concentrations (Fig. 3.2), where locally, the cone density is as high as 6 vents/10 $\mathrm{km}^{2}$. In Fig. 3.2, two of these density concentrations lie along an extension of the trend of the north segment of the Mesa Butte fault. There is also a concentration in the central-northeast part of the area, between the Mesa Butte and Oak Creek Canyon-Doney fault systems that is coincident with NE trending lineaments in the regional magnetic and gravity data (see Chapter 4).

In general, however, maps of vent density alone are difficult to relate to possible linear groupings, especially where vent distribution is dense as this makes alignment recognition difficult. 


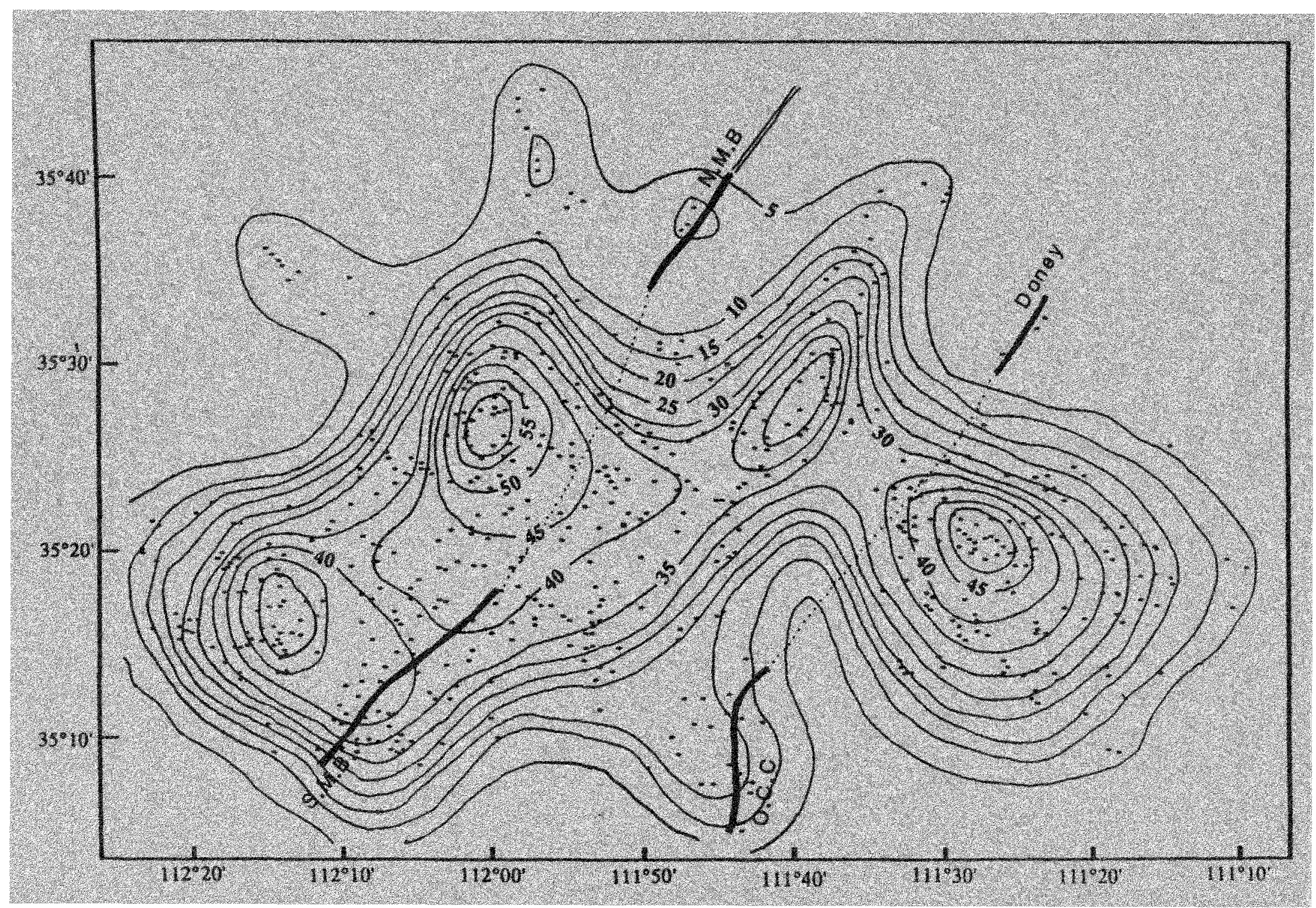

Fig. 3.2: Map of the density distribution of cinder cones in the San Francisco Volcanic Field (grid spacing $2000 \mathrm{~m}$ and search radius $4000 \mathrm{~m}$ ). Contour interval is 5 vents $/ 100 \mathrm{~km}^{2}$. Dark lines are major fault systems. 
Because of the dense vent concentration in the SFVF, the qualitative identification of vent alignments is of limited value. Instead, statistical methods are used which allow a more objective identification of vent alignments. The methods used include cluster analysis, two-point azimuth analysis, and Hough Transform analysis, all of which have been previously used to study point patterns in volcanic fields (Wadge and Cross, 1988; Connor et. al., 1990).

\section{CLUSTER ANALYSIS}

Cluster analysis is used to identify natural spatial groupings of vents. The method was chosen because the outcome depends on the variation in the spatial density of vents rather than on the distribution of individual cones. This is important because quantitative alignment recognition methods are adversely affected by inhomogeneities in vent distribution. By identifying clusters before making the alignment analysis, the effects of inhomogeneities are minimized (Connor, 1992).

A uniform kernel density fusion cluster algorithm (Wong and Lane, 1983; Sarle, 1985) was used, because it is less sensitive to cluster shape than other algorithms, which tend to search for compact or elongate clusters. In this algorithm, density linkage is used to refer to a class of clustering methods using nonparametric probability density estimates. If $f(X)$ is the number of vents within a circle of 
radius $r$ centered at vent $x$, then the dissimilarity matrix, $d^{*}(X i, X j)$, is computed as:

$$
\begin{aligned}
& d^{*}(X i, X j)=1 / 2 \star(1 / f(X i)+1 / f(X j)), d(X i, X j)<r \\
& d^{*}(X i, X j)=i n f i n i t y, \text { otherwise }
\end{aligned}
$$

where $d(X i, X j)$ is the distance between the ith and jth vent. $f(X i)$ and $f(X j)$ are the number of vents within the circle of radius $r$ centered at ith and jth vent respectively. Once this matrix is calculated, individual vents are linked using this matrix and a single linkage clustering algorithm. If the density fusion, $d^{*}$, between two clusters is less than the maximum $d^{*}$ between any two vents within either cluster, the two clusters are not linked. This step makes the recognition of overlapping clusters possible by reducing the importance of individual vents. The single linkage clustering process continues repetitively until a stable number of clusters is found. A full listing of the computer program used can be found in Appendix A.

Maps are then constructed, showing the distribution of individual vents by cluster membership.

Clearly, changing the search radius $r$ will change the number of clusters on this map. Therefore, one goal of the analysis is to find a range of search radii which produce relatively stable cluster groups. If clustering is a significant feature of the vent distribution, then the number of clusters will not change or change only slightly with changes in search radius (Connor, 1992). 
According to this principle, maps of vent distribution by cluster membership are produced for different search radii. The change in the number of vent clusters with changing search radius (interval $250 \mathrm{~m}$ ) is shown in Figure 3.3. For search radii greater than $8500 \mathrm{~m}$, the change in the number of clusters is low, and cluster membership tends to form several extremely large clusters. For search radii less than $5000 \mathrm{~m}$, small clusters separate out and the number of clusters increases rapidly with decreasing search radius. Between search radius $5500 \mathrm{~m}$ and $8000 \mathrm{~m}$, the number of clusters change only slightly with changing search radius. Variation in total number of clusters usually is due to fragmentation of clusters comprising 10 or fewer cones.

Because these clusters do not change membership in a significant way over a search radii range of 5500 to $8000 \mathrm{~m}$, clusters defined by search radii in this interval are viewed as significant features of cinder cone distribution in the SFVF. In addition, previous studies (Wadge and Cross, 1988; Connor, 1990) indicate that best number of clusters to investigate vent alignments in a given area is between five and ten. Hence, a search radius $6500 \mathrm{~m}$ and $7000 \mathrm{~m}$ to do cluster analysis seems reasonable (Eig. 3.3). Fig. 3.4 illustrates the results of a cluster analysis for a search radius $7000 \mathrm{~m}$ which is representative of the vent pattern in the field. Five large clusters (having between 78 and 151 cinder cones each) and four small clusters (between 5 to 22 


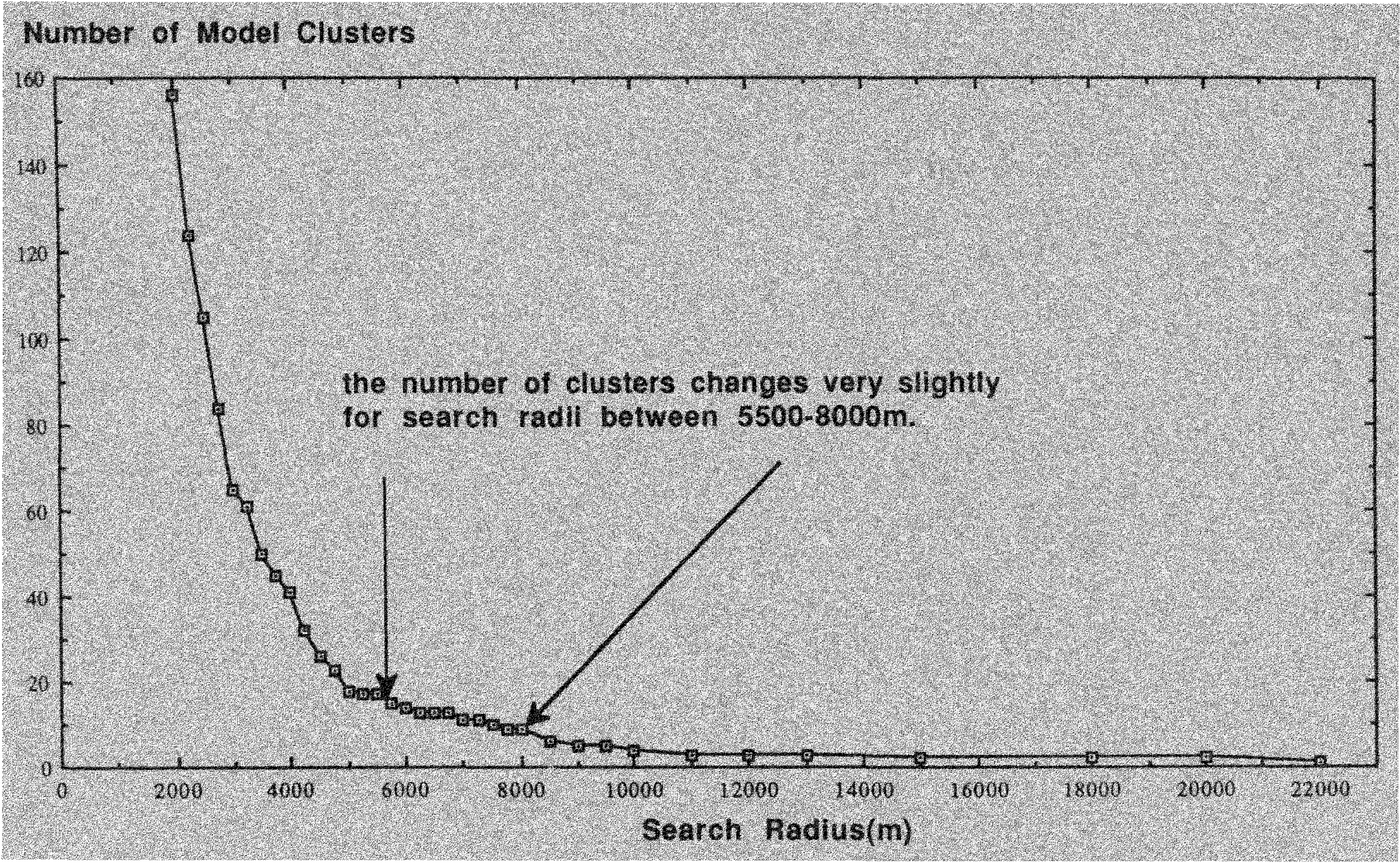

Fig. 3.3: Diagram of the change in the number of vent clusters with changing search radius(interval $250 \mathrm{~m}$ ). 


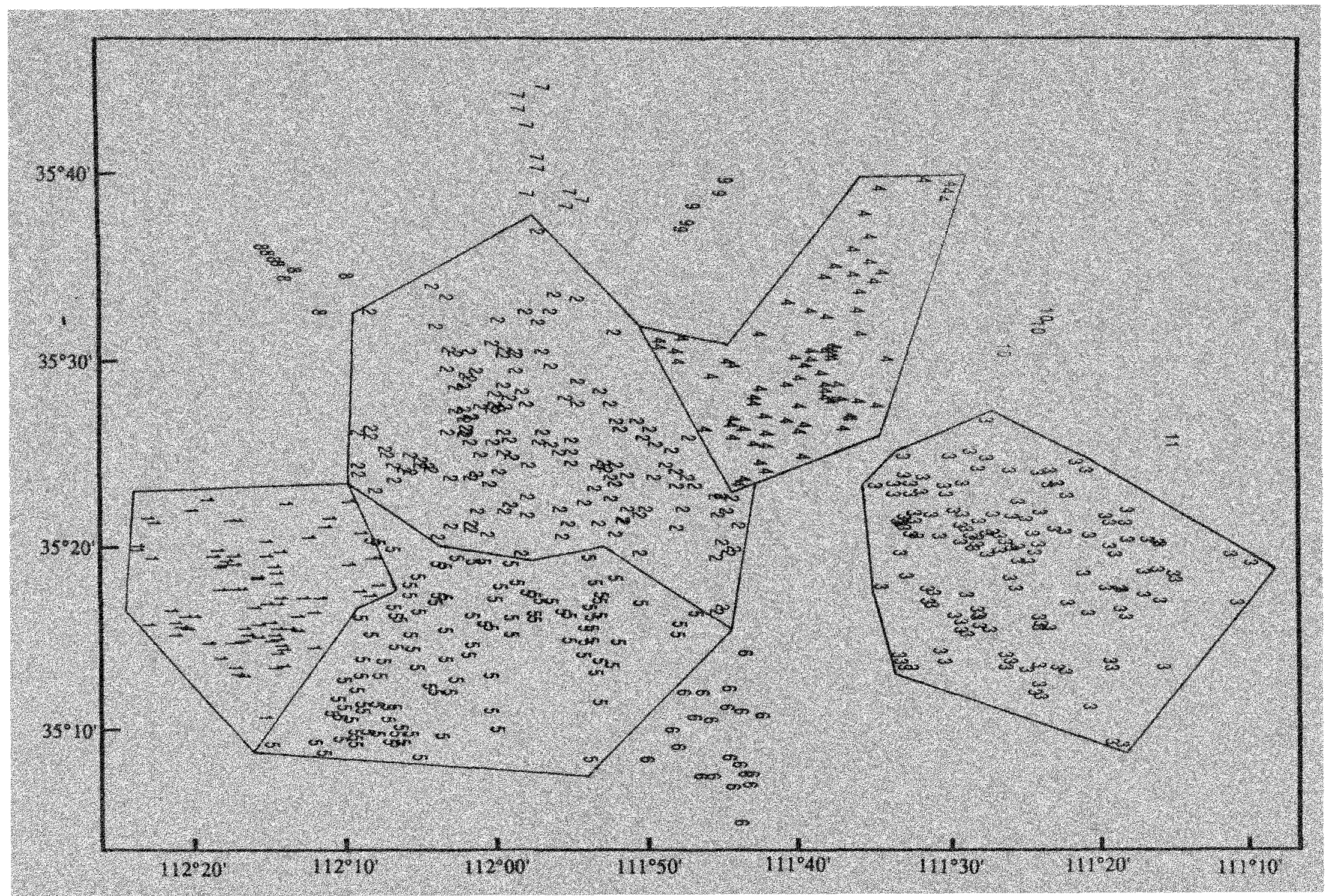

Fig. 3.4: Vents plotted by cluster memberships (search radius $7000 \mathrm{~m}$ ) using uniform kernel density fusion cluster analysis. The solid lines show the bounding polygon. 
cinder cones each) persist over range of search radius with only slight changes in membership. The clusters shown are stable over the following search radii (Table 3.1). Here, approximately $93 \%$ of the cinder cones in the field are found within these 5 large clusters, and the remaining $7 \%$ of cones are distributed within the other small outlying clusters. A comparison of the results of the cluster analysis (Eig. 3.4) with a contour map of the cinder cone density distribution (Eig. 3.2) suggests that the large clusters correspond to concentrations in the cinder cone density distribution.

Table 3.1: Stable clusters over range of search radius

\begin{tabular}{|c|c|c|c|}
\hline stable cluster & search radius & number of vents & average age \\
\hline cluster1 & $4500-7750 \mathrm{~m}$ & 82 & $5.5 \pm 0.5 \mathrm{M} . \mathrm{Y}$. \\
cluster 2 & $4750-8250 \mathrm{~m}$ & 151 & $2.5 \pm 0.3 \mathrm{M} . \mathrm{Y}$. \\
cluster 3 & $6250-12000 \mathrm{~m}$ & 140 & $0.5 \pm 0.1 \mathrm{M} . \mathrm{Y}$. \\
cluster 4 & $5000-9500 \mathrm{~m}$ & 78 & $0.5 \pm 0.1 \mathrm{M} . \mathrm{Y}$. \\
cluster 5 & $6750-7750 \mathrm{~m}$ & 111 & $3.5 \pm 0.3 \mathrm{M} . \mathrm{Y}$. \\
cluster 6 & $5000-8250 \mathrm{~m}$ & 22 & $2.5 \pm 0.3 \mathrm{M} . \mathrm{Y}$. \\
cluster 7 & $5000-8250 \mathrm{~m}$ & 10 & - \\
cluster 8 & $5000-8500 \mathrm{~m}$ & 8 & - \\
cluster 9 & $5000-10000 \mathrm{~m}$ & 5 & - \\
\hline
\end{tabular}

\section{TWO-POINT AZIMUTH ANALYSIS}

The two-point azimuth method, developed by Lutz (1986) and zhang et al. (1989), provides a statistical means of identifying preferred orientations and anisotropy in vent distribution. The basis of the two-point method is a Monte Carlo simulation. Monte carlo simulations provide empirical 
confidence values for azimuthal frequencies that can be used as guides to interpret azimuthal distributions. Here, Lutz's computer program was used (see Appendix A for listing).

Briefly, any two vents in the volcanic field can lie along a line. A line segment connecting two vents in an areal distribution defines an azimuth (Fig. 3.5). The frequency distribution of intersegment azimuths is drawn from all pairs of vents ( $\mathrm{Fig} .3 .6 \mathrm{~A}$ ). The azimuthal distribution responds to both the presence of vent alignments and the shape of the boundary of the volcanic cluster, so vent pairs tend to align in a preferred orientation if the entire cluster is elongate. In order to account for the effect of cluster shape, the shape of the area is defined by a convex polygon (Fig. 3.4) that makes it possible to quantify the field shape effect by Monte Carlo simulations of random patterns. Only vents falling within the polygon selected are used in the analysis. For each simulation, $n$ vents were randomly plotted within this polygon which included the vents at the margin of each cluster, the azimuth from each vent to every other vent within the polygon was found and the cumulative frequency was compared with the observed vent azimuth frequency distribution at $10^{\circ}$ intervals (Fig. 3.6D).

Since the azimuthal frequency distribution is sensitive to the presence of geological inhomogeneities, it is possible to understand the underlying geological mechanisms which form the cinder cone area. If actual vents tend to align 


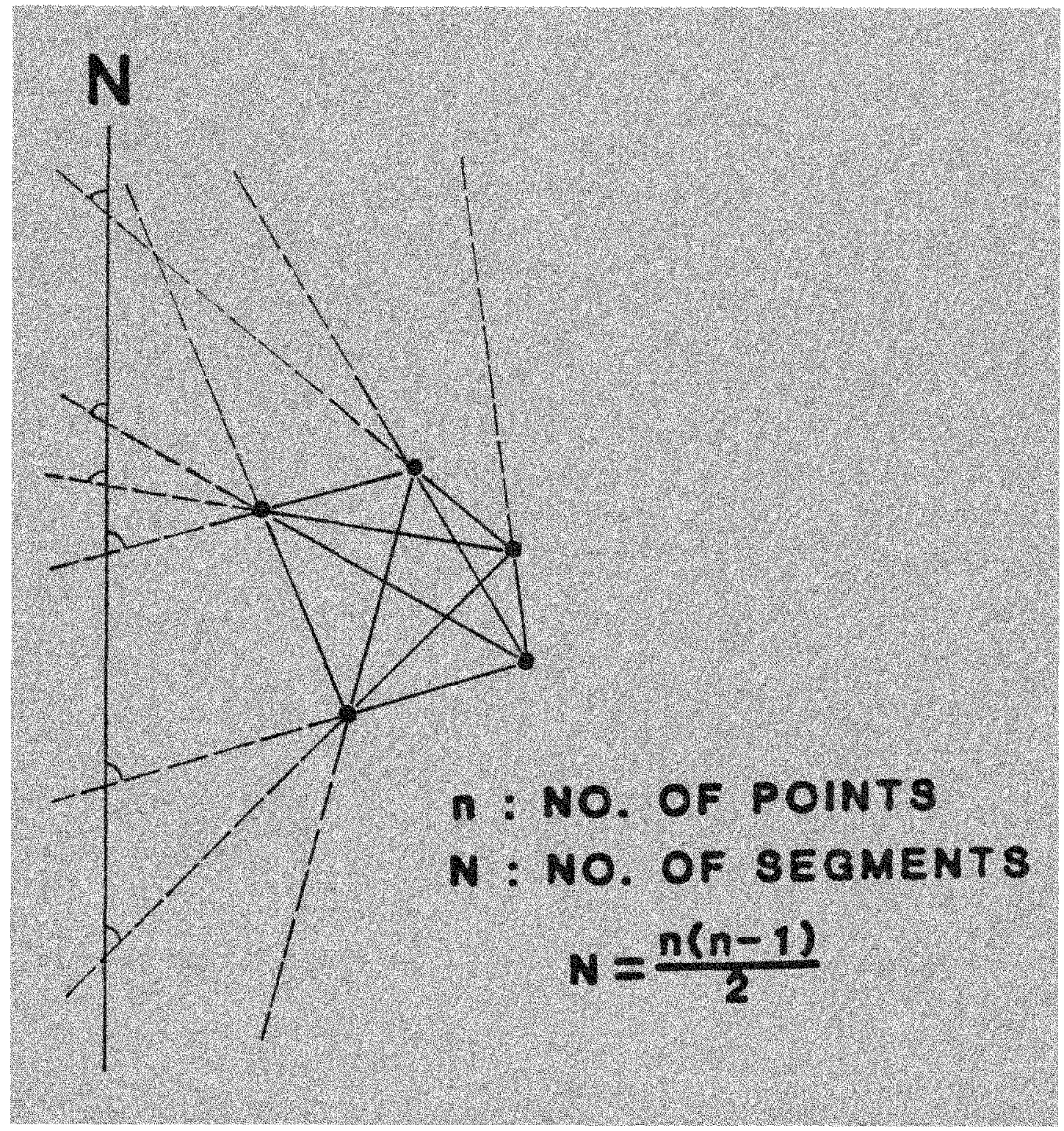

Fig. 3.5: Two-point azimuth method. Intersegments are constructed between all pairs of vents; the angle of intersection of each segment or its extension with a N-S line defines its azimuth. 


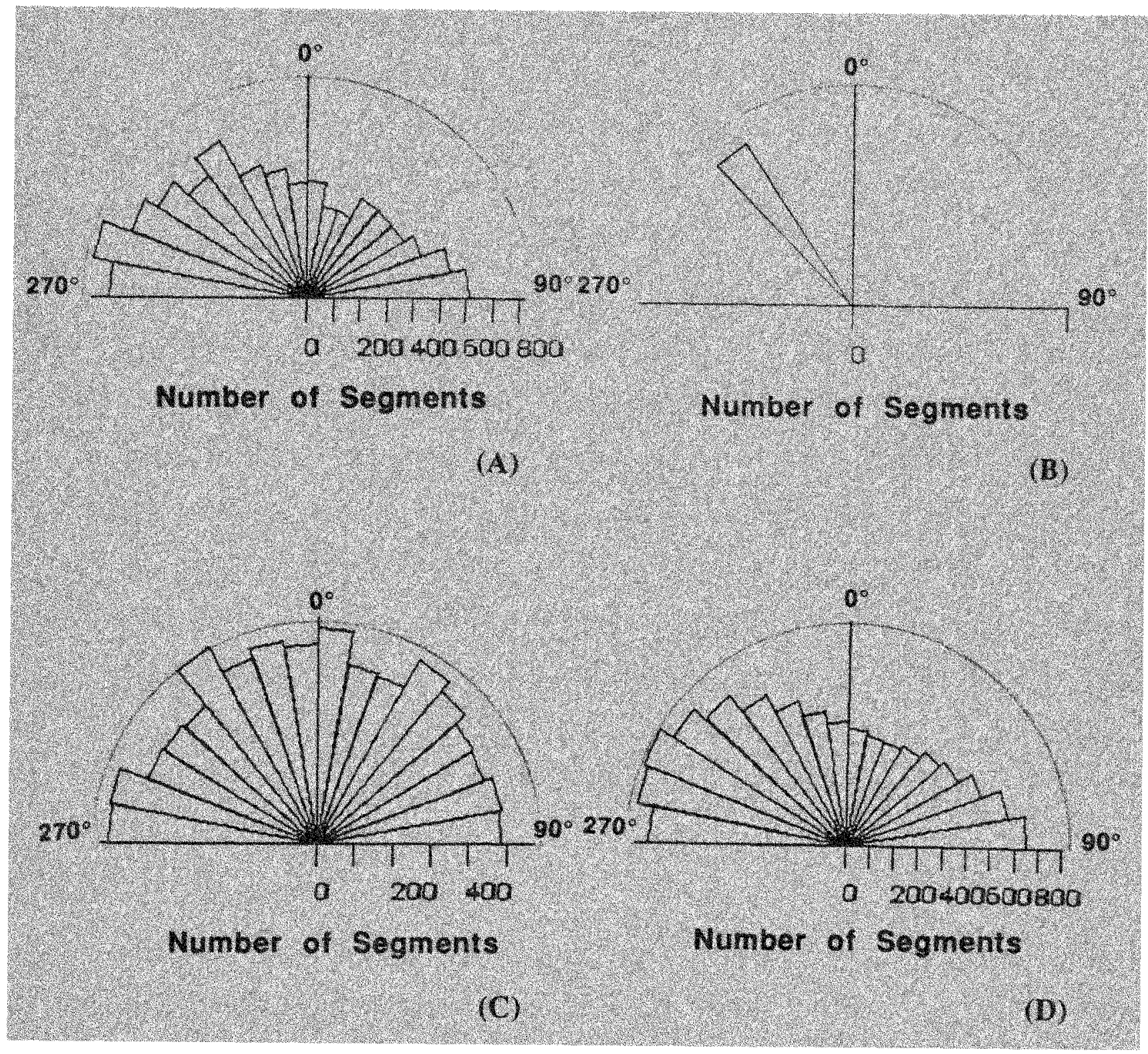

Fig. 3.6: Rose diagrams of two-point azimuth analysis showing prefered the azimuthal direction for cluster 3. A: observed data distribution (the line segment orientation in $10^{\circ}$ interval ). B: preferred azimuthal orientations (the $10^{\circ}$ interval contains more observations which exceed the $90 \%$ confidence limit). $C$ : the normalized distribution (the frequency per class of observed line segment orientations was normalized to take the shape of the study area into account. D: the upper confidence limit based on the Monte Carlo simulation (90\% confidence limit). 
preferentially in a given orientation, this vent alignment will emerge through comparison with the Monte Carlo results. The two-point azimuth method was applied to the significant clusters in the field (Fig. 3.4). The outcome of the analysis indicates that significant alignment exists in the distribution of cinder cones within each cluster. Significant azimuthal orientations are found within each cluster at the $90 \%$ confidence level using a $t$ test. Figure $3.6 \mathrm{~B}$ shows the preferred azimuthal direction for cluster 3 , that is, the observed azimuths (Fig. 3.6A) that exceed the $90 \%$ confidence limits (Fig. 3.6D). The direction is $140^{\circ}-150^{\circ}$ or $320^{\circ}-330^{\circ}$ which compares with the orientation in the diagram of the normalized distribution (Fig. 3.6C). The normalized azimuthal distribution can be calculated on the basis of the upper confidence limit distribution, D, and the mean distribution, $\AA$. The normalized distribution, $c$, is defined as (Lutz, 1986):

$$
\mathrm{C}=(\mathrm{D} / \AA) \star \AA
$$

where $\mathbf{A}$ is the observed distribution. If the preferred azimuthal orientation is significant, then the preferred azimuthal orientation and the normalized azimuthal orientation should be consistent.

\section{HOUGH TRANSFORM ANALYSIS}

While the two-point azimuth method determines the trends of structures, it does not provide any other information 
about their spatial distribution. Application of Hough Transform helps to determine the actual locations of alignment (Wadge and Cross, 1988). The Hough Transform method (see computer program in Appendix A) is a widely used computer method for detecting linear structures.

In the Hough transform method, each vent in a cluster is viewed to lie along an infinite number of lines, each line having a unique azimuth. In the case of a straight line, it can be represented in polar coordinates $\rho$ and $\alpha$, where $\rho$ is the normal distance from that arbitrary origin point to the line, and $\alpha$ is the angle between the normal and the $\mathrm{x}$ axis (Fig. 3.7A). The equation of the line is thus $\rho=X \cos \alpha+Y \sin \alpha$, the axes of the new parameter plane corresponding to $\rho$ and $\alpha$. Each $(x, y)$ point generates a sinusoidal curve in the parameter plane as $\rho$ is calculated for successive values of $\alpha$. Each point $(\rho, \alpha)$ on the sinusoidal curve represents a line containing the fixed point $(x, y)$. It follows that the curves in the $(\rho, \alpha)$ plane generated by two or more collinear points intersect at a common point. The values for $\rho$ and $\alpha$ at this point define their alignments (Fig. 3.7B).

Approximate values for $d \rho$ and $d \alpha$ were determined by considering the likely dimension of an individual vent. Here, A value d $\alpha$ equal to $2^{\circ}-3^{\circ}$ (which corresponds to vent dimension about $350-800 \mathrm{~m}$ diameter) and a corresponding value of dp equal to 300-800 m, were taken because they represent a reasonable dimension of an individual vent as observed in the 


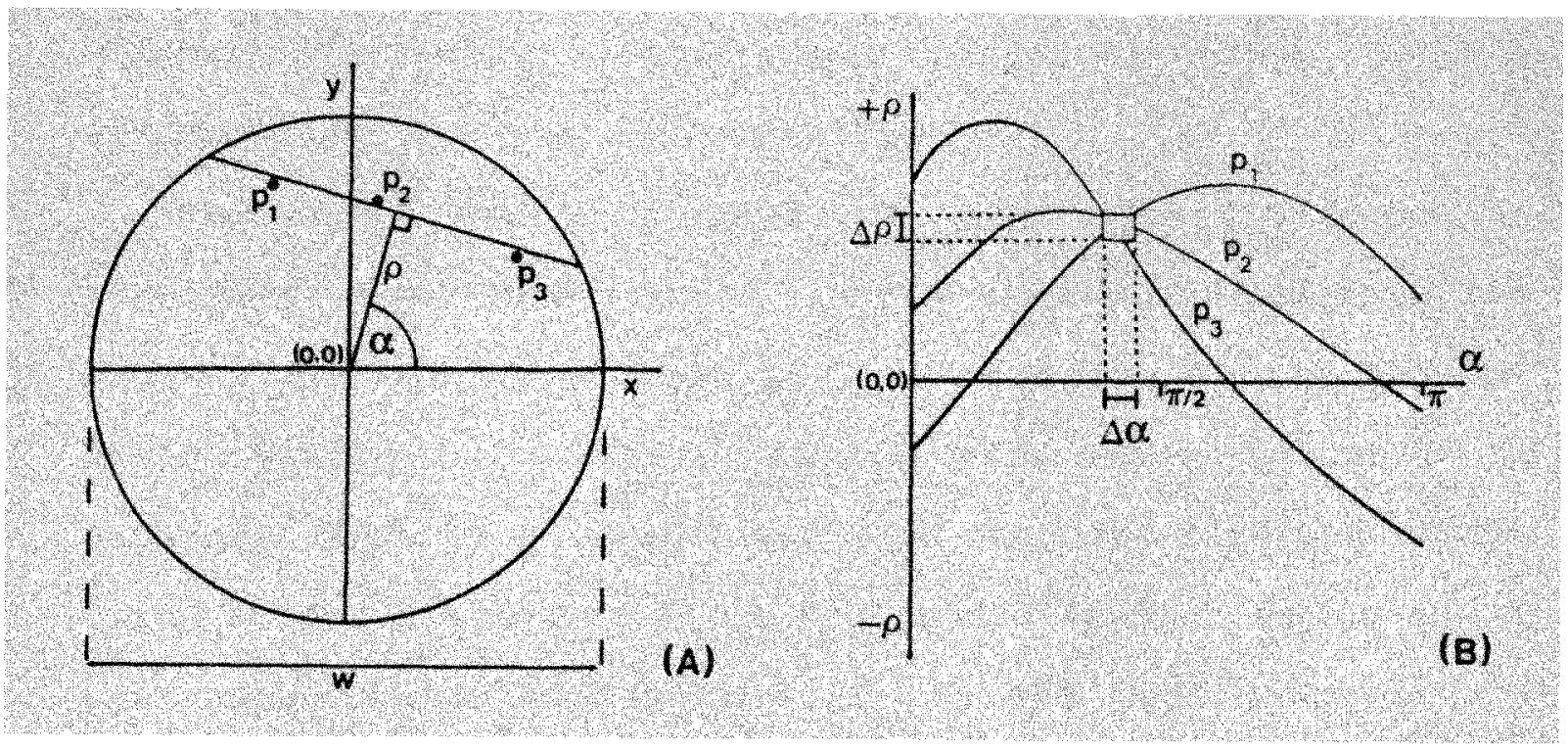

Fig. 3.7: Hough transform method illustrate for three nearly collinear points (p). A: $X$ and $Y$ plane, $w$ is length of cluster diameter. B: corresponding curve in $\rho$ and $\alpha$ plane. 
field. The behavior of this method was investigated with different parameter settings. Fig. 3.8, Fig. 3.9 and Fig. 3.10 show examples of alignment patterns obtained by considering different vent sizes (ie. different $d \rho$ and $d \alpha$ ) for cluster 3 with each alignment having 9 and more vents. Although the number of alignments changed slightly, the vent alignment pattern was remarkably stable.

Because inhomogeneities in vent distributions can adversely affect the results of the alignment analysis, the Hough transform method was applied on a cluster by cluster basis. Within each cluster, several alignments consisting of numerous vents were identified. Most of these alignments have orientations similar to those recognized as significant using the two-point azimuth method at the $90 \%$ confidence level. Figures $3.8,3.9$ and 3.10 show alignments which have almost the same orientation as that determined with the two-point azimuth method (Fig. 3.6).

The Hough transform is sensitive to both the number of cinder cones used in the analysis and the shape of the cinder cone cluster. The more cinder cones in a cluster, the more likely it is that several cinder cones will align. Alignments usually consist of 9-10 vents for large cluster and 4-5 for small clusters in the SEVF. If a cluster is elongate, alignments will likely be found in the direction of elongation. Therefore, care was taken in the final geological interpretation of the results of the Hough transform and a 


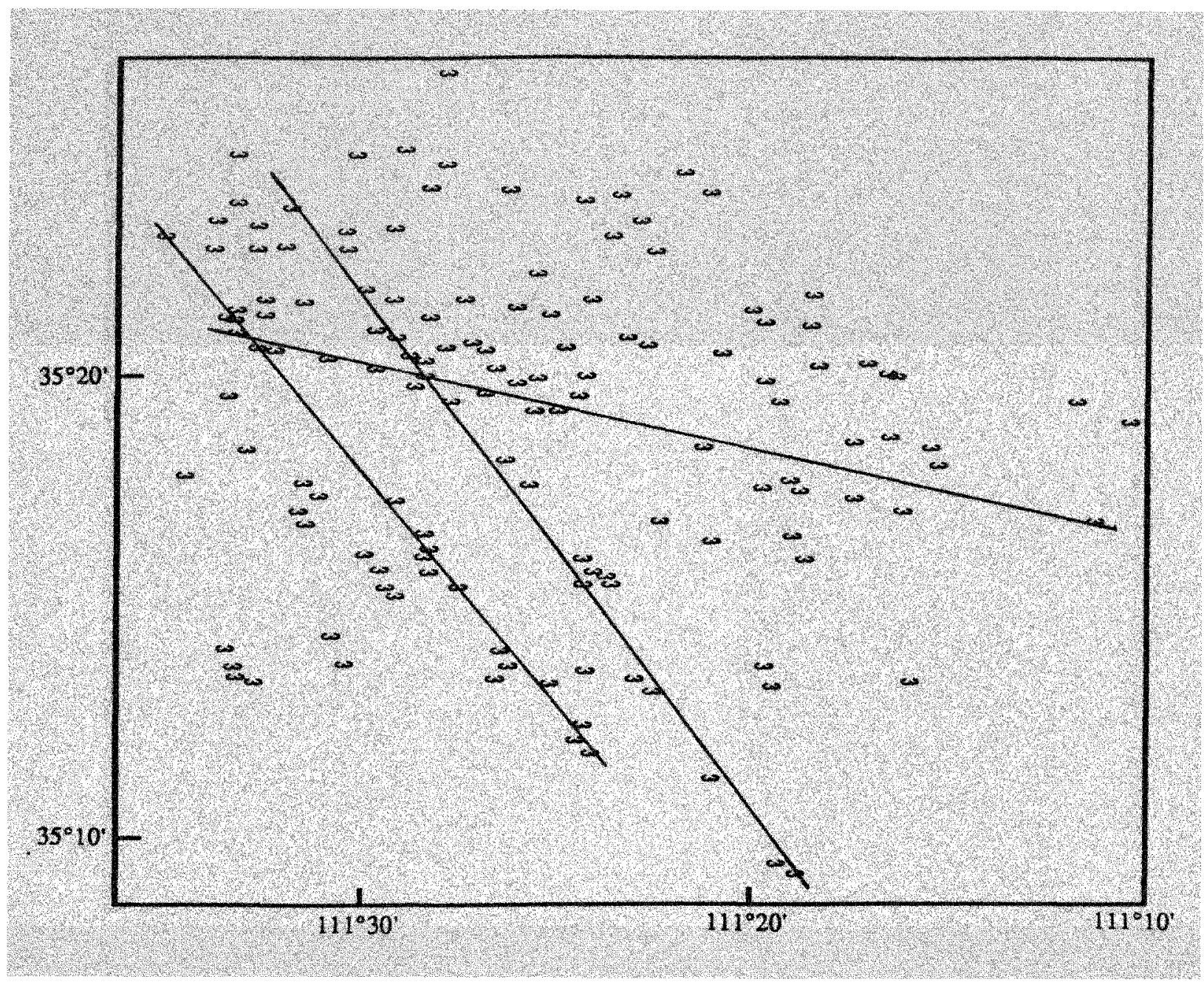

Fig. 3.8: Hough transform alignments with minimum of 10 vents plotted on cluster 3 for parameters $\left(d p=450 \mathrm{~m}, d \alpha=2^{\circ}\right)$. 


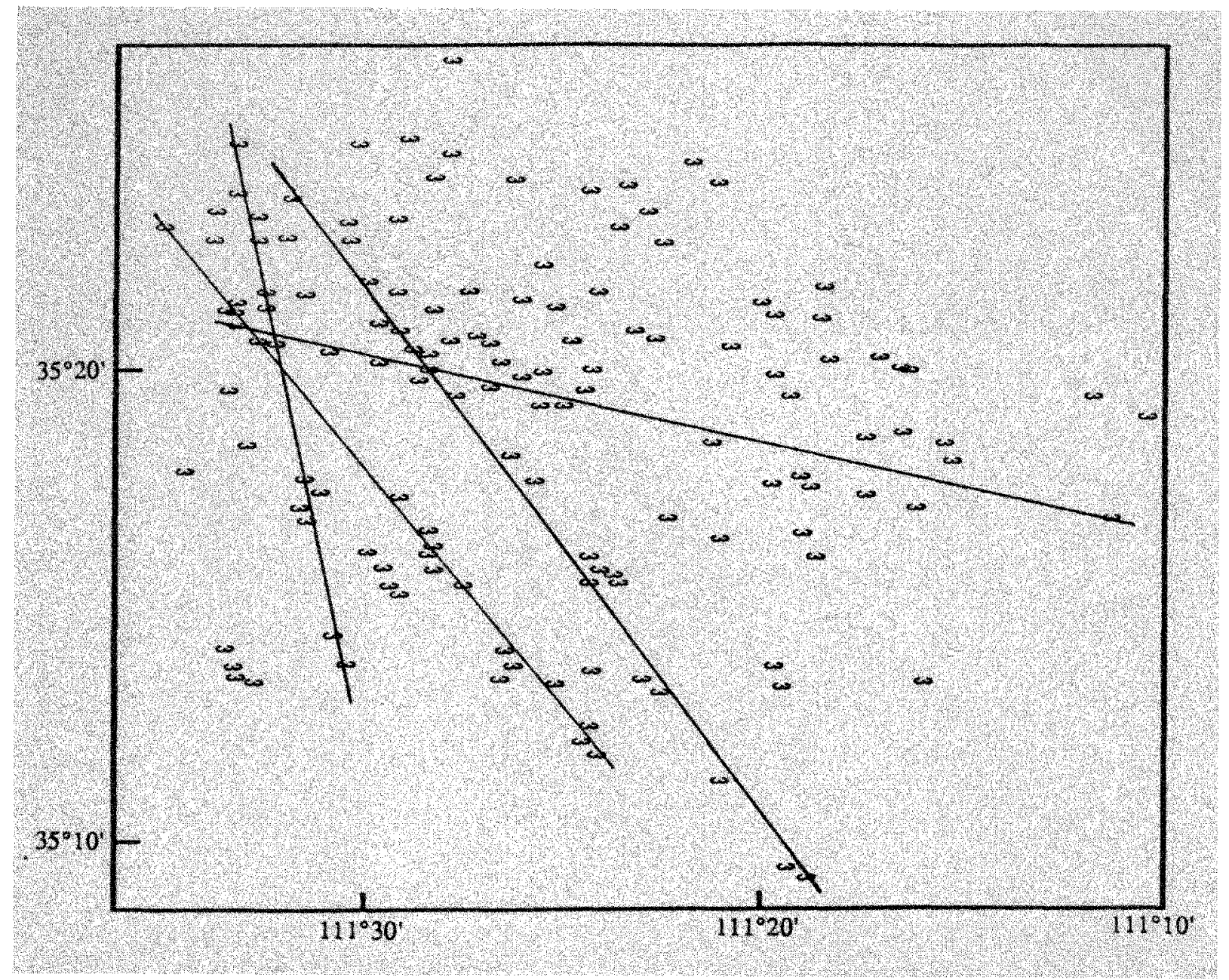

Fig. 3.9: Hough transform alignments with minimum of 10 vents plotted on cluster 3 for parameters $\left(d p=500 \mathrm{~m}, d \alpha=2^{\circ}\right)$. 


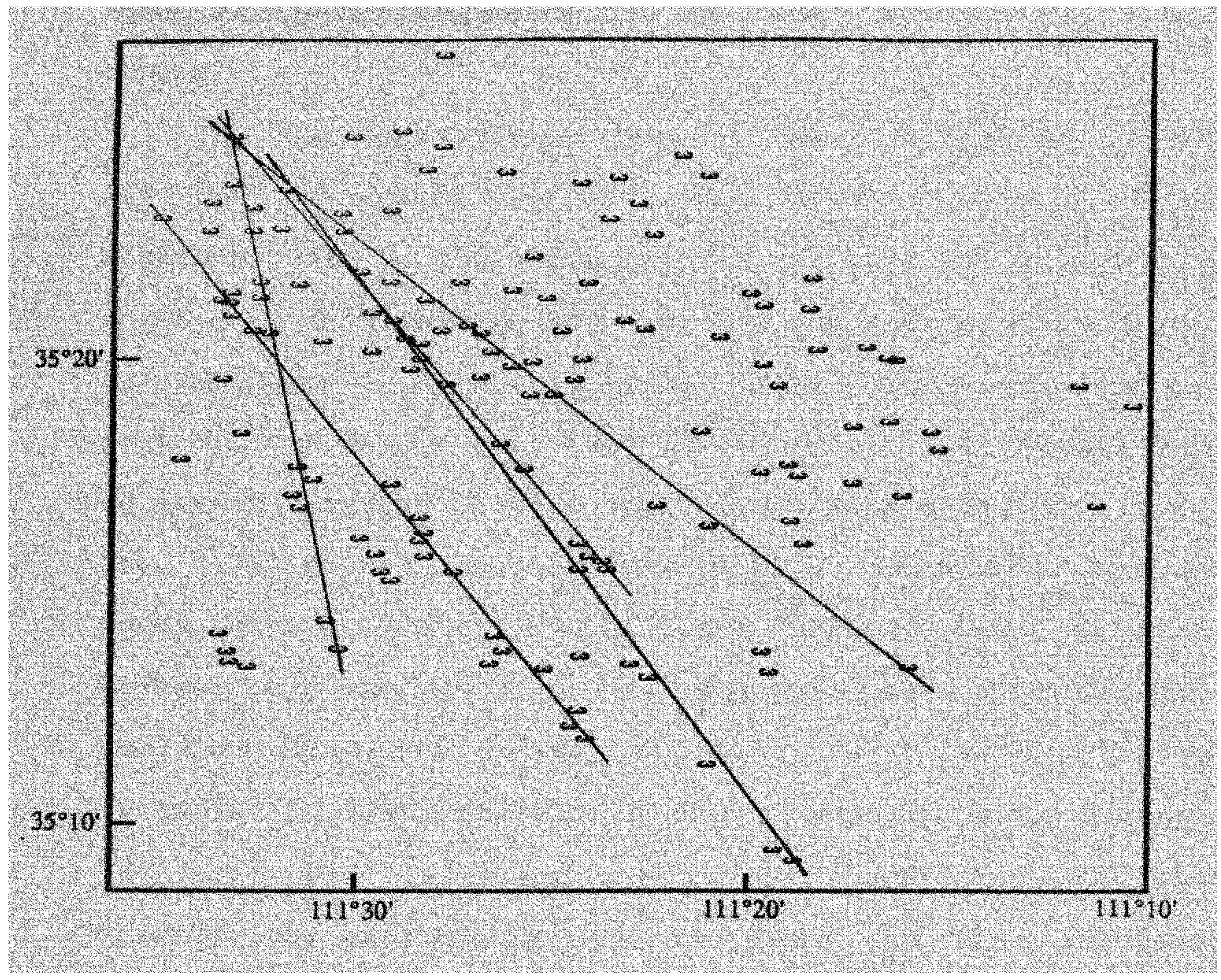

Fig. 3.10: Hough transform alignments with minimum of 10 vents plotted on cluster 3 for parameters $\left(\mathrm{d} \rho=500 \mathrm{~m}, \mathrm{~d} \alpha=3^{\circ}\right)$. 
comparison was made with the results of the two-point azimuth method, which does take cluster shape into account.

\section{VENT ALIGNMENT PATTERNS IN THE SAN FRANCISCO VOLCANIC FIELD}

The alignments derived from the Hough Transform analysis are shown in Figure 3.11 for $d \alpha=2^{\circ}, d p=500 \mathrm{~m}$, and a search radius of $7000 \mathrm{~m}$, and are plotted along with the clusters in which they form and the major faults identified in the area. For clusters situated in the southwestern and northeastern part of the field (clusters 1,4 and 5), alignments are generally oriented in a NE direction. These alignments (A-G, Fig. 3.11) extend approximately $20-38 \mathrm{~km}$, consist of 9 to 10 vents, and generally coincide with the elongate area of highest vent density (Fig. 3.1). For these same clusters, the two-point azimuth method indicates that statistically significant (90\% confidence level) alignments occur between $020^{\circ}$ and $050^{\circ}$ azimuth, which is comparable to the orientations identified using the Hough transform analysis (Table 3.2)

In clusters 2,3 and 8 of Fig. 3.11 in the southeastern and west-central part of the field, a significant number of azimuths are oriented in NW to WNW directions.

The vent alignment patterns for search radius $6500 \mathrm{~m}$ (Fig. 3.12) are similar to those found for search radius of $7000 \mathrm{~m}$. This indicates that this pattern is stable over a 


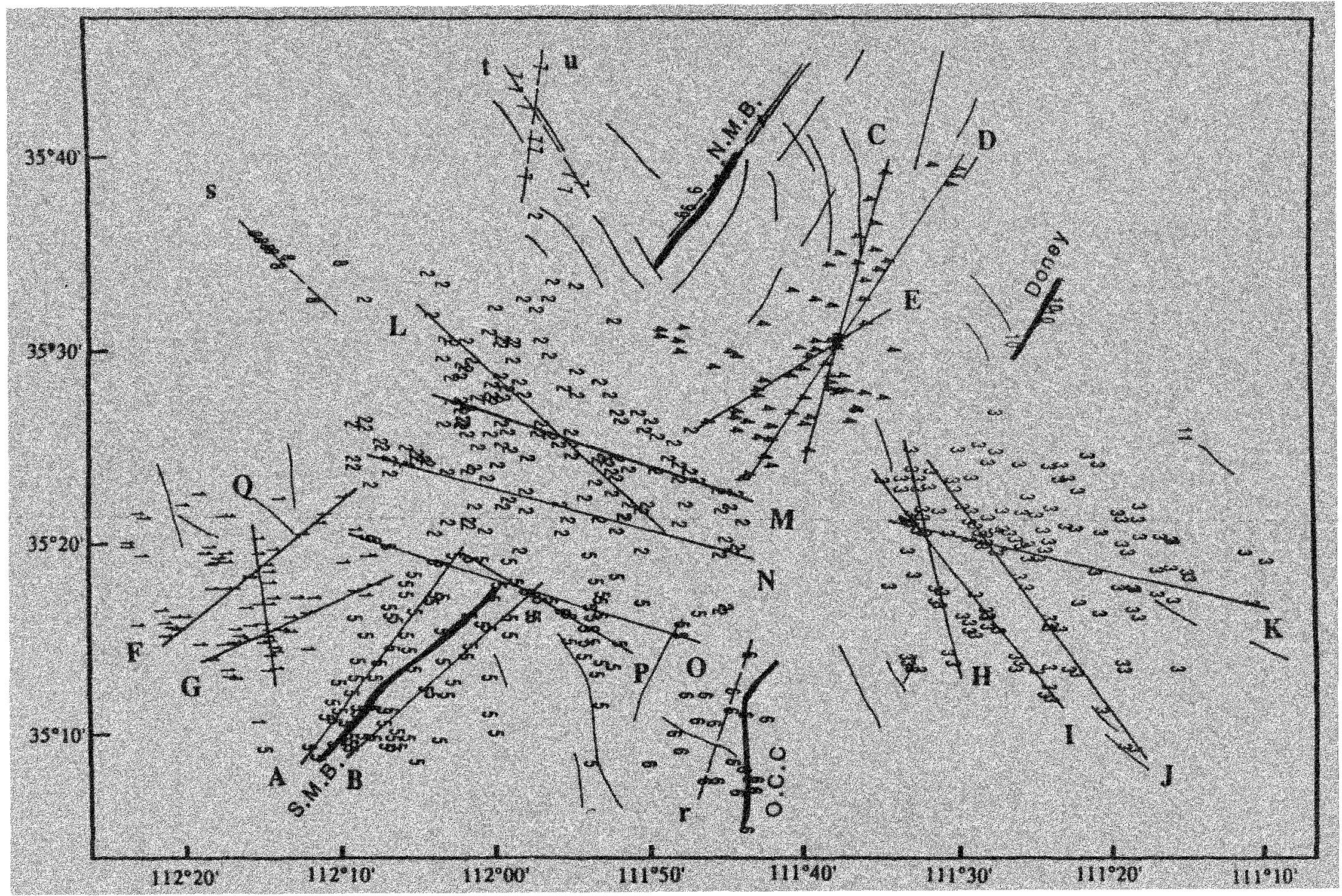

Fig. 3.11: Vent alignment patterns in the San Francisco Volcanic Field(search radius $7000 \mathrm{~m}$ ). Solid lines (upper case letters) are alignments from large clusters and dashed lines (lower case letters) are alignments from small clusters. Thick lines are major fault systems. 
Table 3.2. Summary of the alignment analysis

\begin{tabular}{|c|c|c|c|c|c|c|}
\hline \multirow[b]{2}{*}{ cluster } & \multirow[b]{2}{*}{ No. of Vents } & \multirow{2}{*}{$\begin{array}{c}\text { Two-Point } \\
\text { Azimuth }\end{array}$} & \multicolumn{4}{|c|}{ Hough Transform } \\
\hline & & & Trend & No. of Vents & Length & Vents $/ \mathrm{km}$ \\
\hline \multirow[t]{3}{*}{1} & & $040^{\circ} .050^{\circ}$ & $046^{\circ}(F)$ & 9 & $22 \mathrm{~km}$ & 0.41 \\
\hline & & - & $172^{\circ}(Q)$ & 9 & $17 \mathrm{~km}$ & 0.55 \\
\hline & & - & $058^{\circ}(\mathrm{G})$ & 9 & $20 \mathrm{~km}$ & 0.45 \\
\hline \multirow[t]{4}{*}{2} & 151 & $080^{\circ}-090^{\circ}$ & - & & & \\
\hline & & $090^{\circ}-100^{\circ}$ & $100^{\circ}(\mathrm{N})$ & 10 & $38 \mathrm{~km}$ & 0.26 \\
\hline & & $100^{\circ}-110^{\circ}$ & $102^{\circ}(M)$ & 10 & $34 \mathrm{~km}$ & 0.3 \\
\hline & & - & $132^{\circ}(L)$ & 10 & $34 \mathrm{~km}$ & 0.3 \\
\hline \multirow[t]{4}{*}{3} & 140 & $140^{\circ}-150^{\circ}$ & $145^{\circ}(\mathrm{J})$ & 10 & $38 \mathrm{~km}$ & 0.26 \\
\hline & & & $142^{\circ}(1)$ & 10 & $30 \mathrm{~km}$ & 0.33 \\
\hline & & - & $160^{\circ}(H)$ & 10 & $25 \mathrm{~km}$ & 0.4 \\
\hline & & & $098^{\circ}(K)$ & 10 & $38 \mathrm{~km}$ & 0.26 \\
\hline \multirow[t]{4}{*}{4} & 78 & $100^{\circ}-110^{\circ}$ & - & & & \\
\hline & & $030^{\circ}-040^{\circ}$ & $030^{\circ}(D)$ & 9 & $37 \mathrm{~km}$ & 0.25 \\
\hline & & - & $015^{\circ}(\mathrm{C})$ & 9 & $33 \mathrm{~km}$ & 0.27 \\
\hline & & & $050^{\circ}(E)$ & 9 & $22 \mathrm{~km}$ & 0.41 \\
\hline \multirow[t]{6}{*}{5} & 111 & - & $106^{\circ}(0)$ & 9 & $36 \mathrm{~km}$ & 0.25 \\
\hline & & $060^{\circ}-070^{\circ}$ & - & & & \\
\hline & & $050^{\circ}-060^{\circ}$ & - & & & \\
\hline & & $040^{\circ}-050^{\circ}$ & $040^{\circ}(\mathrm{B})$ & 9 & $27 \mathrm{~km}$ & 0.33 \\
\hline & & $030^{\circ}-040^{\circ}$ & $034^{\circ}(A)$ & 9 & $27 \mathrm{~km}$ & 0.33 \\
\hline & & - & $122^{\circ}(\mathrm{P})$ & 9 & $20 \mathrm{~km}$ & 0.45 \\
\hline \multirow[t]{3}{*}{6} & 22 & $140^{\circ}-150^{\circ}$ & - & & & \\
\hline & & $100^{\circ}-110^{\circ}$ & - & & & \\
\hline & & $020^{\circ}-030^{\circ}$ & $022^{\circ}(r)$ & 5 & - & - \\
\hline \multirow[t]{2}{*}{7} & 10 & $140^{\circ}-150^{\circ}$ & $150^{\circ}(t)$ & 4 & - & - \\
\hline & & $010^{\circ}-020^{\circ}$ & $010^{\circ}(u)$ & 4 & - & - \\
\hline \multirow[t]{2}{*}{8} & 8 & $130^{\circ}-140^{\circ}$ & $135^{\circ}(\mathrm{s})$ & 5 & - & - \\
\hline & & $030^{\circ}-040^{\circ}$ & - & & & \\
\hline 9 & 5 & $020^{\circ}-030^{\circ}$ & $028^{\circ}(\mathrm{v})$ & 4 & - & - \\
\hline
\end{tabular}

Notes: Upper case letters are alignments from large clusters and lower case letters are alignments from small clusters. 


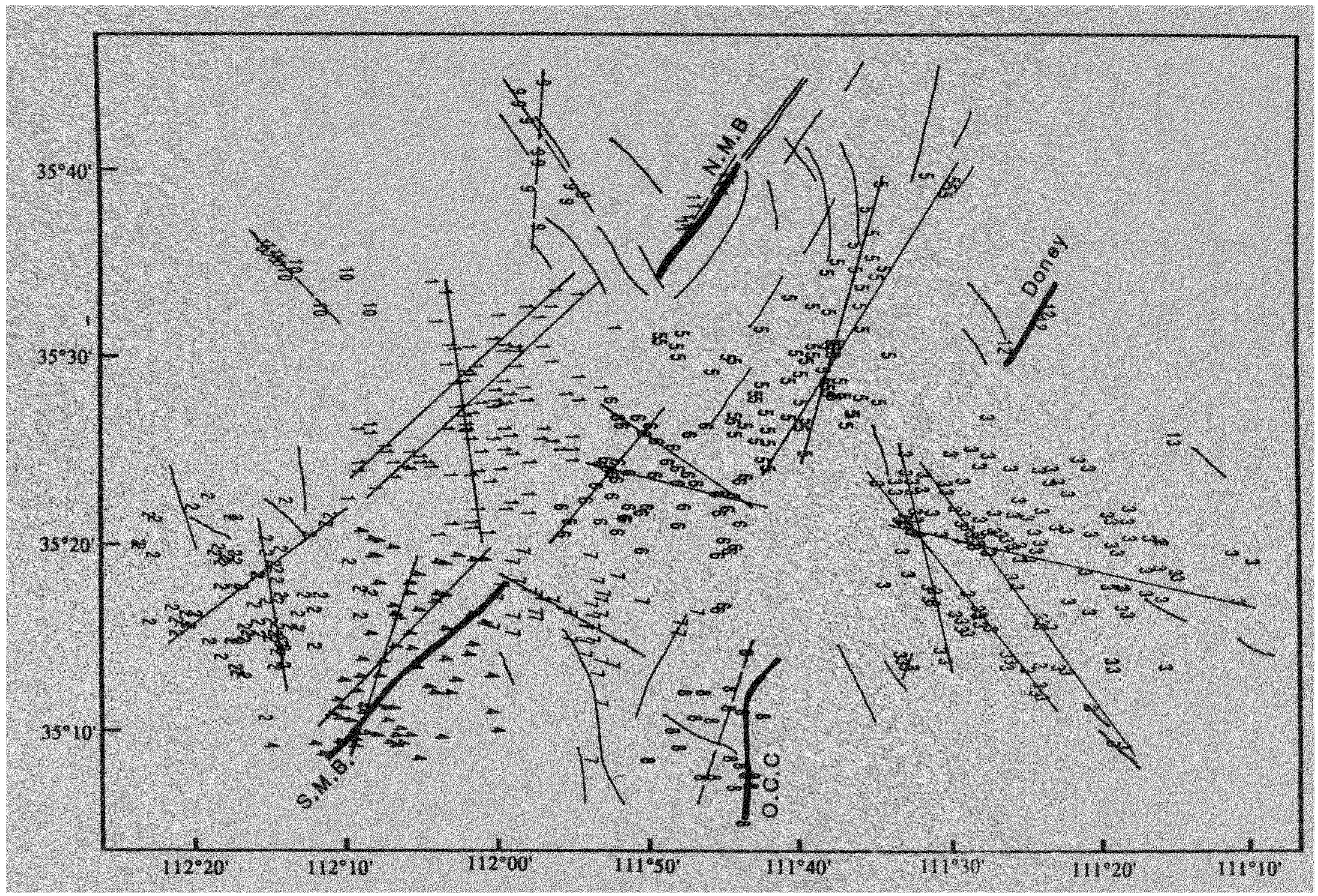

Fig. 3.12: Vent alignment patterns in the San Francisco Volcanic Field(search radius $6500 \mathrm{~m}$ ). Solid line is alignment from large clusters and dash line is alignment from small clusters. 
range of search radii. One exception to this pattern is that the NW and WNW vent alignment orientations of cluster 2 in Eig. 3.11 (7000 $\mathrm{m}$ search radius) changes to the predominant $1 \mathrm{y}$ $\mathrm{NE}$ and NW directions of clusters 1 and 6 in Fig. $3.1216500 \mathrm{~m}$ search radius). Vent alignments determined at larger search radii may reflect deeper-seated features while alignments determined from small search radii may reflect relatively shallow features.

Figs. 3.11 and 3.12 also reveal some interesting relationships between regional fault structures and the Hough transform determined alignments. Some vents are aligned along the northern segment of the Mesa Butte fault, and in both figures, vent alignments appear to occur along a SW extension of this fault in the southwestern part of the field (alignment $F$ in Eig 3.11). In Fig. 3.12 these trends cut across the center of the field (cluster 1). A similar pattern is observed for the southern segment of the Mesa Butte fault, where NE trending alignments appear as possible extensions of the fault, but are parallel, rather than coincident with the northern segment of the Mesa Butte fault. No clear alignment seems to connect the northern and southern segments of the Mesa Butte fault system.

The WNW trending alignments found in the clusters that cross the center of the field are also interesting, as this both the location of clusters and the orientation of the 
alignments are consistent with the cataract Creek fault zone that crosses the area in this location.

Two preliminary speculative conclusions can be drawn from these observations. The first is that the strong correlation of the cinder cone alignments with the older, and deep-seated fault structures suggests that the latter play an important role in controlling cinder cone alignment. A second speculation is that (if the first conclusion is correct) the northern and southern segments of the Mesa Butte fault are not the extremes of a single fault, as suggested previously (Shoemaker et al., 1978), but are really two separate and parallel fault systems whose southern and northern ends respectively have been buried by the volcanism in the san Francisco Volcanic field. 


\section{CHAPTER FOUR}

\section{PRELIMINARY GEOPHYSICAL STUDIES}

This chapter presents an analysis of geophysical data available from regional databases and presents the results and analysis of local geophysical data collected in the field in the summer of 1993. The aim of these preliminary geophysical studies is to investigate the geological setting of regional structures and to interpret the relationships between specific structures and vent alignments.

\section{REGIONAL POTENTIAL FIELD DATA}

Gravity and aeromagnetic data extending from latitude $35^{\circ} 03^{\prime} \mathrm{N}$ to $35^{\circ} 47^{\prime} \mathrm{N}$, and from longitude $247^{\circ} 34^{\prime} \mathrm{E}$ to $248^{\circ} 53^{\prime} \mathrm{E}$ (Eig. 3.2) were utilized in the regional geophysical study. The data are from the Decade of North American Geology geophysical data base (National Geophysical Data Center, 1984). The regional data were interpolated to a 77 by 65 grids with a grid spacing of $1.6 \mathrm{~km}$, which was contoured using a minimum curvature algorithm. This particular grid spacing was chosen because it gives the best anomaly map in the study area.

The wavelength filtering method is generaliy used to obtain separation of long wavelength regional anomalies associated with deep crustal or subcrustal features, from 
short wavelength residual anomalies associated with shallow features. As an aid to the interpretation of gravity anomalies, a best fit plane was removed from the interpolated grid and the resulting residual anomalies are shown in Fig. 4.1. The most prominent features on this map are two $20 \mathrm{mgal}$ negative gravity anomalies surrounded by positive gravity anomalies. Qualitatively, it appears that these negative anomalies coincide with areas underlain by silicic volcanic rocks. Negative anomaly A (Eig. 4.1) is centered approximately with the silicic centers of San Francisco Mountain and O'Leary Peak and negative anomaly B is located exactly over the silicic centers of Bull Basin Mesa and Kendrick Peak. These negative anomalies probably reflect the lower densities of the underlying intermediate to silicic volcanic rocks.

Figure 4.2 shows the residual aeromagnetic anomalies in the San Francisco volcanic field. Several NE trending elements are present in the anomaly pattern. These are parallel to and coincide with the regional fault systems (see Chapter 2) and with some vent alignments identified in Chapter 3. For example, the anomaly patterns support the notion, presented in Chapter 3, that the North Mesa Butte (N.M.B. in Fig. 4.2) trend is a separate and parallel trend to the South Mesa Butte fault (S.M.B. in Fig. 4.2). Another NE trending pattern coincides with the oak Creek Canyon Doney Fault trend (O.C.C.-Doney in Fig. 4.2). As the 


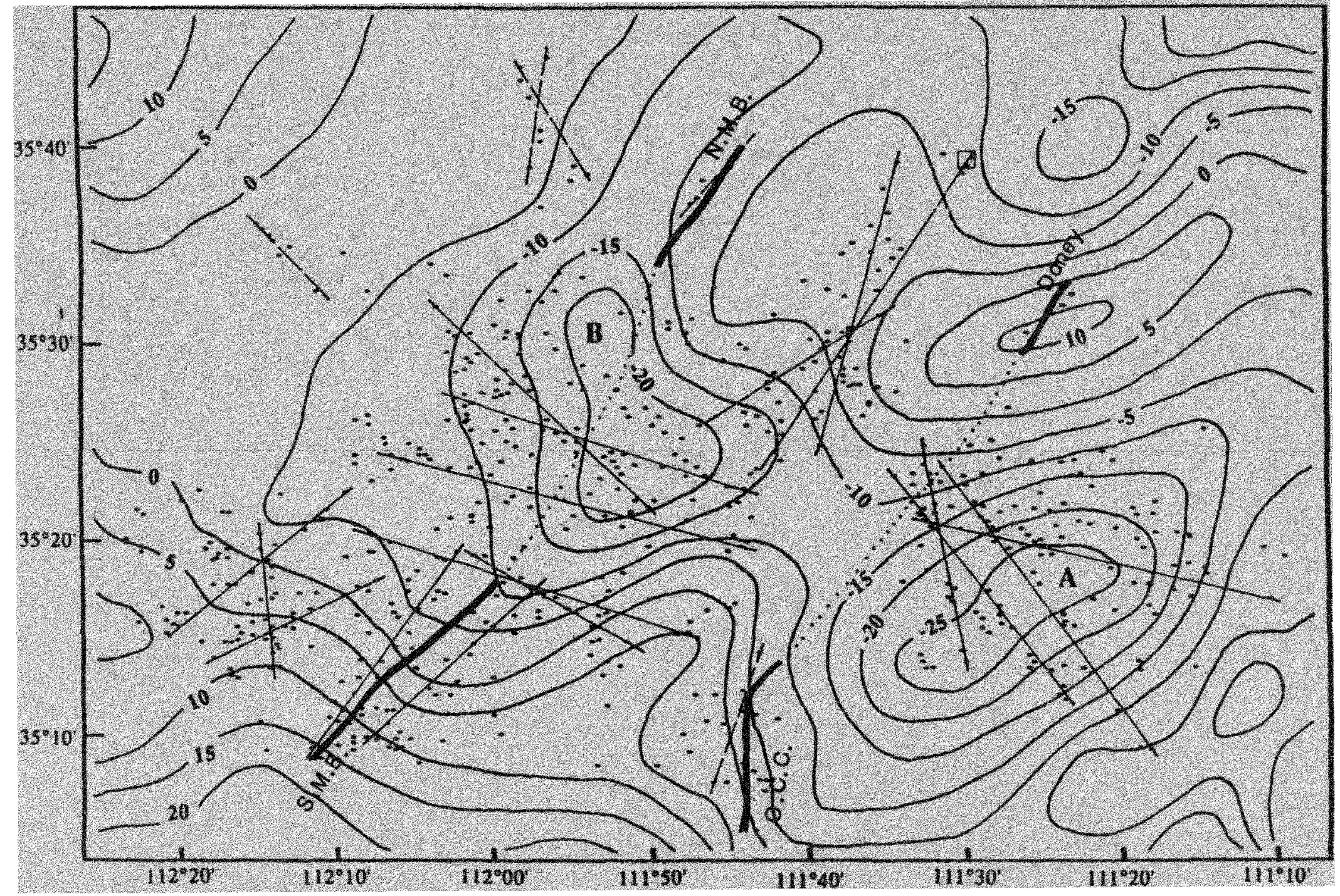

Fig. 4.1: Residual gravity anomalies (mgals) in SFVF overlain by vent alignment pattern (thin lines, search radius $7000 \mathrm{~m}$ ) and major fault systems (thick lines). A and B are two negative gravity anomalies associated with low density surface volcanics. 


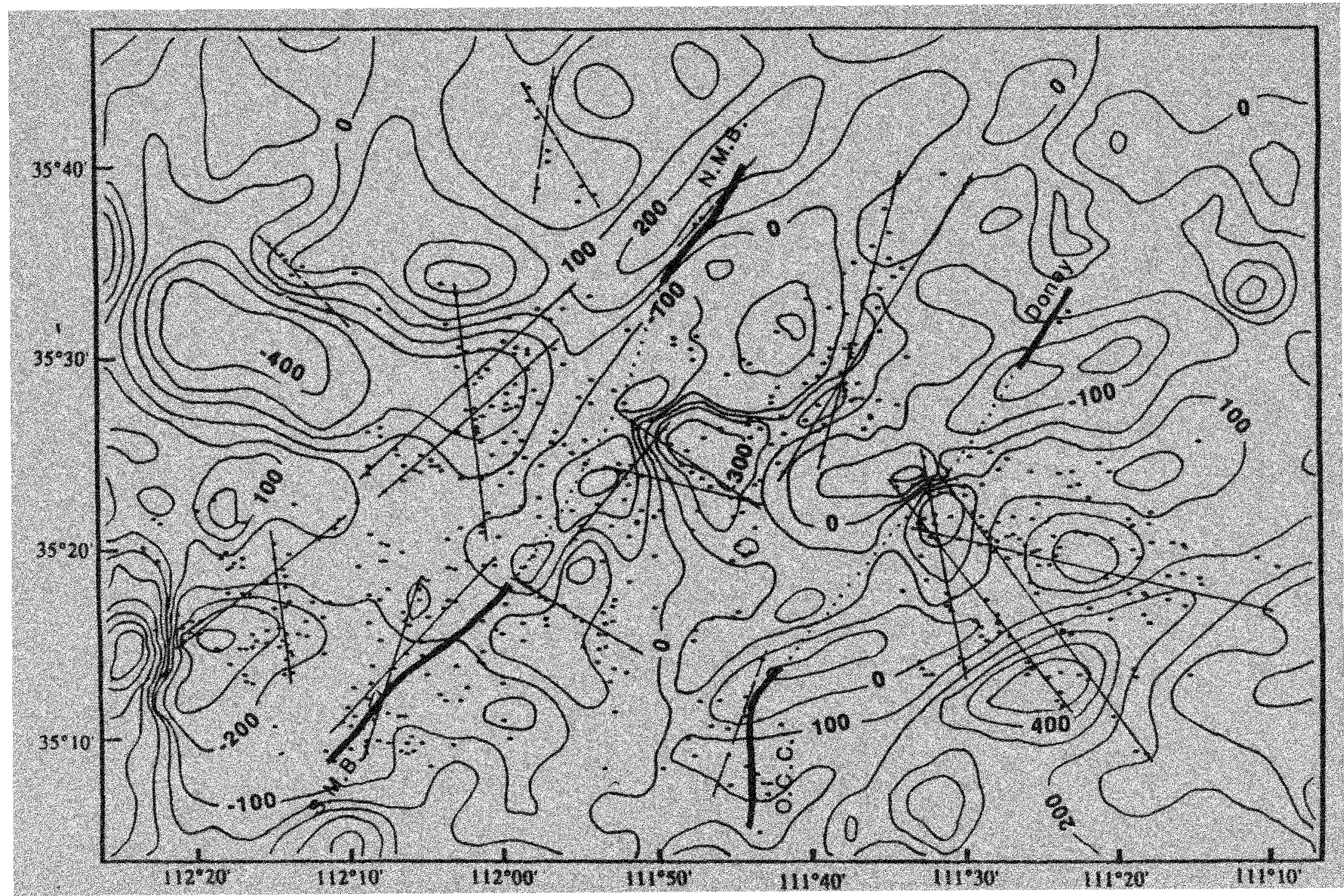

Fig. 4.2: Residual aeromagnetic anomalies (nT) in SFVF (Contour interval 100nT) overlain by vent alignment pattern (search radius $6500 \mathrm{~m}$ ) and major fault systems (thick lines). 
anomalies indicate deep seated features, the coincidence of anomalies and the faults suggests that the fault systems are major basement structures. Another NE orientation anomaly pattern occurs in the northern part of map between the south Mesa Butte and Oak Creek Canyon - Doney Fault trends. Interestingly, this feature coincides with an elongate concentration (Fig. 3.2), clusters ( 4 and 5 in Figs. 3.11 and 3.12 respectively) and Hough transform alignment (D of Eig. 3.11) determined in the statistical studies.

In addition to the NE trending patterns, Figure 4.2 also shows a WNW trend that cuts through the center of the study area. This trend not only coincides with the diffuse cataract Creek fault system that traverses the study area, but also coincides with several cinder cone lineaments identified in the alignment analysis presented earlier (alignments $K, M$ and $\mathrm{N}$ in Fig.3.11).

In an attempt to obtain more information from the gravity anomalies, a NE directional filter (pass band $025^{\circ}-$ $065^{\circ}$ ) was applied to the gravity data and the directional filtered gravity anomaly map is shown in Figure 4.3. The directional filtering produces several high gradient anomaly zones which correspond to density contrasts at depth. A strong high gradient anomaly zone coincides with the oak Creek Canyon-Doney fault system, suggesting that the oak Creek Canyon-Doney fault system is a continuous feature that penetrates basement beneath the surface volcanics. In 


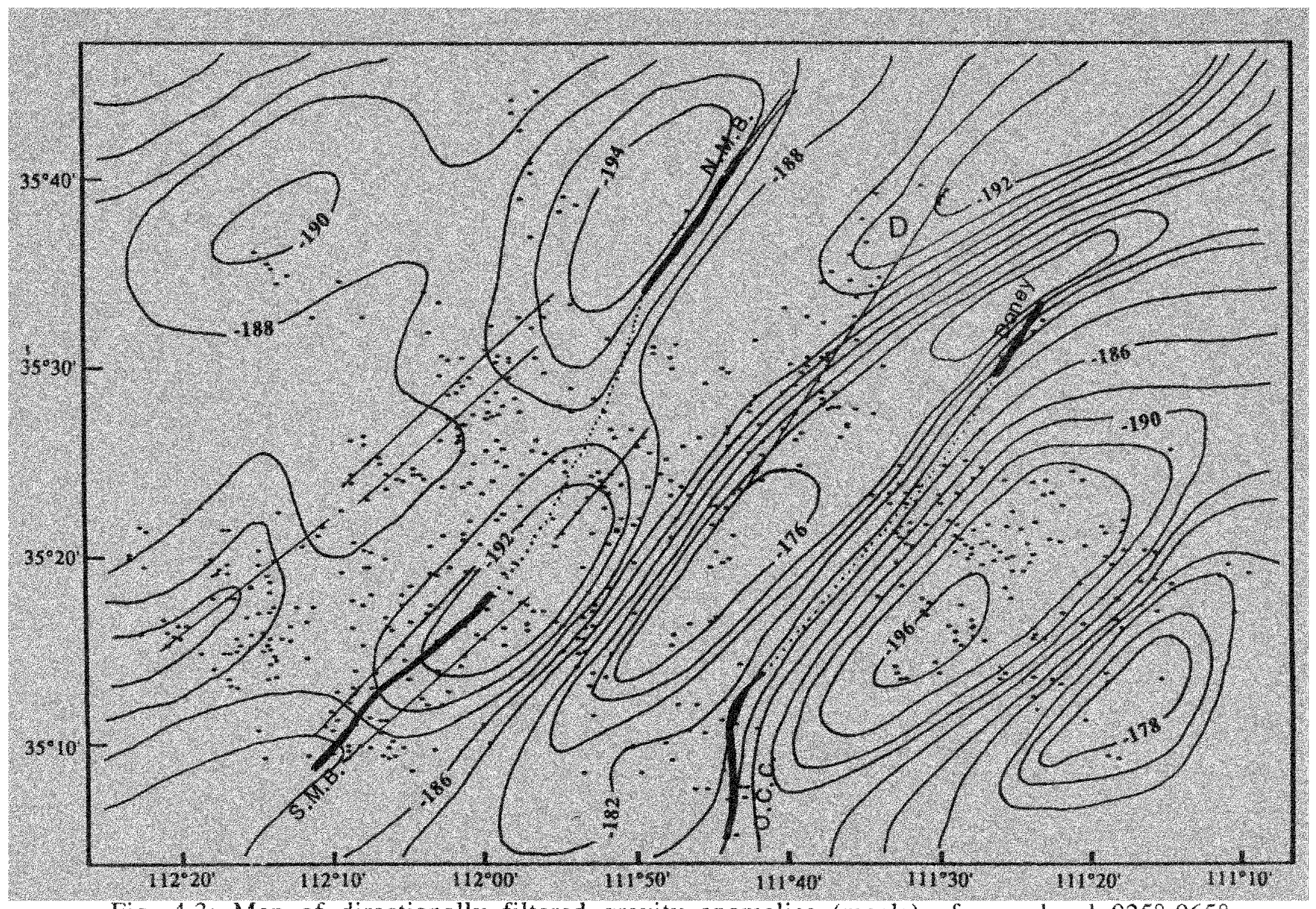

Fig. 4.3: Map of directionally filtered gravity anomalies (mgals) of pass band $025^{\circ}-065^{\circ}$. Thick lines are Mesa Butte and Oak Creek Canyon-Doney fault systems. Straight lines are some NE-trending vent alignments. 
contrast to the Oak Creek Canyon-Doney fault system, the Mesa Butte fault system does not coincide with a steep gravity gradient. Instead, the anomalies suggest, as do the the magnetic anomaly and vent alignment patterns (see chapter 3), that the north and south segments of Mesa Butte fault system are probably two distinct faults (Fig. 4.3). Interestingly, between the South Mesa Butte and Oak Creek Canyon-Doney fault trends, there is a continuous, high gradient zone (Fig. 4.3). This high gradient zone coincides the magnetic trend mentioned above and with vent alignment $D$ shown in Fig. 4.3. It is therefore suggested that this high gradient zone marks the presence of a major fault zone at depth, which has no direct surface manifestation, but that vent alignment $D$ may be related to the same regional fault structure responsible for the gravity anomaly.

In summary, it is suggested that the analysis of the regional geophysical data, in combination with some of the results of the alignment analysis, indicates that there are four large scale, NE trending fault systems in the san Francisco Volcanic Field: (1) a northern segment of the Mesa Butte, (2) a southern segment of the Mesa Butte, (3) an unnamed fault system Between the Mesa Butte and Oak Creek Canyon-Doney, and (4) the Oak Creek Canyon-Doney Fault system.

In addition, NWW trending residual aeromagnetic anomalies shown in Eigure 4.2 form a broad zone which is 
coincident with Cataract Creek system and is also coincident with several cinder cone alignments (specifically, alignments $\mathrm{K}, \mathrm{M}$ and $\mathrm{N}$ of Fig.3.11).

\section{SPIDER WEB RANCH GEOPHYSICAL SURVEYS}

A detailed gravity and magnetic survey was conducted in the spider web Ranch area $\left(35^{\circ} 38^{\prime} 40^{\prime} ' \mathrm{~N}, 35^{\circ} 39^{\prime} 32^{\prime \prime} \mathrm{N}\right.$; $\left.248^{\circ} 29^{\prime} 15^{\prime \prime} \mathrm{E}, 248^{\circ} 30^{\prime} \mathrm{E}\right)$ in the northeastern portion of the study region. This area was chosen to investigate structures associated with a particular vent and vent alignment, such as feeder dikes and faults. This area was chosen because it is not covered by basaltic lava flows and because dikes and normal faults are exposed at the surface (Fig. 4.4). The trend of these features has the same orientation as alignment D identified from the alignment analysis (Fig. 3.11).

The local geological features in spider web Ranch area are shown in Fig. 4.4 (from Ulrich et al., 1987). A 10-40 meter thick sequence of shale, siltstone, and sandstone of the Moenkopi Formation underlies the area. Five to ten meter thick basalt flows and two cinder cone vents overlie these sediments. The lava flows are predominantly plagioclasephyric basalts. A basaltic feeder dike to vent 6802 outcrops in the area and is approximately $0.5 \mathrm{~m}$ wide and $150 \mathrm{~m} \mathrm{long}$. This dike is composed of a plagioclase-phyric basalt that has abundant 1 to $3 \mathrm{~mm}$ plagioclase laths and contains baked sandstone xenoliths of the surrounding Moenkopi Formation 


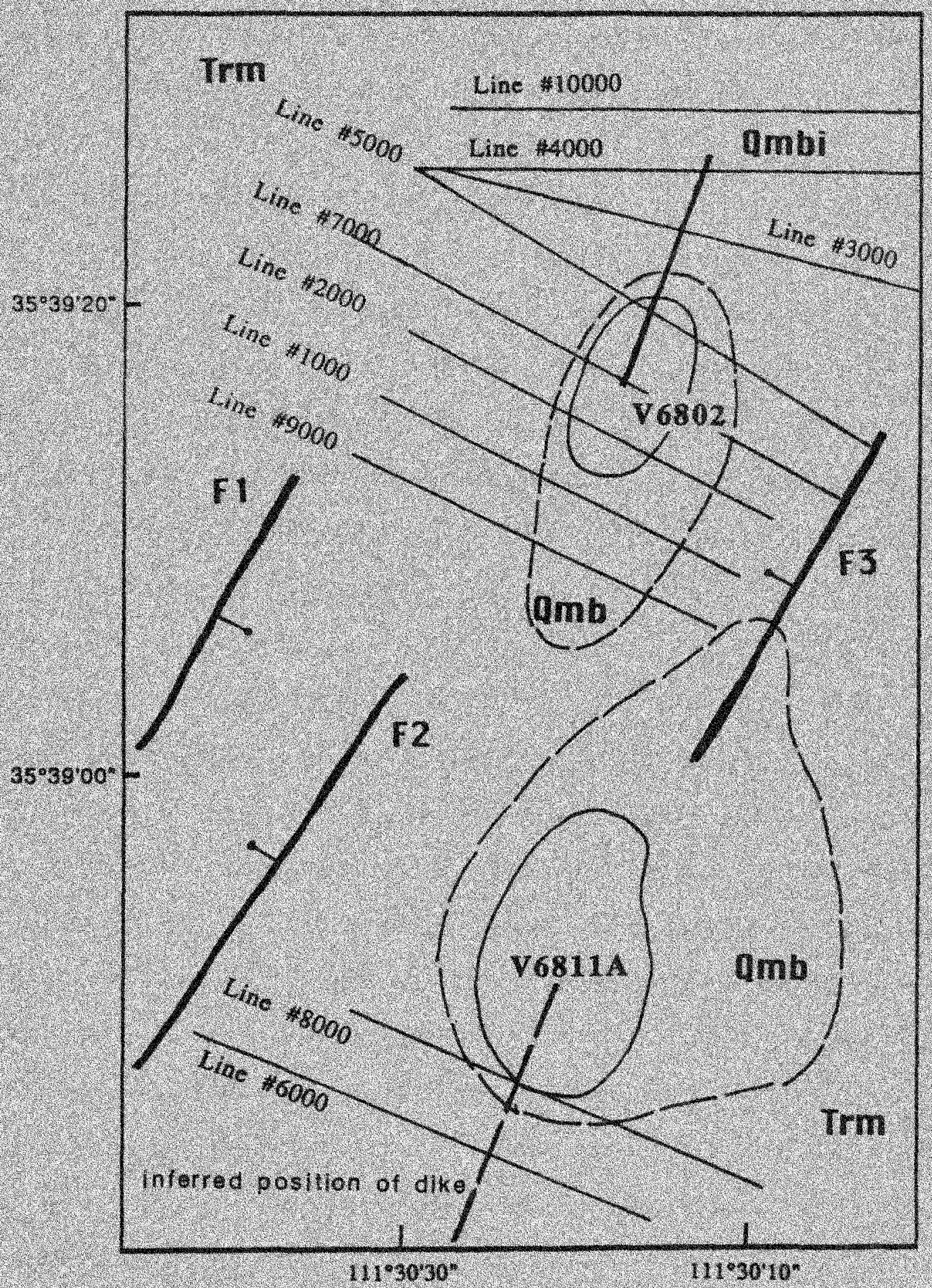

Fig. 4.4: Geological map of Spider Web Ranch area. Qmb: basalt flows erupted from vent V6802 and V6811A; Qmbi: basaltic dike near vent 6802; Trm: Moenkopi Formation. F1, F2 and F3 are local normal faults (bar and ball on downthrown side). 
country rock. Several NE trending normal faults also can be seen in the given area (Fig. 4.4). Field measurements of the trend of these faults range from $018^{\circ}$ to $025^{\circ}$.

Gravity and magnetic data were collected along profiles at $20-50 \mathrm{~m}$ and $2.5-20 \mathrm{~m}$ station spacing respectively. The total area surveyed was about one square kilometer. Gravity measurements were made using a Lacoste and Romberg gravimeter, which has a measured drift of less than $0.1 \mathrm{mgals} / \mathrm{month}$. Magnetic measurements were made using a proton precession magnetometer. Elevations were surveyed in using a precision automatic level. In total, the survey consisted of 10 profiles across the field (Fig. 4.4). A description of the reduction process and a listing of the gravity and magnetic data is shown in Appendix $B$.

Fig. 4.5 shows 8 Bouguer gravity anomaly profiles across vent 6802 and its associated dike. Because of the limited topography, the terrain correction was omitted. The tide correction was also omitted because the measurements were taken over a limited time interval. An assumption of a density of $2.67 \mathrm{~g} / \mathrm{Cc}$ was made for the Bouguer correction. The absolute gravity value for our base station was tied to the Complete Bouguer Gravity Map of SP Mountain Quadrangle (Hendricks, 1975).

\section{Results - Gravity}

The most notable feature on the gravity profiles is an approximately $0.5 \mathrm{mgal}$ low anomaly which is coincident with 


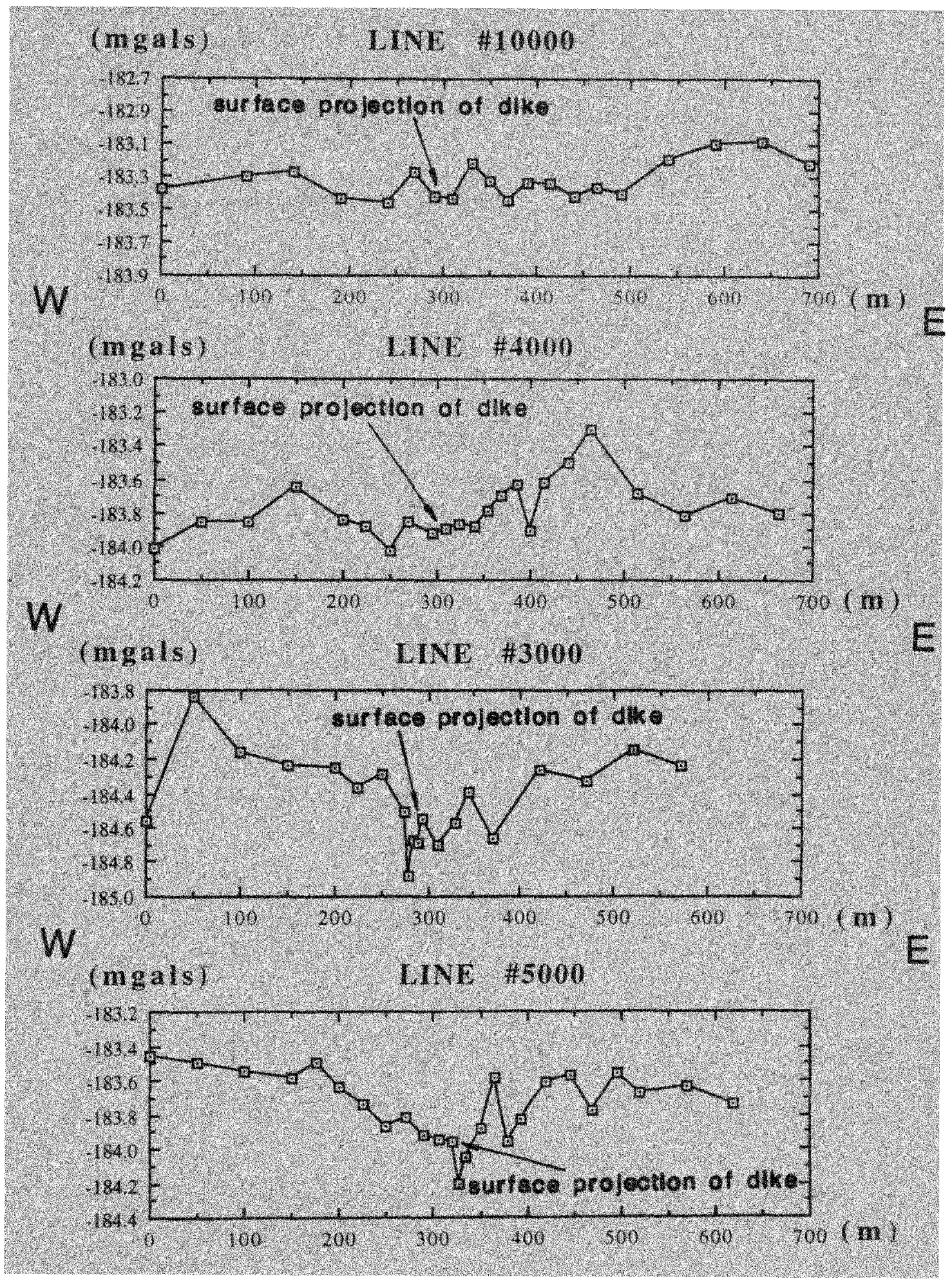

Fig. 4.5: Bouguer anomaly of gravity survey profiles (Line \#10000. Line \#4000, Line \#3000, and Line \#5000). Location of lines is shown on Figure 4.4. 


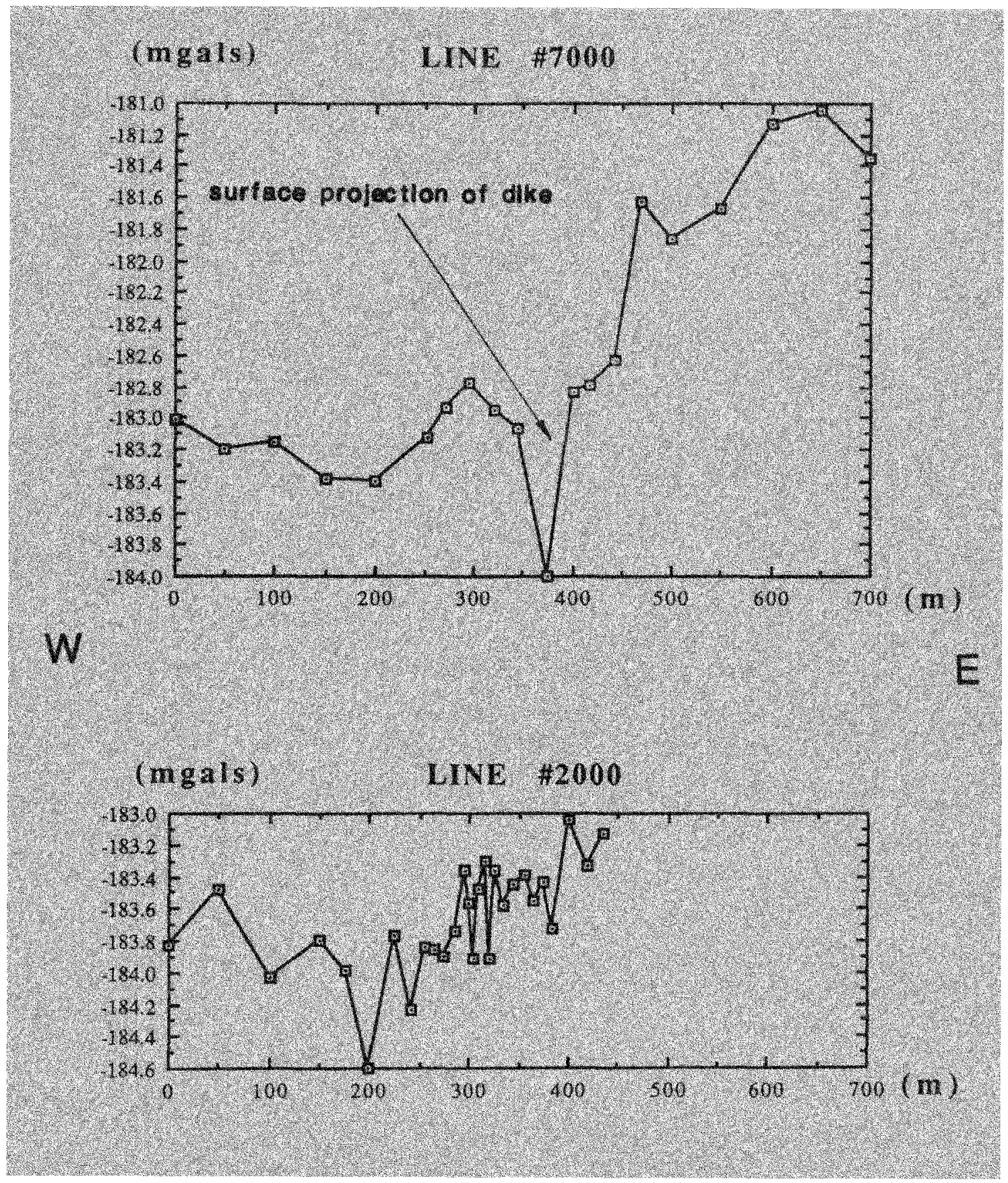

Fig. 4.5(continued): Bouguer anomaly of gravity survey profiles (Line \#7000 and Line \#2000). 


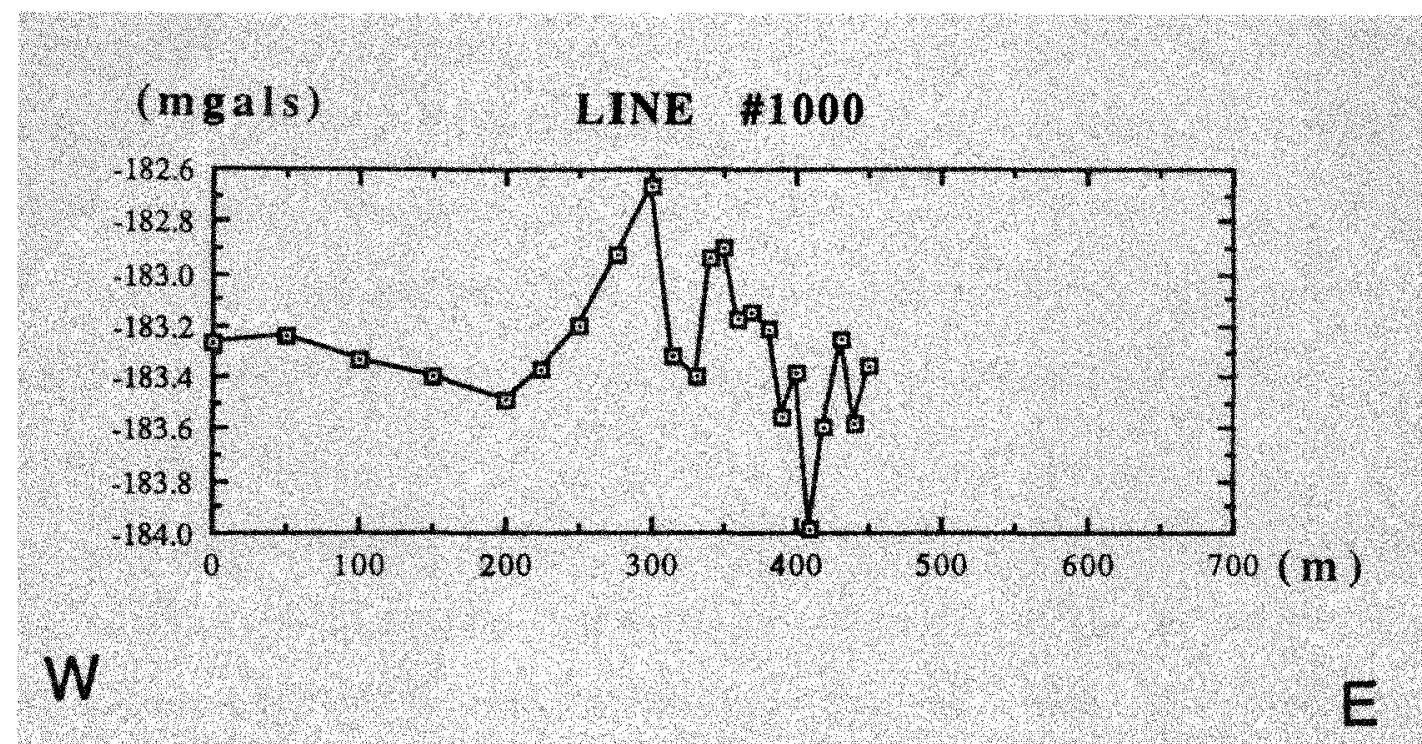

(mgals)

LINE $\$ 9000$

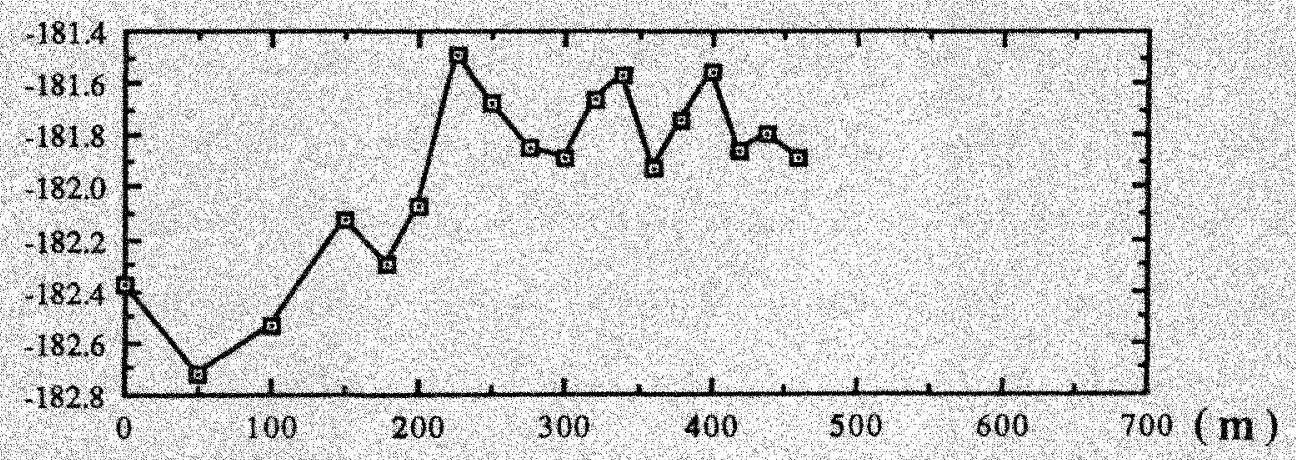

Fig. 4.5(continued): Bouguer anomaly of gravity survey profiles (Line \#1000 and Line \#9000). 
the dike and vent (Fig. 4.5, Line \#3000, Line \#5000 and Line \#4000). Further away from the dike, the anomalies disappear. A contour map of the gravity data is shown in Fig. 4.6. In order to produce this map, point data were smoothed with a 3 point moving average and contoured with a minimum curvature contouring algorithm. The contour map clearly shows a small negative anomaly that is elongate with the orientation of the dike (Fig. 4.6).

Since the amplitude of the anomaly is relatively small, the assumed Bouguer reduction density may have a large relative effect on the anomaly, and an incorrect reduction density will result in a correlation between the Bouguer anomaly and topography. In order to test for this possibility, a plot of observed free air anomaly verses station elevation was made (Fig. 4,7). The slope of best fitting line is used to find the reduction density for Bouguer correction. This analysis resulted in a reduction density of $2.865 \mathrm{~g} / \mathrm{cc}$. For this reduction density, the amplitude of the negative anomaly is actually slightly larger than that calculated using a density of $2.67 \mathrm{~g} / \mathrm{cc}$. Therefore, the negative anomaly in this survey is not simply an artifact of the reduction process.

The density of cinder cone volcanic eruption materials and dike has a positive difference with the surrounding Moenkopi Formations. If so, the anomalies of profiles should be the reverse of that which is observed. Therefore, some 


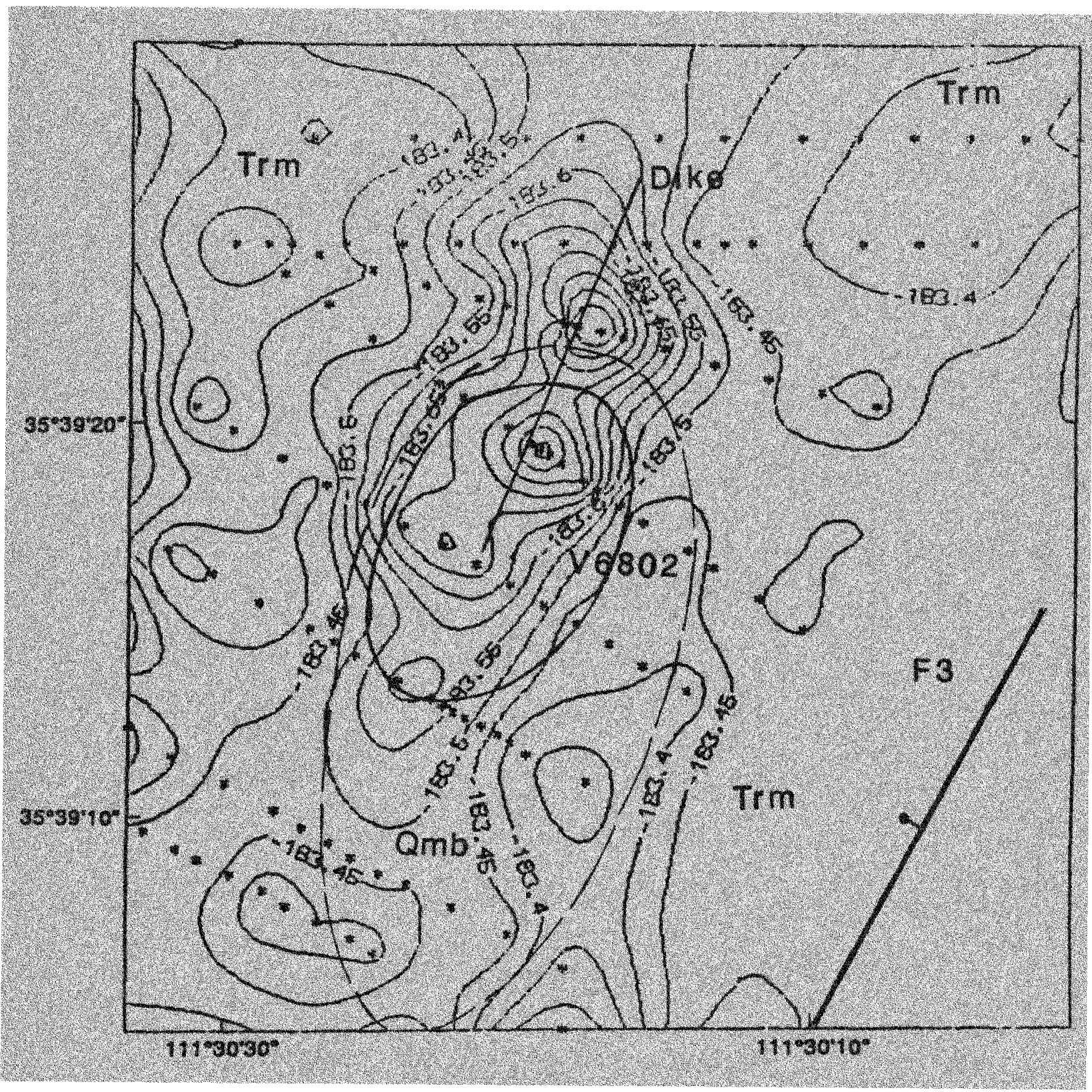

Fig. 4.6: Plane map of gravity anomalies (mgals) and geological features in vent 6802 area. Asterisk represents survey stations. 


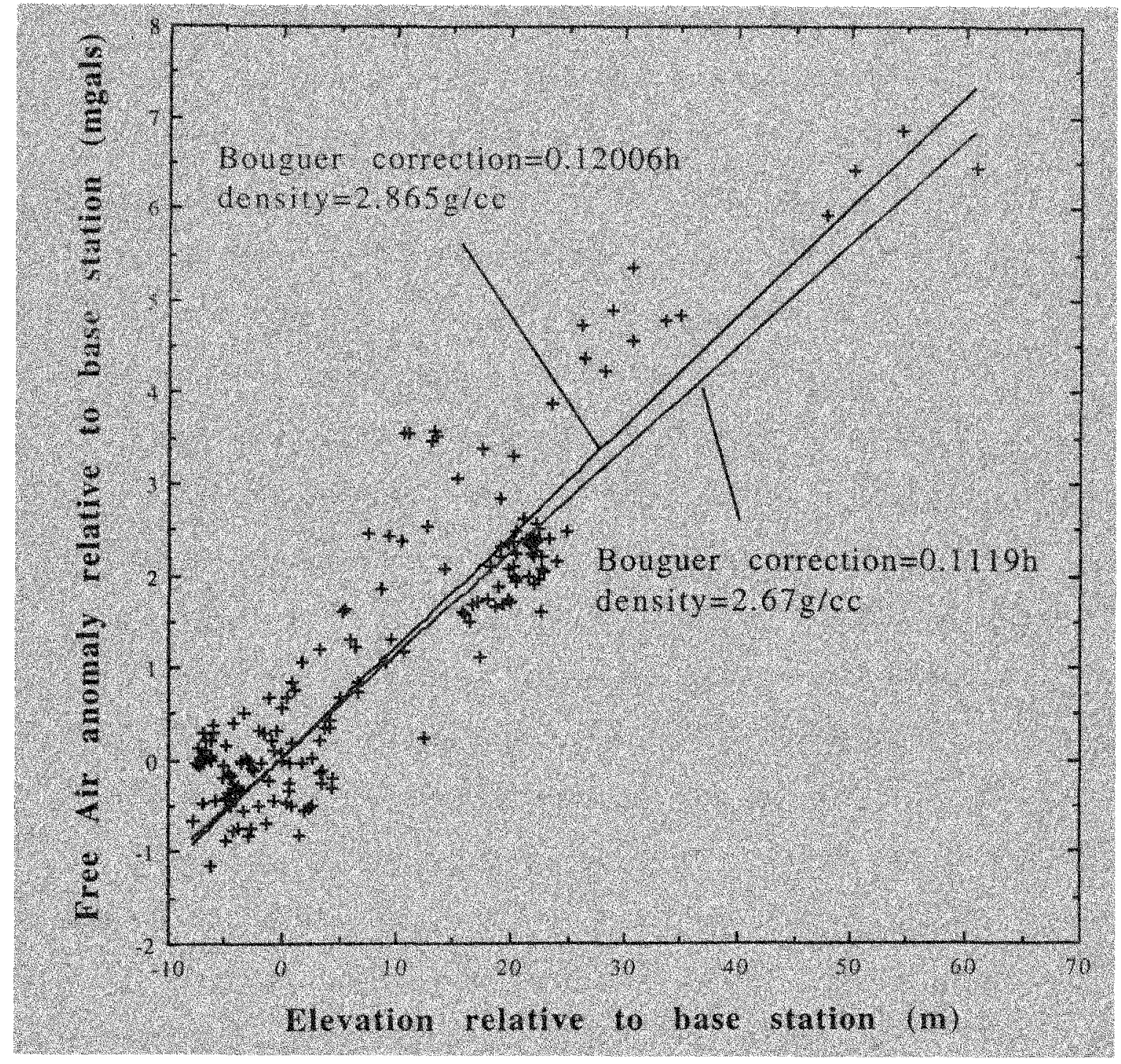

Fig. 4.7: Scatter plot showing the relationship between Free Air anomaly and elevation. The best fitting line corresponds to a Bouguer reduction density of $2.865 \mathrm{~g} / \mathrm{cc}$. For comparison, a line corresponds to density of $2.67 \mathrm{~g} / \mathrm{cc}$ is shown. 
geological processes might have occurred to make this area less dense when forming the dike. The anomaly in Fig. 4.6 is elongate exactly with the trend of the dike and this suggests that processes related to dike emplacement may be responsible for the small negative anomaly. One possibility may be that hydrothermal brecciation during dike intrusion has lowered the bulk density of the country rock immediately around the dike and beneath the anomaly.

\section{Results - magnetism}

The basaltic rocks in the field area show a strong magnetic signature (Fig. 4.8). This signature is the strongest on profiles which are situated on the basalt flows (Fig. 4.8, Line \#5000 and Line \#7000). These profiles are difficult to interpret because of the strong isothermal remnant magnetization due to frequent lightning strikes in this region. The magnetic anomaly of survey line \#10000 which situated on Moenkopi Formation area is much smaller than on the basalt flows (Line \#5000 and Line \#7000). In this survey Iine, the dike does not outcrop beneath the profile, but the magnetic anomaly has a remarkable dike signature (Fig. 4.9). This indicates that a dike must exist beneath the surface because a dike usually has a higher magnetite composition than Moenkopi Formation in this area.

In order to investigate the gravity and magnetic anomalies near other vents, two survey lines were conducted at vent $6811 \mathrm{~A}$ which is aligned with vent 6802 and offset 800 


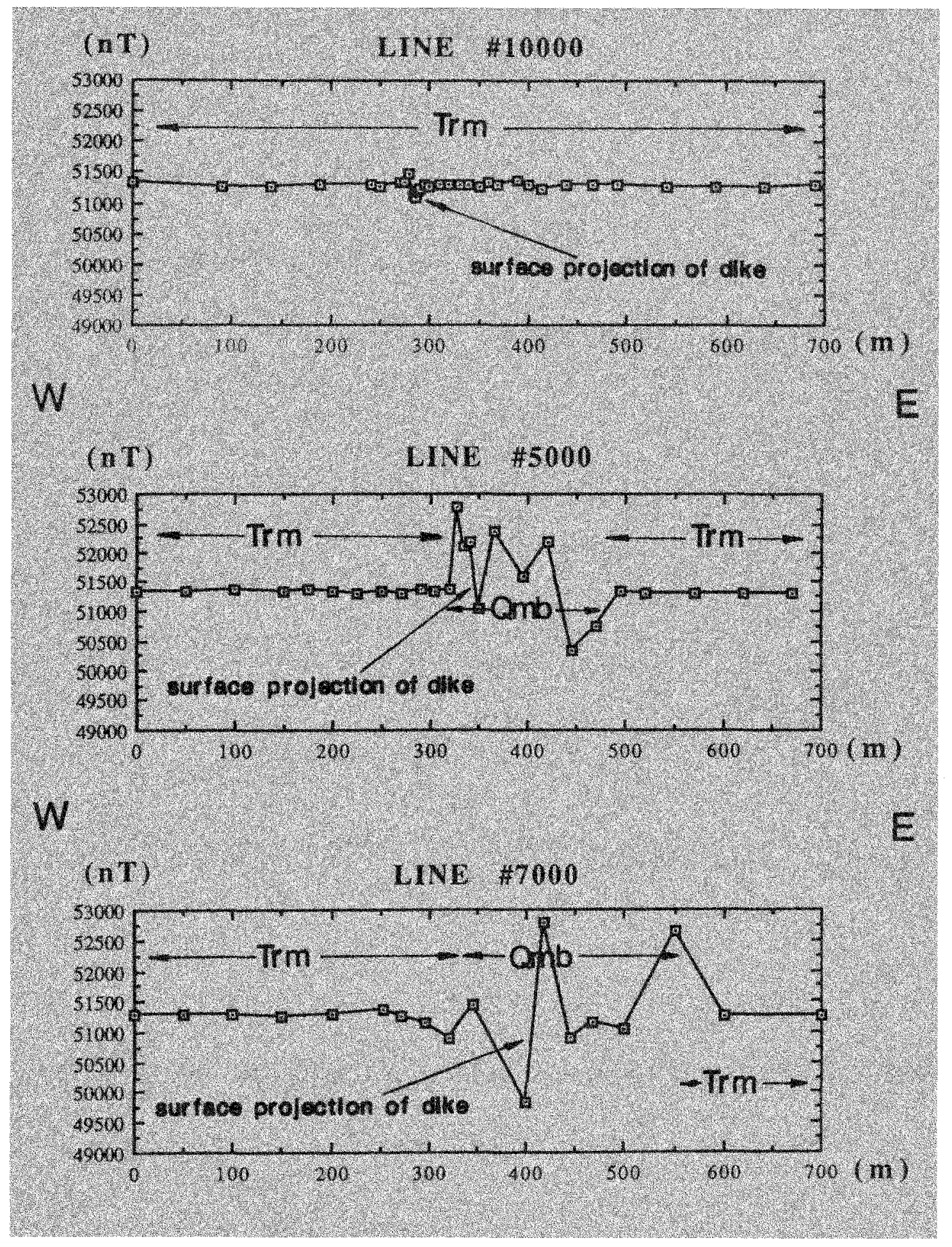

Fig. 4.8: The anomaly of 3 magnetic profiles (Line \#10000, Line $\# 5000$ and Line $\# 7000$ ) across the dike. 


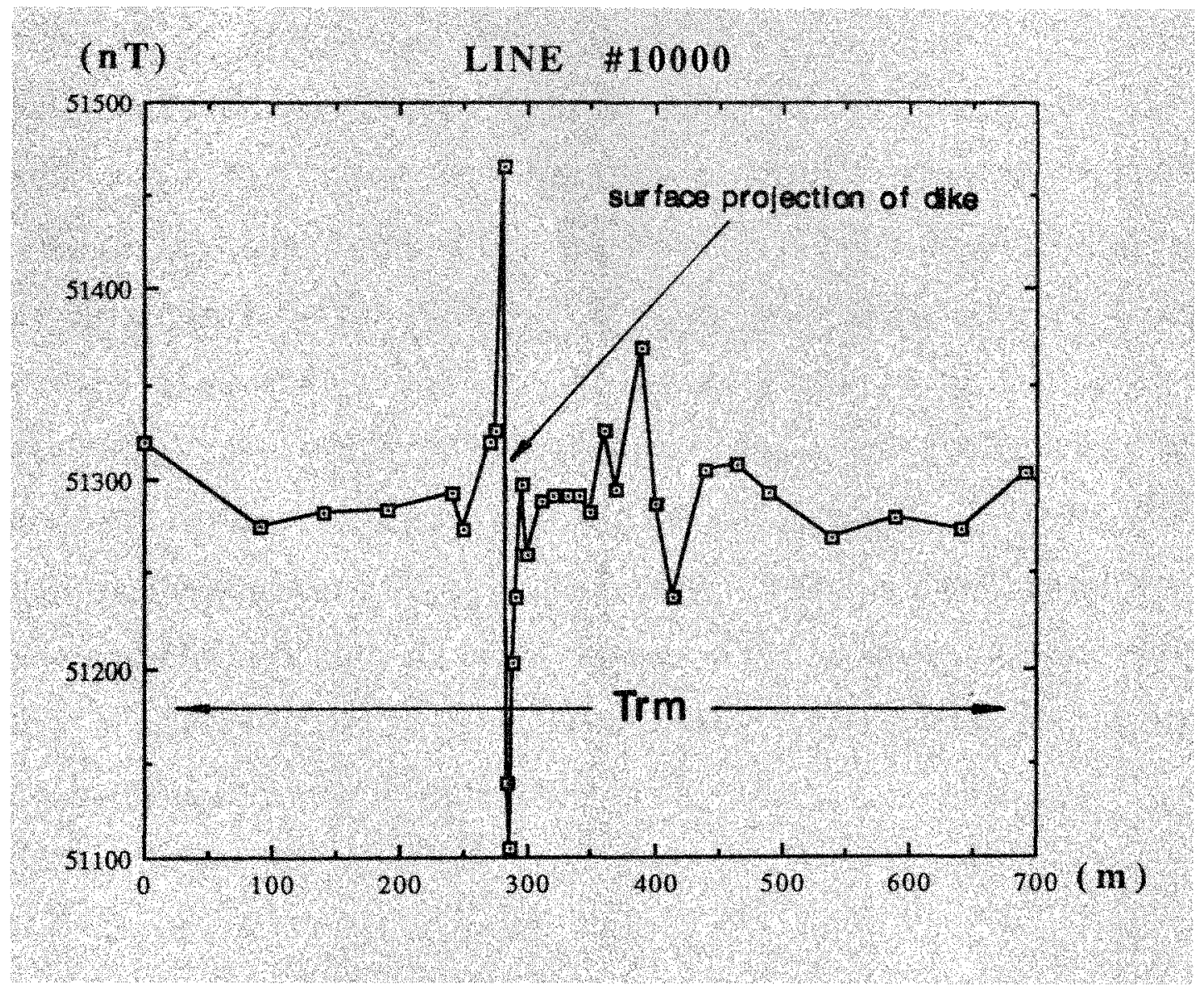

Fig. 4.9: The magnetic anomaly of Line \#10000 in expanded scale. 
meters to the south. Fig. 4.10 and Fig. 4.11 show the gravity and magnetic anomaly profiles. The gravity anomaly for the survey line \#6000 has a low similar to those on lines \#5000 and \#3000, and survey line \#8000 looks very similar to line $\# 7000$ (Fig. 4.5). Also. the survey line \#8000 and line \#6000 show the same magnetic anomaly shape as the line \#10000 in Fig. 4.9. The only difference is that the amplitude of anomaly in line \#8000 and line \#6000 is much bigger than the one of line \#10000. This may suggest that the size of a dike beneath line \#8000 and line \#6000 is bigger than the dike in vent 6802 . The gravity and magnetic anomalies associated with vent 6811 A have features similar to those near vent 6802 . This suggests that similar to vent 6802 , a dike must exist beneath the surface of vent 6811A (Fig. 4.4) like vent 6802 . This suggests that many aligned vents may be associated with a dike beneath the surface. 


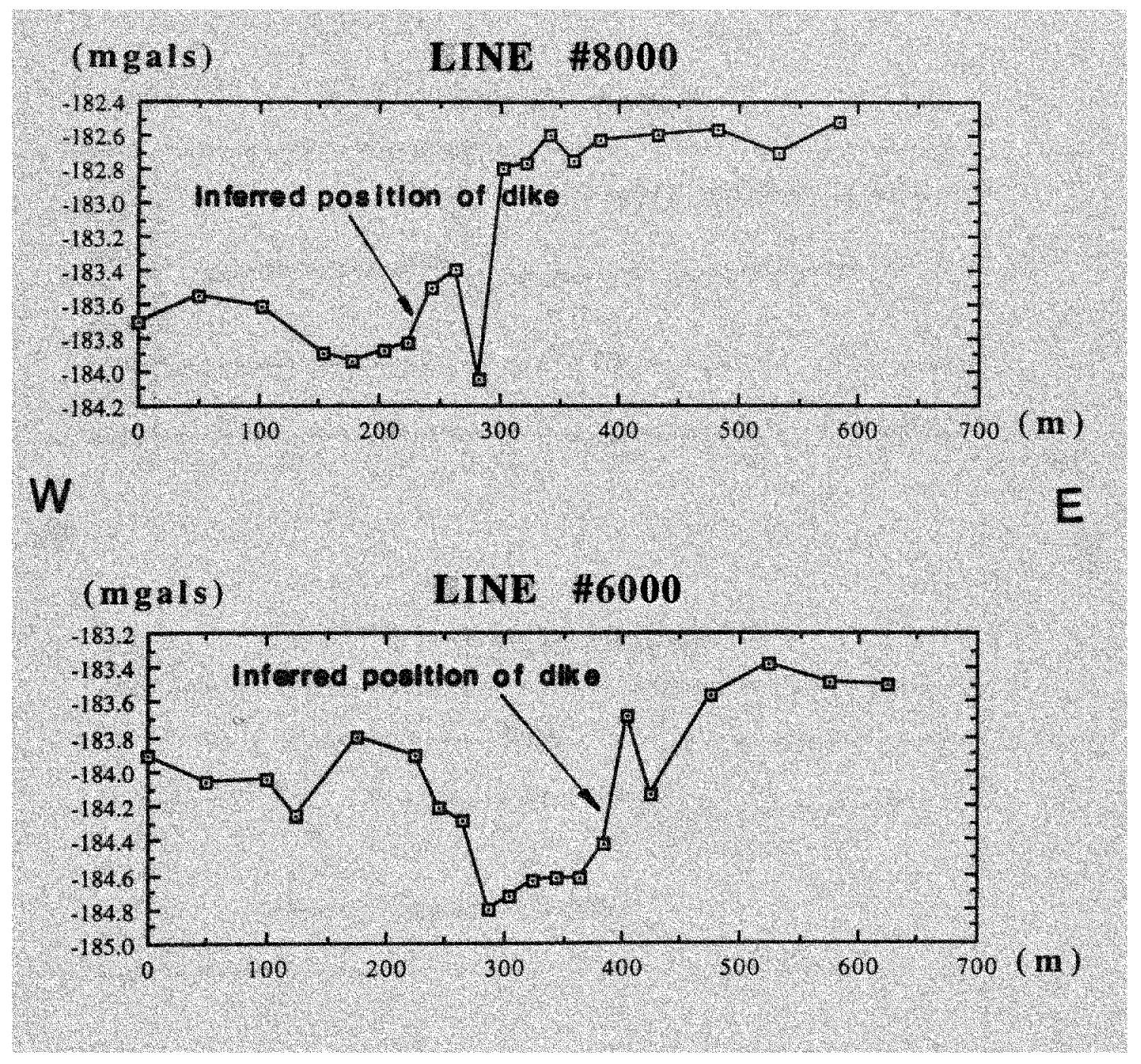

Fig. 4.10: Bouguer anomaly of gravity survey profiles (Line $\# 8000$ and Line \#6000) near vent 6811A. refer to map figure which shows location of profiles (Fig. 4.4). 


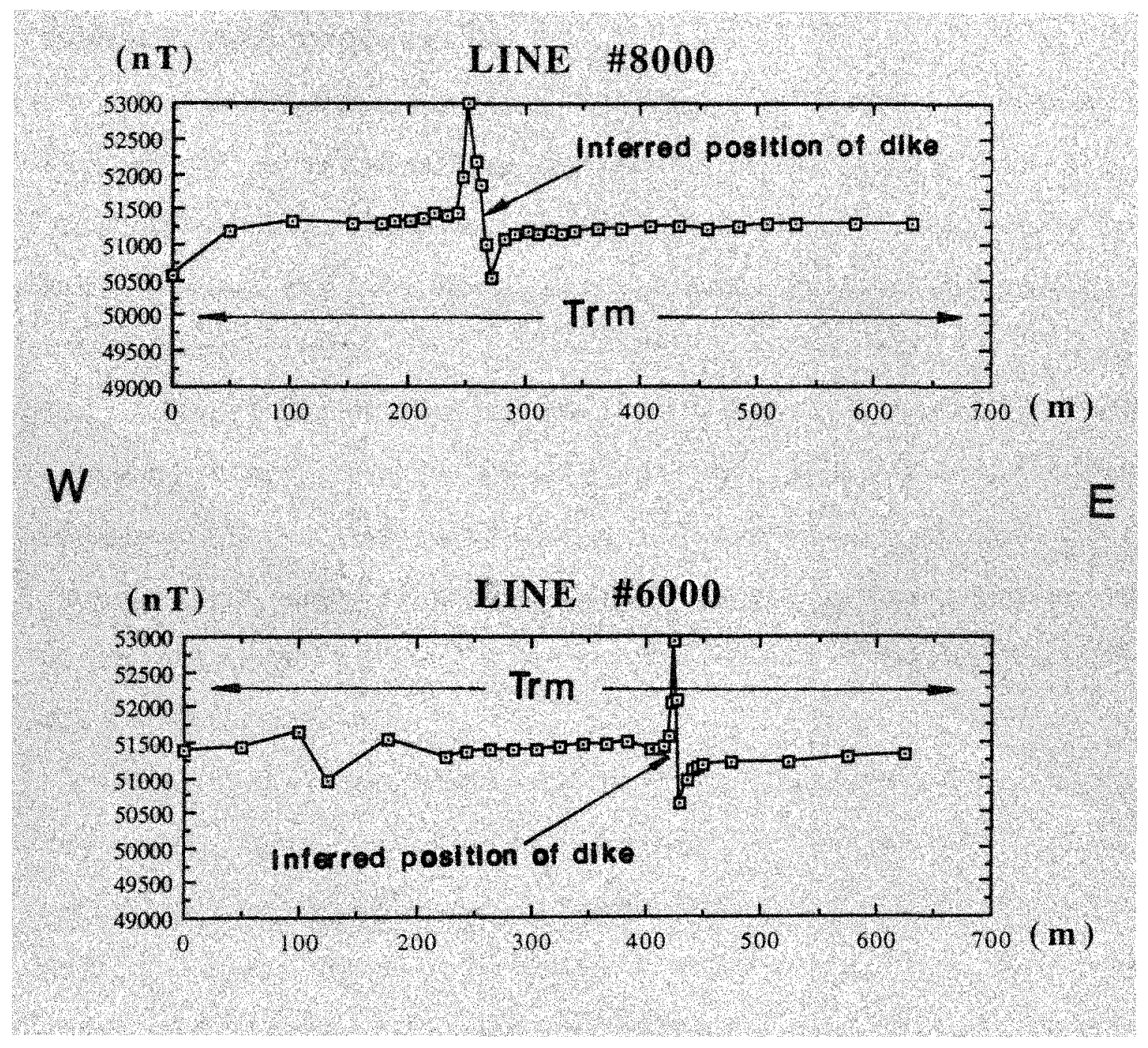

Fig. 4.11: The anomaly of magnetic profiles (Line \#8000 and Line \#6000) near vent 6811A. refer to map figure which shows location of profiles (Fig. 4.4). 


\section{CHAPTER FIVE}

\section{DISCUSSIONS AND CONCLUSIONS}

\section{SUMMARY AND DISCUSSION}

The statistical studies described in Chapter 3 establish a strong correspondence between cinder cone, density, clustering and alignments with old fault structures in the substrate of the San Francisco Volcanic Field, especially in its western portion.

Density distribution maps (Figs. 3.1 and 3.2) show concentrations of vent density adjacent and collinear to the segments of the Mesa Butte fault. There is a high density of vents to the east of the Oak Creek Canyon - Doney trend, but it is not elongate and does not coincide directly with the ocC-Doney trend.

Cluster analysis defines several clusters of vents that are distributed broadly over the north, central and southern parts of the field. Vent alignment patterns, determined in each of these using the Hough Transform method, show well developed Iineaments whose orientations are parallel to, and in some cases correspond exactly to the major fault systems that cut the Pre-Cambrian to Mesozoic rocks that underlie the area. In the western part of the field, both in the north and the south, the vent alignments are predominantly oriented in a NE direction. These vent alignments are usually $20-38 \mathrm{~km}$ in 
length and include 9-10 vents. Some of these alignments are collinear with and appear to be an extension of the northern segment of the Mesa Butte fault system. Similarly, alignments in the northern part of the field are collinear with the southern segment of the Mesa Butte fault system. These relationships suggest that the volcanic alignments are strongly controlled by the old, deep seated faults such as the Mesa Butte fault system.

Furthermore, as no alignments (or geophysical data) link the southern and northern segments of the Mesa Butte fault "system", it is suggested that these two fault segments are not connected, but are separate and parallel fault systems. The regional geophysical data also support this view. Gravity anomaly maps (Eig. 4.1), and particularly the aeromagnetic anomaly maps (Eig. 4.2), show patterns that suggest that these two trends are separate and parallel.

Cinder cone concentration, alignment analysis and regional geophysics indicate another strong $\mathrm{NE}$ trend in the north-central part of the field, between the Mesa Butte systems and the OCC-Doney systems (Figs. 3.2, 3.11, 3.12 and 4.2). It is suggested that these features indicate another major NE trending fault in the basement.

In contrast, cinder cone concentration, alignment analysis and regional geophysics do not show a particularly strong correlation with the ocC-Doney fault in the eastern part of the field. This poor correlation suggests that this 
particular $N E$ trending fault system does not seem to have heavily influenced vent alignment patterns.

Clusters in the center of the SFVE form a WNW trend as do the Hough transform determined alignments. This trend is both parallel and coincident with the trend of the diffuse WNW Cataract Creek fault system. A similar trend can be seen crossing the study area in the regional geophysical patterns (Eigs. 4.1 and 4.2). These patterns again suggest that old fault trends in the substrate of the field are an important influence in cinder cone alignment.

In summary, it is suggested that the correspondence of statistically defined alignments, regional geophysical anomalies and mapped older faults indicate that vent alignments in the SEVE are strongly controlled by major regional fault structures. In addition, almost all the intermediate to silicic centers in the SEVE occur over buried extensions of the two Mesa Butte and Oak Creek Canyon-Doney fault systems, which suggests that these fault systems play an important role in determining the location of the intermediate to silicic volcanic centers.

If this hypothesis is correct, then this suggests a reinterpretation of the regional structure of the area. It is suggested that the San Francisco Volcanic Field is underlain by four major NW trending fault systems: (1) a northern segment of the Mesa Butte, (2) a southern segment of the Mesa Butte, (3) an unnamed fault system Between the Mesa Butte and 
Oak Creek Canyon-Doney, and (4) the Oak Creek Canyon-Doney Fault system. In addition, the central part of the field is crossed by the more diffuse cataract creek fault system. This new interpretation is compared with the older interpretation (Shoemaker et al, 1978; Tanaka and others, 1979) in Eig. 5.1.

The major intermediate to silicic centers are located adjacent to and along the two Mesa Butte and Oak Creek Canyon-Doney fault systems, and also lie within the Cataract Creek fault system. This coincidence strongly suggests that the intersection of these older fault systems are important in controlling the pathways for silicic magma ascent, although the precise mechanism is unclear.

Field observations and the geophysical studies indicate that dikes underlie and extend into several vents, including those examined in detail at Spider Web Ranch area. At Spider Web Ranch area, at least, the trend of the dikes and the elongation of the volcanic edifice are parallel to the alignment in which they are found.

In the following section, I try to discuss the geological significance of vent alignments and possible mechanism of cinder cone emplacement.

\section{MAGMA EMPLACEMENT IN THE SAN FRANCISCO VOLCANIC FIELD}

Many volcanic vents in the study area are aligned with major regional structures. Intermediate to silicic centers in particular seem to be associated with major fault systems. 


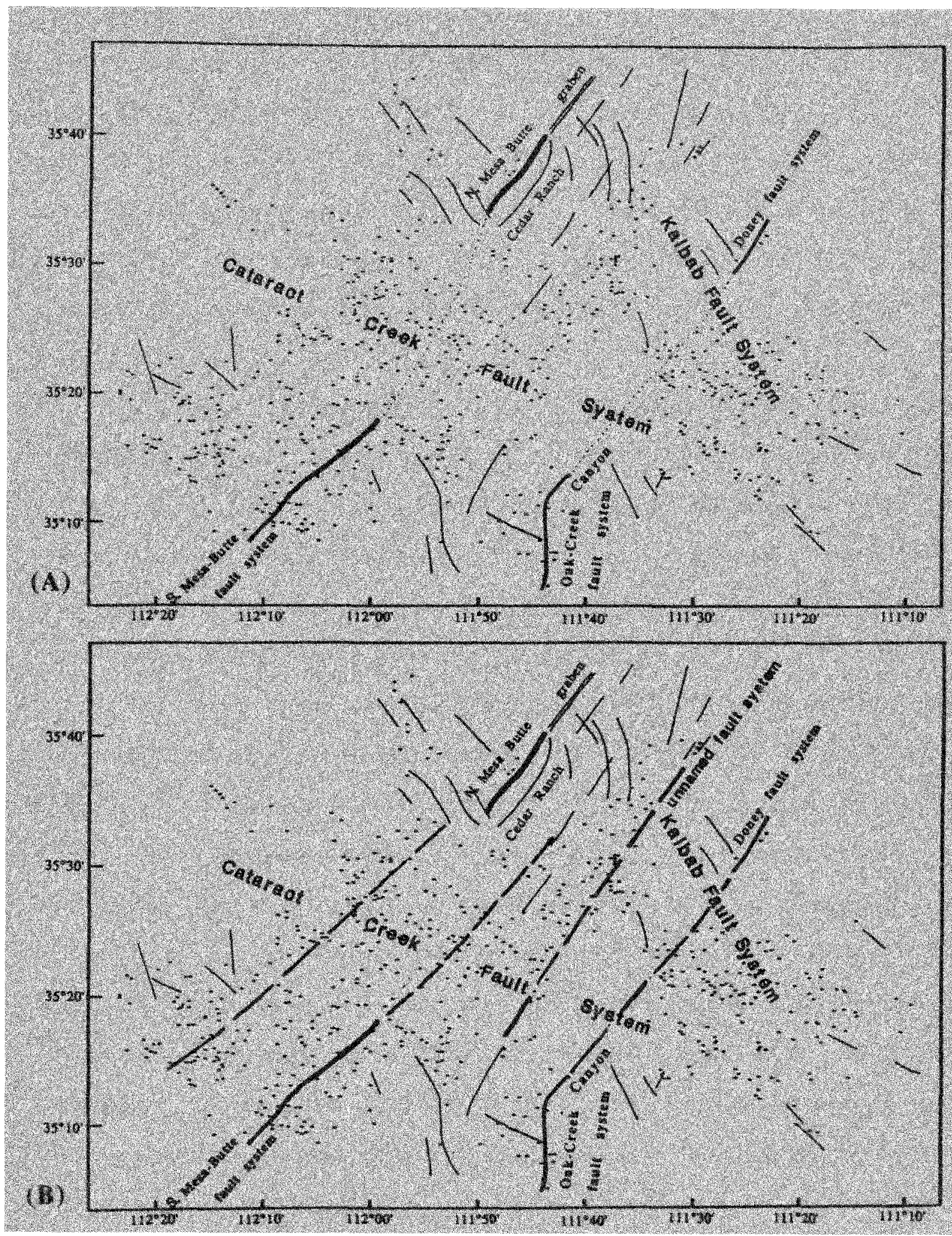

Fig. 5.1: Structural features in the SFVF. (A). previous suggested structural features:-(B). new interpretation of structural features suggested in this study. 
Vent locations, are not entirely controlled by structural features however, as examination of vent alignment patterns (Figs. 3.11 and 3.12 ) indicates that only $30 \%$ of the vents belong to alignments. Most vents in the SFVF are, therefore, not part of the identified alignments. Moreover, vent clusters close to the OCC-Doney Fault show no NE trending alignment.

Density distribution analysis and cluster analysis demonstrate that vents occur in clusters, rather than having an uniform random distribution. These observations suggest that through time there is a tendency for successive pulses of magma injection to occur near one another, rather than randomly over the entire area of the field.

The following simple model is proposed to describe the process of magma emplacement in the SFVF. Magma in a particular pulse rises through the lower crust. When it reaches the upper crust where brittle structural features such as faults are encountered, the faults may act as pathways for the magma, especially if they are large fault systems that penetrate deeply into the crust. If no large faults are encountered then the magma pulse rises up more complex pathways and produces a random pattern of distribution in the cluster it produces. This might explain why only about one third of vents are found in alignments. Final dike orientation and edifice alignment are probably controlled by near surface brittle features such as faults 
and joints (G. Draper personal communication, 1994), but this aspect needs further study.

The role of active (neotectonic) stresses in the SFVF is difficult to evaluate. If active tension were oblique to alignments, then this would indicate that the old, large crustal structures are the main controlling factor in alignment formation. In other words, magma does not rise up a newly formed fracture, but up an older fracture. Tensional stress axes as derived from earthquake data as shown on the Stress Map of North America (Zoback and others, 1991) trend NW in the study area, perpendicular the old NW trending structures (Fig. 5.2). It is therefore impossible to evaluate the influence of the neotectonic stress orientation on the vent alignment orientation. The presence of the WNW trending vent alignments in the Cataract Creek fault system suggests, however, that the role of neotectonic stress orientation is minimal.

\section{CONCLUSIONS}

1. Correspondence of vent alignments, major faults and geophysical trends in the san Francisco Volcanic Field suggests that regional structural fault systems are a major control on vent alignment. Cinder cone alignments which are generally more than $20 \mathrm{~km}$ in length and consist of 9-10 cinder cones in the SEVF also indicates that vent alignments are controlled by regional scale features. Only about one 


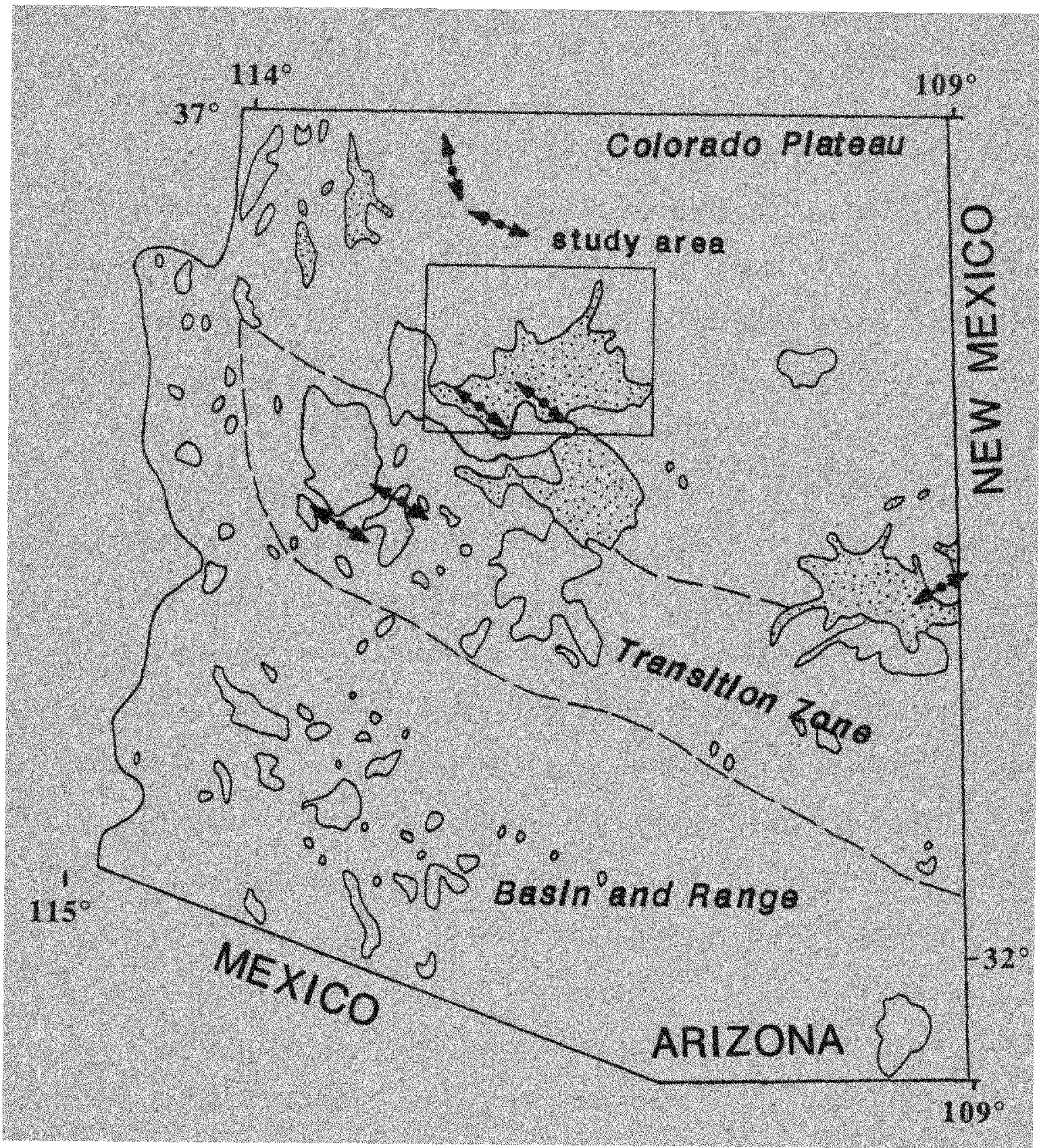

Fig. 5.2: Neotectonic stress orientations derived from fault slip and earthquake focal mechanisms (after Zoback et al., 1991). Shaded areas indicate volcanic fields less than 5 million years old and outlined areas show volcanic fields 5 to 16 million years old. Arrows represent an azimuth of maximum horizontal stress. 
third of the vents in the field are contained in alignments, so these structures do not influence the location of all magma conduits.

2. The Mesa Butte and Oak Creek Canyon-Doney fault systems may serve as pathways for the intermediate to silicic magma to ascend. Large silicic centers form close the intersection of the Cataract Creek fault system with the segments of Mesa Butte, Oak Creek Canyon-Doney fault systems respectively.

3. Statistical alignment and geophysical studies suggest that Mesa Butte fault is not a single continuous system as originally suggested by shoemaker (1978). It is suggested instead that is two separate, but parallel fault systems. Geophysical and alignment studies suggest that a buried $\mathrm{NE}$ trending fault may lie between the Mesa Butte and Oak Creek Canyon-Doney faults. Geophysics confirms that the Oak Creek Canyon-Doney fault is indeed a single continuous structure. Vent alignment patterns indicate that the wNW-trending Cataract Creek fault system (Shoemaker, 1978) transects the field.

4. The orientation of neotectonic stresses is probably not an important factor in controlling vent alignment. 


\section{REFERENCES}

Baker, M.C.W., 1974, Volcanoes, spacing, fractures and the thickness of the lithosphere--A discussion, Earth Planet. Sci. Lett., V.23, p.161-162.

Brumbaugh, D.S., 1987, A tectonic boundary for the southern Colorado Plateau, Tectonophysics, V.136, p.125-136.

Breed, W.J., Stefanic, and Billingsley, G.H., 1986, Geologic guide to the Bright Angel trail, Grand Canyon, Arizona: Carr, M.J, 1976, Underthrusting and Quaternary faulting in northern Central America, Geol. Soc. Am. Bull., V.87, p. $825-829$.

Condit, C.D., L.S. Crumpler, J.C. Aubele and W.E. Elston, 1989, Patterns of volcanism along the southern margin of the Colorado Plateau: The springerville Field, J. Geophys. Res., V.94, p.7975-7986.

Connor, C.B., 1987, Cluster analysis and two-dimensional Fourier analysis of cinder cone distribution: Central Mexico and SE Guatemala (abstract), EOS Trans. AGU, V. $68, p .1526$.

Connor, C.B., and C.D. Condit, 1989, Evidence of structural controls on vent distribution: Springerville volcanic field, Arizona, Geol. Soc. Am. Abstr. program, V.21, A15.

Connor, C.B., and C.D. Condit, and L.S. Crumpler, 1992, Evidence of regional structure controls on vent 
distribution: Springerville volcanic field, Arizona, Journal of Geophysical Research, v.97, p.12349-12359.

Connor, C.B., 1990, Cinder cone clustering in the

Transmexican volcanic belt: implications for structural and petrologic models, Journal of Geophysical Research, V.95(B12): p.19395-19405.

Decade of North American Geology geophysical data base, National Geophysical Data Center, 1984.

Delaney, P.T., D.D. Pollard, J.I. Ziony and E.H. Mchee, 1986, Field relations between dikes and joints: Emplacement processes and paleostress analysis, J. Geophys. Res., V.91, p.4920-4938.

Fedotov, S.A., 1981, Magma rates in feeding conduits of different volcanic centers, Jour. Volcan. Geotherm. Res., V.9, p.379-394.

Hasenaka, T., and Carmichael, I.S.E., 1985, The cinder cones of the Michoacan-Guanajuato, Central Mexico, their age, volume, distribution and magma discharge rate, J. Volcan, Geotherm.Res., V.25, p.105-204.

Heming, R.E., 1980, Patterns of Quaternary basaltic volcanism in the northern North Island, New Zealand, N.Z.J. Geol. Geophys., V.23, p.335-344.

Hendricks, John D., 1975, Complete Bouguer gravity map of SP mountain quadrangle, Coconino county, Arizona. 
Kear, D., 1964, Volcanic alignments north and west of New Zealand's central volcanic region, N.Z. J. Geol. Geophys., V.7, p.24-44.

Lutz, T.M., 1986, An analysis of the orientations of large scale crustal structures: A statistical approach based on areal distributions of pointlike features, J. Geophys. Res., V.91, p.421-434.

Moore, R.B., and Wolfe, E.W., 1987, Geologic map of the east part of the San Francisco volcanic field, north-central Arizona, U.S. Geological Survey Map MF-1960.

Nakamura, K., 1977, Volcanoes as possible indicators of tectonic stress orientation-Principles and proposal, J. Volcanol. Geotherm. Res., V.2, p.1-6.

Nakamura, K., Plafker, G., Jacob, K.H., and Davies, J.N., 1979, A tectonic stress trajectory map using information from volcanoes and faults: Bulletin of the Earthquake Institute, Tokyo, V.55, p.89-100.

Newhall, C.G., Ulrich, G.E. and Wolfe, E.W., 1987, Geologic map of the southwest part of the San Erancisco volcanic field, north-central Arizona, U.S. Geological Survey Map MF-1958.

Perry, E.V., W.S. Baldridge, D.J. DePaolo and M. Shafiqullah, 1990, Evolution of a magmatic system during continental extension: the Mount Taylor volcanic field, New Mexico, J. Geol. Geophys., V.95, p.19327-19348. 
Peterson, F., and Turner-Peterson, C., 1989, Geology of the Colorado Plateau: Grand Junction to Denver, Colorado. Field Trip Guidebook T130, 28th International Geological Congress.

Raisz, E., 1939, Physiographic map of the Colorado Plateau: Landforms of the United States, 1:1,000,000 scale. Sarle, W.S., 1985, The cluster procedure in SAS User's Guide: Statistics, 956pp., SAS Institute Inc., Cary, N.C. Settle, M., 1979, The structure and emplacement of cinder cone fields, American Journal of Science, V.279, p.10891107.

Shoemaker, E.M., R.I. Squires and M.J. Abrams, 1978, Bright Angel and Mesa Butte fault systems in northern Arizona, Cenozoic Tectonics and Regional Geophysics of the Western Cordillera, Geological Society of America, Memoir 152, p.341-368.

Tanaka, K.L., E.M. Shoemaker, G.E. Ulrich, and E.W. Wolfe, 1986, Migration of volcanism in the San Francisco volcanic field, Arizona, Geological Society of America Bulletin, v.97, p.129-141.

Tanaka, K.L., T.C. Onstott, and E.M. Shoemaker, 1989, Magnetostratigraphy of the San Erancisco volcanic field, Arizona. U.S.Geological Survey Bulletin 1929, p.35. Thompson, G.A., and Zoback, M.L., 1979, Regional geophysics of the Colorado Plateau, in T.R. McGetchin and R.B. 
Merrill, editors, Plateau uplift, mode and mechanism, Tectonophysics, V.61, p.149-181.

Ulrich, G.E. and Bailey, N.G., 1987, Geologic map of the SP Mountain part of the San Erancisco volcanic field, north-central Arizona, U.S. Geological Survey Map ME1956 .

Ulrich, G.E. Billingsley, G.H., Hereford, R.,Wolfe, E.W., Nealey, L.D. and Sutton, 1984, Map showing geology, structure and uranium deposys of the Flagstaff $10 \times 20$ quadrangle, Arizona:U.S. Geological Survey Miscellaneous investigation series, Mapn I-1446 (sheet 1).

Wadge, G., and Cross, A., 1988, Quantitative methods for detecting aligned points: An application to the volcanic vents of the Michoacan-Guanajuato volcanic field, Mexico, Geology, V.16, p.815-818.

Walker, J., 1981, Petrogenesis of lavas from cinder cone fields behind the volcanic front of Central America, J. Geol., V.89, p.721-739.

Wolfe, E.W., G.E. Ulrich, and R.B. Moore, 1983, San Erancisco Volcanic Eield, Arizona, Volcano News, V.13, p.1-3. Wolfe, E.W., G.E. Ulrich, R.F. Holm, R.B. Moore and C.G. Newhall, 1987, Geologic map of the central part of the San Francisco volcanic field, north-central Arizona, U.S. Geological Survey Map ME-1959.

Wolfe, E.W., G.E. Ulrich, C.G. Newhal1, 1987, Geologic map of the northwest part of the San Francisco volcanic field, 
north-central Arizona, U.S. Geological Survey Map ME1957.

Wong, M.A., and T. Lane, 1983, A kth nearest neighbor clustering procedure, J. R. Stat. Soc., Ser. B, V.45, p. $362-368$.

Zhang, D., and T. Lutz, 1989, Structural controls on igneous complexes and kimberlites: A new statistical method, Tectonophys., V.159, p.137-148.

Zoback, M.L., Zoback, M.D., Abrams, J. Bell, S, Suter, M, Suarez, G. Jacob, K., Estabrook, C. and Magee, 1991, Stress map of North America: Geological Society of America, Decade of North American Geology, Continental Scale map 005, 4 sheets. 
Appendix A

Computer Programs 


\section{Cluster Analysis Program}

Option Linesize $=66$ nocenter;

Filename vent 'vent.dat';

Data spring;

Infile vent;

Input ventno east north;

Proc cluster outtree $=$ tree method $=$ twostage $r=2000-18000 \mathrm{~m}$

Var east north;

Run; 


\section{Two Point Azimuth Program}

! PROGRAM: point azimuth

! Language: TrueBasic

! Author: Chuck Connor

! Dept. of geology

! Florida International University

$! \quad$ Miami, FL, 33199

!Date: Feb. 29, 1988

!

!Summary: This program looks for preferred orientations in !point pattern data. The method used is developed from:

Lutz, T.M., 1986, An Analysis of the orientations of Large-scale crustal structures: a statistical approach based on the analysis of pointlike features. Journal of Geophysical Research, 91:421-434.

In this program, the coordinates of points are input from a file. The user then defines the area $\mathrm{s} / \mathrm{he}$ wishes to analysis, inputting vertex corrdinates using the mouse. Only data points falling within the area selected are used in the analysis. Several factors concerning this area are important:

1) the verticies must be input in a clockwise manner. If the verticies are input in a counter-clockwise manner, the program will use points only found OUTSIDE the polygon in the analysis.

2) the polygon will be rectilinear and concave inwards. This is because of the algorithm uses the orientation of line segments to discriminate between points within and outside the area selected.

3) the area selected will close automatically. For instance, if you select 5 verticies, 5 line segments will be drawn, connecting the verticies. The last line segment will be drawn connecting the first and last verticies. 
! Once the area of analysis is selected, the program

! takes a minute to find the points within the area.

!

Next select the frequency interval of the calculations

! for instance 10 gives 10 degree increments on the rose diagrams.

Suggested loops for the monte carlo simulation are 50 or 100. Simulation with smaller runs are also possible.

The program compares the observed number of line segments in each interval with the expected number, based on the 1 simulation results, using a $t$ - test. The results are plotted on rose diagrams. The t-test is done with 90,95 , and 97.5 percent confidence (one-tailed).

!four rose diagrams appear at each level of confidence: the ! obs (observed data distribution), the enorm: the normalized distribution, based on the simulation results, uci: the upper confidence interval, based on the monte carlo results, and a histogram plotting the intervals which contain ! more observations than expected (that is which exceed the ! uci values).

! As each histogram appears: click the mouse at the spot you want a label for that rose diagram to appear.

You can print the screen at any time by pressing the propeller-shift-four keys simultaneously.

! The screen can be saved as a MacPaint document at any

! time by pressing the propeller-shift-three keys simultaneously.

DIM pts(200,2), moncar(200,2), $\operatorname{vert}(30,2)$

DIM obs(90), azm(90), ehat(90), ehat2(90), enorm(90)

DIM uci1(90), uci05(90), uci025(90)

DIM maxed1(90), maxed05(90), maxed025(90)

! mat pts is the matrix which holds point locations located ! within the selected area.

$!$

! mat moncar is the matrix that holds random points generated ! by the monte carlo subroutine. this matrix is scratched after ! each simulation 
! mat vert holds the coordinated of the vertices selected by the user while

! the program is running

!

! mat obs holds the frequency per class of line segment

! orientrations in the input data set (matrix pts)

!

! mat azm holds the frequency per class of line segment

! orientrations in the monte carlo data set (matrix moncar)

! mat ehat holds the empirical mean frequency of

! observations per class, based on the monte carlo simulation

! mat ehat 2 holds the empirical mean frequency of

! observations per class squared, based on the monte carlo

! mat uci1,05,025 hold the upper confidence limits $(90,95,97.5)$

! percent, respectively of expected observations

! per class, based on the monte carlo simulation

! mat enorm contains the frequency per class of observed

! line segment orientations, normalized to take the shape

! of the study area into account

!

! mat maxed contain the intervals which exceed the

! confidence limit. (ie: obs - uci, if this is positive)

! these matricies are also for $90,95,97.5 \%$ confidence

! levels

PRINT " type the name of the file containing the observed"

PRINT " data points"

INPUT file\$

OPEN \#1: name file\$

OPEN \#10: screen $.25,1, .25,1$

OPEN \#11: screen $0,1,0, .25$

OPEN \#12: screen $0,24, .75, .8$

OPEN \#13: screen $0, .24, .6, .74$ 
let yymin $=10000000$

let $\mathrm{xxmin}=10000000$

let $y y \max =-1000000$

let $\mathrm{xxmax}=-1000000$

DO while more \#1

INPUT \#1: $\mathrm{x}, \mathrm{y}$

if $x<x x \min$ then let $x x \min =x$

if $x>x x \max$ then let $x x \max =x$

if $y<$ yymin then let yymin $=y$

if $y>$ yymax then let yymax $=y$

\section{LOOP}

reset \#1:begin

!plot all the points

print "xmin $=" ; x x \min , " x \max =" ; x x \max$

print "ymin = ";yymin,"ymax = ";yymax

PRINT "type in the dimensions of the area you want to see"

PRINT "xmin, xmax, ymin, ymax"

INPUT $s 1, s 2, s 3, s 4$

!dimension the window to be square

WINDOW \#10

LET scrfix $=$ s2-s 1

SET window s1-(scrfix*28/128),s2+(scrfix*28/128),s3,s4

DO while more \#1

INPUT \#1: $\mathrm{x}, \mathrm{y}$

IF $x<=s 2$ and $x=>s 1$ and $y=>s 3$ and $y<=s 4$ then

PLOT $x, y$

END IF

LOOP

!plot the frame

PLOT s1,s3;s1,s4;s2,s4;s2,s3;s1,s3

RESET \#1: begin

WINDOW \#11

PRINT " how many vertices will you select"

INPUT numvts

PRINT "click in the vertex coordinates using the mouse" 
MAT vert $=$ zer(numvts, 2)

! the routine below locates the verticies when the

! mouse is clicked, and plots the line segments

! between verticies.

WINDOW \#10

LET count $=0$

DO

LET count $=$ count +1

DO

GET MOUSE vert(count,1), vert(count,2), state

LOOP until state $=2$

PLOT vert(count, 1), vert(count,2);

LOOP until count $=$ numvts

PLOT vert $(1,1)$, vert $(1,2)$;

PLOT

!this routine now locates those observations within the ! area selected (enclosed in the polygon just defined

! by the verticies

!find the extreme $\mathrm{x}$ and $\mathrm{y}$ coordinates to speed the search

LET $y \min 2=1000000$

LET $x \min 2=1000000$

LET $x \max 2=-1000000$

LET $y \max 2=-1000000$

FOR look $=1$ to numvts

IF $x \max 2<\operatorname{vert}($ look, 1$)$ then LET $x \max 2=\operatorname{vert}($ look, 1$)$

IF $x \min 2>\operatorname{vert}($ look, 1$)$ then LET $x \min 2=\operatorname{vert}($ look, 1$)$

IF $y \max 2<\operatorname{vert}($ look,2) then LET ymax $2=\operatorname{vert}($ look, 2$)$

IF $y \min 2>\operatorname{vert}($ look,2) then LET ymin2 $=\operatorname{vert}($ look,2)

NEXT look

! count the number of points in file $\$$

DO while more \#1

INPUT \#1: xpt, ypt 
!the logical statement eliminates points located outside

! the smallest rectangle that completely encloses the

! polygon (this speeds the search)

IF ypt $\Rightarrow$ ymin2 and ypt $<=y \max 2$ and $x p t ~ \Rightarrow x \min 2$ and $x p t<=$ $x \max 2$ then

!this curvt loop finds points inside the polygon by

Irejecting points found outside the polygon

FOR curvt $=1$ to numvts

IF curvt $=$ numvts then

LET $x 1=\operatorname{vert}($ curvt, 1$)$

LET $\mathrm{x} 2=\operatorname{vert}(1,1)$

LET y1 $=\operatorname{vert}($ curvt, 2$)$

LET y $2=\operatorname{vert}(1,2)$

\section{ELSE}

- LET $\times 1=\operatorname{vert}($ curvt, 1$)$

LET $\times 2$ = vert (curvt $+1,1)$

LET y $1=\operatorname{vert}($ curvt, 2$)$

LET y2 $=\operatorname{vert}($ curvt $+1,2)$

END IF

WHEN error in $\quad !$ error when $\mathrm{x} 2-\mathrm{x} 1=0$

LET $m=(y 2-y 1) /(x 2-x 1) \quad$ !slope of line bet. vertices

LET $b=y 1-m^{*} x 1$ !intercept of line

LET ytest $=m^{*} x p t+b \quad$ ! point on line

! don't want points outside line segments: use

! the following tests

IF $\mathrm{x} 1>\mathrm{x} 2$ and $\mathrm{y} 1>\mathrm{y} 2$ and ytest $>$ ypt then EXIT FOR

IF $\mathrm{x} 1>\mathrm{x} 2$ and $\mathrm{y} 1<\mathrm{y} 2$ and ytest $>$ ypt then EXIT FOR

IF $\mathrm{x} 1<\mathrm{x} 2$ and $\mathrm{y} 1>\mathrm{y} 2$ and ytest $<\mathrm{ypt}$ then EXIT FOR

IF $\mathrm{x} 1<\mathrm{x} 2$ and $\mathrm{y} 1<\mathrm{y} 2$ and ytest $<\mathrm{ypt}$ then EXIT FOR

USE

luse this test instead if vertical line 
IF $y 2<y 1$ and $x p t>x 1$ then EXIT FOR

IF $y 2>y 1$ and $x p t<x 1$ then EXIT FOR

\section{END WHEN}

!if the random point has passed the above tests for

! every line segment, the point lines within

! the selected area

IF curvt $=$ numvts then

LET totpts $=$ totpts +1

LET pts(totpts, 1$)=\mathrm{xpt}$

LET pts(totpts,2) = ypt

\section{END IF}

NEXT curvt

\section{END IF}

LOOP

!replot the area of interest

CLEAR

LET $\operatorname{scrfix}=x \max 2-x \min 2$

SET window $x \min 2$ -

$(\operatorname{scrfix} * 28 / 128), x \max 2+(\operatorname{scrfix} * 28 / 128), y \min 2, y \max 2$

FOR co $=1$ to totpts

PLOT pts(co,1), pts(co,2)

NEXT co

LET count $=0$

DO

LET count $=$ count +1

PLOT vert(count, 1), vert(count,2);

LOOP until count $=$ numvts

PLOT vert $(1,1)$, vert $(1,2)$;

PLOT

!redimension the point matrices

MAT moncar $=$ zer(totpts,2) 
!lineseg is the total number of line segments

LET lineseg $=$ totpts* $($ totpts-1)/2

LET count $=0$

\section{CLOSE \#1}

\section{WINDOW \#11}

PRINT " what class interval do you want $(180 /$ interval $=$ integer $) "$ INPUT interval

LET classnum $=180 /$ interval +1

!redimension all the rose diagram matrices

MAT obs $=$ zer(classnum)

MAT azm $=$ zer(classnum)

MAT ehat $=$ zer(classnum)

MAT ehat2 = zer(classnum)

MAT enorm $=$ zer(classnum)

MAT ucil $=$ zer(classnum $)$

MAT uci05 = zer(classnum)

MAT uci025 = zer(classnum)

MAT $\operatorname{maxed} 1=$ zer(classnum)

MAT maxed05 $=$ zer(classnum)

MAT maxed025 $=$ zer(classnum)

CALL azimuth(pts, totpts, interval, obs)

!now do the monte carlo

PRINT " How many loops do you want in the monte carlo simulation" PAUSE 1

PRINT "ENTER one of the following numbers and the t-test"

PRINT "will be done automatically: 10,20,30,40,50,100"

PRINT "or enter any number (you'll need to know the T statistic)"

INPUT montesum 
!look table for t-statitics, or enter your own SELECT CASE montesum

CASE 10

LET ttest $1=1.383$

LET ttest05 $=1.833$

LET test025 $=2.262$

CASE 20

LET ttest $1=1.328$

LET ttest05 $=1.729$

LET ttest025 $=2.093$

CASE 30

LET ttest $1=1.311$

LET test05 $=1.699$

LET ttest025 $=2.045$

CASE 40

LET ttest $1=1.304$

LET test $05=1.685$

LET test025 $=2.023$

CASE 50

LET ttest $1=1.299$

LET test05 $=1.676$

LET test025 $=2.010$

CASE 100

LET ttest $1=1.290$

LET ttest05 $=1.660$

LET test $025=1.984$

CASE else

PRINT "degrees of freedom $=$ "; montesum -1

PRINT "enter t-statistic, alpha $=.1$ ";

INPUT ttest1

PRINT "enter t-statistic, alpha $=.05 "$; 
INPUT ttest05

PRINT "enter t-statistic, alpha $=.025$ ";

INPUT ttest025

\section{END SELECT}

LET count $=0$

WINDOW \#10

!clear the window

CLEAR

!replot the vertex coordinates

LET count $=0$

DO

LET count $=$ count +1

PLOT vert(count, 1), vert(count,2);

LOOP until count $=$ numvts

PLOT vert $(1,1)$, vert $(1,2)$;

PLOT

WINDOW \#11

PRINT "now plotting simulations";

WINDOW \#12

PRINT "simulation:"

LET count $=0$

DO

LET count $=$ count +1

WINDOW \#13

SET window $-1,1,-1,1$

CLEAR

LET cout $\$=$ str $\$$ (count)

PLOT TEXT, at 0,2 : cout\$

CALL findrnd(vert, moncar, numvts, totpts)

MAT azm = zer(classnum)

WINDOW \#10

this loop plots the random points for each simulation, land lets you make sure the random points are in the ! area selected 
FOR alp $=1$ to totpts

PLOT moncar(alp,1), moncar(alp,2)

NEXT alp

CALL azimuth(moncar, totpts, interval, azm)

!begin cumulating stats for each interval of each simultion

FOR $\mathrm{i}=1$ to classnum

LET ehat(i) $=$ ehat $(\mathrm{i})+\operatorname{azm}(\mathrm{i})$

LET ehat $2(i)=$ ehat $2(i)+(\operatorname{azm}(i))^{\wedge} 2$

NEXT i

LET $i=0$

LOOP until count $=$ montesum

LET $\mathrm{i}=0$

LET count $=0$

WHEN error in !an error if class is 0

FOR $\mathrm{i}=1$ to classnum

LET chat $=($ lineseg $) /$ classnum

LET ehat $(\mathrm{i})=$ ehat $(\mathrm{i}) /$ montesum

LET std $=\left(\left(\text { ehat2(i) }-(\text { ehat }(\mathrm{i}))^{\wedge} 2\right) /(\text { montesum-1 })\right)^{\wedge} .5$

LET enorm $(i)=\operatorname{chat} /$ ehat $(i) * \operatorname{obs}(\mathrm{i})$

!for alpha $=.1$

LET ucil(i) $=$ ehat $(\mathrm{i})+$ ttest $^{*}{ }^{*} \operatorname{std} /\left(\right.$ montesum $\left.^{\wedge} .5\right)$

LET unicl $=$ chat/ehat $(\mathrm{i}) * \operatorname{ucil}(\mathrm{i})$

IF enorm(i) $\Rightarrow$ unicl then

LET maxed $1(i)=$ enorm $(i)-$ unicl

ELSE

LET $\operatorname{maxed} 1(\mathrm{i})=0$

END IF

!for alpha $=.05$

LET uci05(i) $=\operatorname{ehat}(\mathrm{i})+\operatorname{ttest}{ }^{*} \mathrm{std} /\left(\right.$ montesum $\left.^{\wedge} .5\right)$

LET unic05 $=$ chat/ehat $(\mathrm{i}) *$ uci05(i)

IF enorm(i) $\Rightarrow$ unic05 then

LET maxed05(i) $=$ enorm(i) - unic05

\section{ELSE}

LET $\operatorname{maxed05}(\mathrm{i})=0$ 


\section{END IF}

!for alpha $=.025$

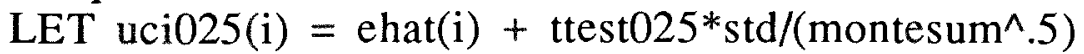

LET unic025 = chat/ehat(i) * uci025(i)

IF enorm(i) $\Rightarrow$ unic025 then

LET maxed025(i) $=$ enorm $(i)-$ unic025

\section{ELSE}

LET maxed025(i) $=0$

END IF

\section{NEXT i}

\section{USE}

LET enorm(i) $=0$

END WHEN

!signal that the simulation is done

WINDOW \#11

DO until signal $=30$

SOUND 600, .03

SOUND 1500, .03

LET signal $=$ signal +1

LOOP

PRINT

PRINT "done with simulation, click mouse to continue"

DO

GET MOUSE xx,yy,state

LOOP until state $=2$

CLOSE \#10

CLOSE \#11

CLOSE \#12

CLOSE \#13

!now plot the results on rose diagrams

OPEN \#20: screen $0, .5,0, .5$

OPEN \#30: screen $0, .5, .5,1$

OPEN \#40: screen $.5,1,5,1$

OPEN \#50: screen .5,1,0,.5 
FOR looper $=1$ to 3

!there are three

!screens of results

WINDOW \#20

CALL rosy(interval,enorm)

DO

GET MOUSE $u, v$, state

LOOP until state $=2$

PLOT TEXT, at u,v: "enorm"

WINDOW \#30

lobserved frequencies don't change

DO

CALL rosy(interval,obs)

GET MOUSE $u, v$, state

LOOP until state $=2$

PLOT TEXT, at u,v: "obs"

WINDOW \#40

IF looper $=1$ then

CALL rosy(interval,maxed 1 )

ELSEIF looper $=2$ then

CALL rosy(interval,maxed05)

ELSE

CALL rosy(interval,maxed025)

END IF

DO

GET MOUSE $u, v$, state

LOOP until state $=2$

IF looper $=1$ then

PLOT TEXT, at u,v: "intervals > alpha $=.1 "$

ELSEIF looper $=2$ then

PLOT TEXT, at u,v: "intervals > alpha $=.05 "$

ELSE

PLOT TEXT, at u,v: "intervals > alpha $=.025 "$

END IF

WINDOW \#50 
IF looper $=1$ then

CALL rosy(interval,uci1)

ELSEIF looper $=2$ then

ELSE

CALL rosy(interval,uci05)

CALL rosy(interval,uci025)

END IF

DO

GET MOUSE $u, v$, state

LOOP until state $=2$

PLOT TEXT, at u,v: "uci"

!now loop until you are ready to continue

DO

GET MOUSE m,p, state

LOOP until state $=2$

lafter the click, clear all the windows

CLEAR

WINDOW \#40

CLEAR

WINDOW \#30

CLEAR

WINDOW \#20

CLEAR

NEXT looper

END

EXTERNAL

SUB AZIMUTH(pt(,), numpts, interval, azm())

!azimuth looks at each line segment, calculates its orientation $!$ and puts it into a class interval, to be plotted

! on the rose diagram

! $\mathrm{pt}()$ is the input matrix containing points

! numpts is the total number of points in $\mathrm{pt}()$, input 
! interval is the degree interval (class frequency), input

! $\operatorname{azm}()$ is the returned matrix containing the number of

! observations per class

\section{LET counter $=0$}

FOR $\mathrm{i}=1$ to numpts- 1

FOR $\mathrm{j}=\mathrm{i}+1$ to numpts

WHEN error in terror when line segment in $\mathrm{N}-\mathrm{S}$

LET theta $=\operatorname{atn}((\mathrm{pt}(\mathrm{j}, 2)-\mathrm{pt}(\mathrm{i}, 2)) /(\mathrm{pt}(\mathrm{j}, 1)-$

$\operatorname{pt}(\mathrm{i}, 1))) * 180 / 3.1416$

USE

\section{END WHEN}

LET theta $=90$ !theta is 90 if segment is N-S

! this statement lets results be plotted on

! standard structural rose diagram

IF theta $<0$ then LET theta $=$ theta +180

FOR peg $=$ interval to 180 step interval

LET keeper $=$ keeper +1

!criterion for the classification of orientations

IF theta $<$ peg then

LET azm(keeper $)=\operatorname{azm}($ keeper $)+1$

EXIT FOR

END IF

NEXT peg

LET keeper $=0$

NEXT $j$

NEXT i

END SUB

SUB FINDRND(vert(,), moncar(,), numvts, rndtot)

RANDOMIZE

!this subroutine finds random points within a known

larea defined by a definite number of vertices 
!vert() is the input matrix of vertex coordinates

!moncar() is the output matrix of random points found

! by the subroutine, which lie within the area defined by

$!$ vert()

! numvts is the number of vertices (input)

Indtot is the number of random points to be found

! with in the area (input)

LET curvt $=0$

LET rndct $=0$

MAT moncar $=$ zer(rndtot, 2) $!$ make sure this mtx is empty

LET $\mathrm{x} 1=0$

LET $x 2=0$

LET $\mathrm{y} 1=0$

LET y $2=0$

!find the extreme $x$ and $y$ coordinates to speed the search

LET $y \min 2=1000000$

LET $x \min 2=1000000$

LET $x \max 2=-1000000$

LET $y \max 2=-1000000$

FOR look $=1$ to numvts

IF $\mathrm{xmax} 2<\operatorname{vert}($ look, 1$)$ then LET $\mathrm{xmax} 2=\operatorname{vert}($ look, 1$)$

IF $x \min 2>\operatorname{vert}($ look, 1$)$ then LET $x \min 2=\operatorname{vert}($ look, 1$)$

IF $y \max 2<\operatorname{vert}($ look, 2$)$ then LET ymax $2=\operatorname{vert}($ look, 2$)$

IF $y \min 2>\operatorname{vert}($ look,2) then LET ymin $2=\operatorname{vert}($ look,2)

NEXT look

!now select random points within this range DO

LET $x$ rndpt $=(x \max 2-x \min 2)^{*} \mathrm{rnd}+\mathrm{x} \min 2$

LET yrndpt $=(y \max 2-\mathrm{ymin} 2)^{*} \mathrm{rnd}+\mathrm{ymin} 2$

!now that we have found likely random points,

! check to see if they are in the specified area

FOR curvt $=1$ to numvts

IF curvt $=$ numvts then 
LET $\times 1=\operatorname{vert}($ curvt, 1$)$

LET $\times 2=\operatorname{vert}(1,1)$

LET $y 1=\operatorname{vert}($ curvt, 2$)$

LET y $2=\operatorname{vert}(1,2)$

\section{ELSE}

LET $\times 1=\operatorname{vert}($ curvt, 1$)$

LET $\times 2=\operatorname{vert}($ curvt $+1,1)$

LET y $1=\operatorname{vert}($ curvt, 2$)$

LET y $2=\operatorname{vert}($ curvt $+1,2)$

END IF

WHEN ERROR IN $\quad$ !X2-X1 $=0$

LET $m=(y 2-y 1) /(x 2-x 1) \quad$ !slope of line bet. vertices

LET $b=y 1-m^{*} x 1 \quad$ !intercept of line

LET ytest $=m^{*} x$ rndpt $+b \quad$ ! point on line

! don't want points outside line segments: use

! the following tests

IF $\mathrm{x} 1>\mathrm{x} 2$ and $\mathrm{y} 1>\mathrm{y} 2$ and ytest $>$ yrndpt then EXIT FOR

IF $\mathrm{x} 1>\mathrm{x} 2$ and $\mathrm{y} 1<\mathrm{y} 2$ and ytest $>$ yrndpt then EXIT FOR

IF $\mathrm{x} 1<\mathrm{x} 2$ and $\mathrm{yl}>\mathrm{y} 2$ and $\mathrm{ytest}<\mathrm{yrndpt}$ then EXIT FOR

IF $\mathrm{x} 1<\mathrm{x} 2$ and $\mathrm{y} 1<\mathrm{y} 2$ and $\mathrm{ytest}<\mathrm{yrndpt}$ then EXIT FOR

USE

IF $y 1<y 2$ and yrndpt $<y 2$ then EXIT FOR

IF $y 1>y 2$ and yrndpt $>$ y 2 then EXIT FOR

END WHEN

!if the random point has passed the above tests for

! every line segment, the point lines within

! the selected area

$\mathrm{IF}$ curvt $=$ numvts then

LET rndct $=$ rndet +1

LET moncar $(\operatorname{rndct}, 1)=\mathrm{xrndpt}$

LET moncar $(\mathrm{rndct}, 2)=\mathrm{yrndpt}$

END IF 
NEXT curvt

LOOP UNTIL rndet $=$ rndtot

\section{END SUB}

SUB rosy(interval,total())

!this subroutine plots rose diagrams

linterval: the class interval for the rose diagram (eg: 10

! means 10 degrees per class

! total: is a one dimensional matrix containing the number

! of observations per class.

OPTION ANGLE degrees

SET color "black"

!find the maximum value in the intervals

this value is used to dimension the rose diagram

FOR $\mathrm{q}=$ interval to 180 step interval

LET counter $=$ counter +1

IF maxin $<$ total(counter) then LET maxin = total(counter)

\section{NEXT q}

IF $\operatorname{maxin}=0$ then LET $\operatorname{maxin}=1$

!set the window and correct the aspect ratio

SET window (-maxin- $(28 / 64 * \max i n)),(\operatorname{maxin}+(28 / 64 * \operatorname{maxin}))$,maxin, $\max$ in

!plot the E-W and N-S axes

PLOT 0,0;0,maxin

PLOT -maxin,0; maxin, 0

!decide about the frequency of

! tic marks on your rose diagram

IF maxin $<1$ then

LET lab $=.1$

ELSEIF maxin $<10$ then

LET lab $=1$ 
ELSEIF maxin $<50$ then

LET $l a b=5$

ELSEIF maxin $<100$ then

LET lab $=10$

ELSEIF maxin $<200$ then

LET $1 \mathrm{ab}=20$

ELSEIF maxin $<1000$ then

LET lab $=100$

ELSE

LET $l a b=500$

END IF

FOR tic $=0$ to maxin step lab

PLOT tic,0;tic, -maxin/10 !make tics on the

! positive axis

NEXT tic

LET maxtic $=$ tic

FOR tic $=0$ to - maxin step lab PLOT tic, 0 ;tic, $-\operatorname{maxin} / 50 \quad$ !negative axis

NEXT tic

FOR tic $=0$ to maxtic- 1 step lab $* 2$ !label every other tic

PLOT TEXT, at tic,-maxin/4: str\$(tic)

NEXT tic

LET counter $=0$

FOR $\mathrm{q}=$ interval to 180 step interval

LET counter $=1+$ counter

LET $r=$ total(counter)

LET $x 1=r^{*} \cos (q)$

LET $y 1=r^{*} \sin (q)$

LET $\times 2=r^{*} \cos (q-i n t e r v a l)$

LET y $2=\mathrm{r}^{*} \sin (\mathrm{q}-$ interval $)$

PLOT 0,$0 ; \mathrm{x} 1, \mathrm{y} 1 ; \mathrm{x} 2, \mathrm{y} 2 ; 0,0$ PLOT

NEXT q

END SUB 


\section{Hough Transform Analysis Program}

$\operatorname{dim} x(155,2), \operatorname{pmtx}(155,90)$

print "type in file name"

input file\$

open \#1: name file\$

open \#10: screen $.25,1,25,1$

open \#11:screen $0,1,0, .25$

window \#11

let $y \min =100000000$

let $y \max =-100000000$

let $x \min =100000000$

let $x \max =-100000000$

Do while more \#1

input \#1: $x x x$,yyy

if $\mathrm{xxx}>\mathrm{xmax}$ then let $\mathrm{xmax}=\mathrm{xxx}$

if $x x x<x$ min then let $x \min =x x x$

if $y y y>$ ymax then let $y \max =y y y$

if $y y y<y m i n$ then let ymin = yyy

loop

close \# 1

let $\mathrm{s} 1=\mathrm{xmin}$

let $\mathrm{s} 2=\mathrm{xmax}$

let $\mathrm{s} 3=\mathrm{ymin}$

let $\mathrm{s} 4=\mathrm{ymax}$

print $\mathrm{s} 1, \mathrm{~s} 2, \mathrm{~s} 3, \mathrm{~s} 4$

window \#10

let $\operatorname{scrfix}=\mathrm{s} 2-\mathrm{s} 1$

set window $\mathrm{s} 1-(\mathrm{scrfix} * 28 / 128), \mathrm{s} 2+(\mathrm{scrfix} * 28 / 128), \mathrm{s} 3, \mathrm{~s} 4$

!set window $x \min , x \max , y \min , y \max$

let kount $=0$

library "pictlib*"

call copy_printer

set color "red" 
open \#1: name file\$

do while more \#1

let kount $=$ kount +1

input \#1: $\mathrm{x}$ (kount, 1), $\mathrm{x}$ (kount,2)

box circle $x($ kount, 1$)-200, x($ kount, 1$)+200, x($ kount, 2$)-$

$200, x$ (kount, 2$)+200$

let $\operatorname{sum} x=\operatorname{sum} x+\mathrm{x}($ kount, 1$)$

loop

let sumy $=$ sumy $+x($ kount, 2$)$

close \#1

let numpts $=$ kount

let $\mathrm{xmean}=$ sum $\mathrm{x} / \mathrm{numpts}$

let ymean $=$ sumy/numpts

plot $\mathrm{s} 1, \mathrm{~s} 3 ; \mathrm{s} 1, \mathrm{~s} 4 ; \mathrm{s} 2, \mathrm{~s} 4 ; \mathrm{s} 2, \mathrm{~s} 3 ; \mathrm{s} 1, \mathrm{~s} 3$

let $\operatorname{pmax}=0$

for kount $=1$ to numpts

let dist $=\left((x \text { mean-x }(\text { kount, } 1))^{\wedge} 2+(\text { ymean- } x(\text { kount }, 2))^{\wedge} 2\right)^{\wedge} .5$

if dist $>$ pmax then let $\operatorname{pmax}=$ dist

next kount

let $\operatorname{pmax}=\operatorname{pmax}+500$

window \#11

print "xmean =";xmean,"ymean=";ymean; "kount="; kount

print "pmax = ";pmax

print "what rank?"

input rank

print "what thet range"

input lowrang, hirang

let lowrang $=$ lowrang*pi $/ 180$

let hirang $=$ hirang*pi $/ 180$

for kount $=1$ to numpts

let $\mathrm{x} 11=\mathrm{x}($ kount, 1$)-\mathrm{xmean}$

let $\mathrm{y} 11=\mathrm{x}($ kount, 2$)$-ymean

let ele $2=0$

for theta $=0$ to pi step pi/90

let ele $2=$ ele $2+1$

let $\mathrm{p}=\mathrm{x} 11^{*} \cos ($ theta $)+\mathrm{y} 11 * \sin ($ theta $)$ 


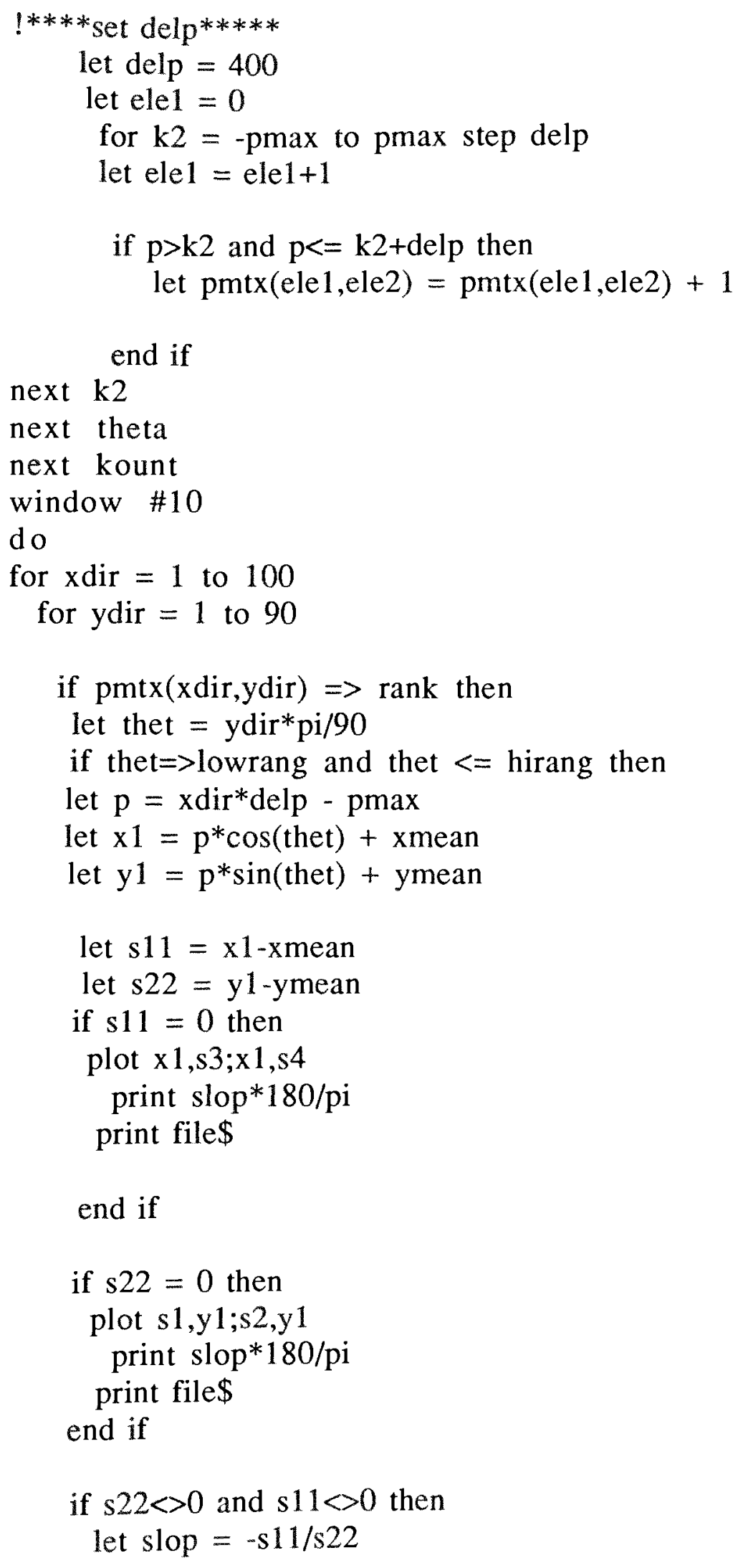


let $\mathrm{y} 22=\operatorname{slop}^{*}(\mathrm{~s} 1-\mathrm{x} 1)+\mathrm{y} 1$

let $\mathrm{y} 33=\operatorname{slop}^{*}(\mathrm{~s} 2-\mathrm{x} 1)+\mathrm{y} 1$

plot $\mathrm{s} 1, \mathrm{y} 22 ; \mathrm{s} 2, \mathrm{y} 33$

print slop*180/pi

print file\$

!find the slope intercept, b1

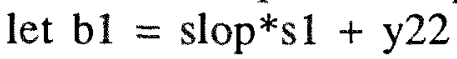

open \#1: name file\$

open \#2: name "outdum", create newold

reset \#2:end

print \#2: "slope (from East) = ", slop*180/pi

do while more \#1

input \#1: $\mathrm{x} 2, \mathrm{y} 2$

let $\mathrm{b} 2=-1 /$ slop $* x 2-\mathrm{y} 2$

let xint $=(b 2-b 1) /($ slop $+1 /$ slop $)$

let yint $=$ slop ${ }^{*}$ xint $+b 1$

let dist $=\left((\mathrm{x} 2 \text {-xint })^{\wedge} 2+(\mathrm{y} 2 \text {-yint })^{\wedge} 2\right)^{\wedge} .5$

if dist $<=\operatorname{delp} / 2$ then

let $\mathrm{ct}=\mathrm{ct}+1$

print \#2: ct, $x 2, y 2$

end if

loop

close \#1

close \#2

let $\mathrm{ct}=0$

end if

end if

end if

next ydir

next $x$ dir

call copy_done

window \#11

print "new rank?"

input rank

window \#10

loop

end 


\section{Appendix B}

\section{Geophysical Survey Data}




\section{Reduction Formula of Bouguer Anomaly}

The formula from Hendricks (1975) used for the reduction to the complete Bouguer anomaly is:

$\mathrm{CBG}=\mathrm{G}_{\mathrm{obs}}+\mathrm{FAC}+\mathrm{BC}+\mathrm{ECC}+\mathrm{TC}-\mathrm{G}_{\text {theor }}$

The terms being:

CBG Complete Bouguer anomaly

Gobs Observed gravity (after drift correction)

EAC Eree air correction $=\mathrm{h}(0.30877-0.0013398 \sigma+$

$\left.0.0013553 \sigma^{2}-0.0005329 \sigma^{3}+0.0000911 \sigma^{4}\right)-h^{2}\left(0.072 \star 10^{-6}\right)$

$\mathrm{BC}$ Bouguer correction $=-0.1119 \mathrm{~h}$

ECC Earth curvature correction $=-1.4639108 * 10^{-3} \mathrm{~h}+$

$3.532715 * 10^{-7} \mathrm{~h}^{2}-4.449648 * 10^{-14} \mathrm{~h}^{3}$

TC Terrain correction (neglected in this study)

Gtheor Theoretical Gravity $=978031.843+15727.66 \sigma-$

$15762.337 \sigma^{2}+6083.534 \sigma^{3}-1089.748 \sigma^{4}+69.43 \sigma^{5}$

where: $h=$ elevation (in meters)

$\sigma=0.0001 \varphi^{2}$

$\varphi=$ latitude in degrees 


\begin{tabular}{|r|r|l|l|l|r|}
\hline & SAN & FRANCISCO & VOLCANIC & FIELD & \\
\hline & SPIDER & WEB & RANCH & GRAVITY & SURVEY \\
\hline & & LINE \#1000 & & N120 $0^{\circ}$ from & base \#26 \\
\hline & & & & & \\
\hline STATION\# & DISTANCE & ELEVATION & LATITUDE & Sigma & GOBS(mgals \\
\hline & (M) & (M) & (DEGREE) & & \\
\hline base \#1 & & 1598.676 & & & \\
\hline base \#26 & 0 & 1605.236 & 35.6551 & 0.1271286 & 2852.8285 \\
\hline 1050 & 50 & 1603.846 & 35.654875 & 0.127127 & 2853.1055 \\
\hline 1100 & 100 & 1602.866 & 35.65465 & 0.1271254 & 2853.1902 \\
\hline 1150 & 150 & 1602.996 & 35.654424 & 0.1271238 & 2853.0762 \\
\hline 1200 & 200 & 1601.336 & 35.654199 & 0.1271222 & 2853.2857 \\
\hline 1225 & 225 & 1602.036 & 35.654087 & 0.1271214 & 2853.2647 \\
\hline 1250 & 250 & 1605.436 & 35.653974 & 0.1271206 & 2852.7525 \\
\hline 1275 & 275 & 1608.266 & 35.653861 & 0.1271198 & 2852.4629 \\
\hline 1300 & 300 & 1612.936 & 35.653749 & 0.127119 & 2851.7985 \\
\hline 1315 & 315 & 1614.586 & 35.653681 & 0.1271185 & 2850.8115 \\
\hline 1330 & 330 & 1616.586 & 35.653614 & 0.127118 & 2850.345 \\
\hline 1340 & 340 & 1617.806 & 35.653569 & 0.1271177 & 2850.5494 \\
\hline 1350 & 350 & 1619.016 & 35.653523 & 0.1271174 & 2850.3508 \\
\hline 1360 & 360 & 1620.296 & 35.653478 & 0.1271171 & 2849.8177 \\
\hline 1370 & 370 & 1620.526 & 35.653433 & 0.1271167 & 2849.8016 \\
\hline 1380 & 380 & 1621.171 & 35.653388 & 0.1271164 & 2849.6069 \\
\hline 1390 & 390 & 1621.396 & 35.653343 & 0.1271161 & 2849.2117 \\
\hline 1400 & 400 & 1621.326 & 35.653298 & 0.1271158 & 2849.3927 \\
\hline 1410 & 410 & 1621.246 & 35.653253 & 0.1271155 & 2848.8115 \\
\hline 1420 & 420 & 1621.596 & 35.653208 & 0.1271151 & 2849.1301 \\
\hline 1430 & 430 & 1622.056 & 35.653163 & 0.1271148 & 2849.3698 \\
\hline 1440 & 440 & 1622.686 & 35.653118 & 0.1271145 & 2848.914 \\
\hline 1450 & 450 & 1623.641 & 35.653073 & 0.1271142 & 2848.954 \\
\hline
\end{tabular}




\begin{tabular}{|r|r|r|r|r|r|}
\hline & & & & & \\
\hline & & & & & \\
\hline & & & & & \\
\hline & & & & & \\
\hline & & & & & \\
\hline & & & & & 976438.5 \\
\hline 495.22322 & -179.6259 & -1.439803 & 979788.75 & -976621.8 & -183.2637 \\
\hline 494.79456 & -179.4704 & -1.439343 & 979788.73 & -976621.7 & -183.2401 \\
\hline 494.49234 & -179.3607 & -1.439018 & 979788.71 & -976621.8 & -183.3283 \\
\hline 494.53243 & -179.3753 & -1.439061 & 979788.69 & -976621.9 & -183.3975 \\
\hline 494.02051 & -179.1895 & -1.43851 & 979788.67 & -976622 & -183.4944 \\
\hline 494.23638 & -179.2678 & -1.438743 & 979788.66 & -976621.9 & -183.3684 \\
\hline 495.28491 & -179.6483 & -1.439869 & 979788.65 & -976621.7 & -183.204 \\
\hline 496.15765 & -179.965 & -1.440799 & 979788.64 & -976621.4 & -182.9288 \\
\hline 497.59783 & -180.4875 & -1.442323 & 979788.63 & -976621.2 & -182.6676 \\
\hline 498.10667 & -180.6722 & -1.442858 & 979788.63 & -976621.8 & -183.325 \\
\hline 498.72345 & -180.896 & -1.443504 & 979788.62 & -976621.9 & -183.3935 \\
\hline 499.09968 & -181.0325 & -1.443896 & 979788.62 & -976621.5 & -182.9459 \\
\hline 499.47283 & -181.1679 & -1.444284 & 979788.62 & -976621.4 & -182.9033 \\
\hline 499.86756 & -181.3111 & -1.444694 & 979788.61 & -976621.7 & -183.1814 \\
\hline 499.93849 & -181.3369 & -1.444767 & 979788.61 & -976621.7 & -183.1485 \\
\hline 500.1374 & -181.409 & -1.444973 & 979788.6 & -976621.7 & -183.2128 \\
\hline 500.20679 & -181.4342 & -1.445045 & 979788.6 & -976622.1 & -183.5601 \\
\hline 500.18521 & -181.4264 & -1.445022 & 979788.6 & -976621.9 & -183.3889 \\
\hline 500.16054 & -181.4174 & -1.444997 & 979788.59 & -976622.5 & -183.982 \\
\hline 500.26847 & -181.4566 & -1.445108 & 979788.59 & -976622.1 & -183.5908 \\
\hline 500.41033 & -181.5081 & -1.445255 & 979788.58 & -976621.8 & -183.257 \\
\hline 500.60461 & -181.5786 & -1.445455 & 979788.58 & -976622.1 & -183.5854 \\
\hline 500.89912 & -181.6854 & -1.445758 & 979788.58 & -976621.9 & -183.3542 \\
\hline & & & & & \\
\hline
\end{tabular}




\begin{tabular}{|c|c|c|c|c|c|}
\hline & SAN & FRANCISCO & VOLCANIC & FIELD & \\
\hline & SPIDER & WEB & RANCH & GRAVITY & SURVEY \\
\hline & & LINE \#2000 & & $\mathrm{N} 120^{\circ}$ from & base \#22 \\
\hline STATION\# & DISTANCE & ELEVATION & LATITUDE & Sigma & GOBS(mgals \\
\hline & (M) & (M) & (DEGREE) & & \\
\hline base \#1 & & 1598.676 & & & \\
\hline base $\# 26$ & & 1605.236 & & & 2852.4246 \\
\hline base \#22 & 0 & 1600.441 & 35.6564 & 0.1271379 & 2853.3168 \\
\hline 2050 & 50 & 1599.531 & 35.656175 & 0.1271363 & 2853.8296 \\
\hline 2100 & 100 & 1599.046 & 35.65595 & 0.1271347 & 2853.3533 \\
\hline 2150 & 150 & 1599.436 & 35.655724 & 0.1271331 & 2853.4807 \\
\hline 2175 & 175 & 1602.086 & 35.655612 & 0.1271323 & 2852.7638 \\
\hline 2200 & 200 & 1611.216 & 35.655499 & 0.1271315 & 2850.353 \\
\hline 2225 & 225 & 1615.016 & 35.655387 & 0.1271307 & 2850.4327 \\
\hline 2240 & 240 & 1616.096 & 35.655319 & 0.1271302 & 2849.7421 \\
\hline 2255 & 255 & 1617.336 & 35.655251 & 0.1271297 & 2849.8914 \\
\hline 2265 & 265 & 1617.966 & 35.655206 & 0.1271294 & 2849.7418 \\
\hline 2275 & 275 & 1618.621 & 35.655161 & 0.1271291 & 2849.5698 \\
\hline 2285 & 285 & 1619.166 & 35.655116 & 0.1271287 & 2849.6189 \\
\hline 2295 & 295 & 1619.943 & 35.655071 & 0.1271284 & 2849.8479 \\
\hline 2300 & 300 & 1620.448 & 35.655049 & 0.1271283 & 2849.5342 \\
\hline 2305 & 305 & 1620.733 & 35.655026 & 0.1271281 & 2849.1226 \\
\hline 2310 & 310 & 1620.941 & 35.655004 & 0.1271279 & 2849.5188 \\
\hline 2315 & 315 & 1621.009 & 35.654981 & 0.1271278 & 2849.6836 \\
\hline 2320 & 320 & 1621.143 & 35.654959 & 0.1271276 & 2849.0385 \\
\hline 2325 & 325 & 1621.128 & 35.654936 & 0.1271275 & 2849.5937 \\
\hline 2335 & 335 & 1620.97 & 35.654891 & 0.1271271 & 2849.4027 \\
\hline 2345 & 345 & 1620.873 & 35.654846 & 0.1271268 & 2849.5586 \\
\hline 2355 & 355 & 1620.738 & 35.654801 & 0.1271265 & 2849.6272 \\
\hline 2365 & 365 & 1620.61 & 35.654756 & 0.1271262 & 2849.4909 \\
\hline 2375 & 375 & 1620.451 & 35.654711 & 0.1271258 & 2849.6426 \\
\hline 2385 & 385 & 1620.158 & 35.654666 & 0.1271255 & 2849.3969 \\
\hline 2400 & 400 & 1619.808 & 35.654598 & 0.127125 & 2850.1413 \\
\hline 2420 & 420 & 1619.164 & 35.654508 & 0.1271244 & 2849.9687 \\
\hline 2435 & 435 & 1618.446 & 35.654441 & 0.1271239 & 2850.3079 \\
\hline
\end{tabular}




\begin{tabular}{|r|r|r|r|r|r|}
\hline & & & & & \\
\hline & & & & & \\
\hline & & & & & \\
\hline & & & & & \\
\hline & & & & & \\
\hline & & & & & 976438.5 \\
\hline 495.46319 & -179.6259 & -1.439803 & 978031.84 & -974865 & 1573.4791 \\
\hline 493.74447 & -179.0894 & -1.438212 & 979788.86 & -976622.3 & -183.8273 \\
\hline 493.46384 & -178.9875 & -1.437908 & 979788.84 & -976622 & -183.4737 \\
\hline 493.31428 & -178.9333 & -1.437746 & 979788.82 & -976622.5 & -184.0259 \\
\hline 493.43455 & -178.9769 & -1.437876 & 979788.8 & -976622.3 & -183.8027 \\
\hline 494.25179 & -179.2734 & -1.438759 & 979788.79 & -976622.5 & -183.9901 \\
\hline 497.06738 & -180.2951 & -1.441764 & 979788.78 & -976623.1 & -184.6003 \\
\hline 498.23926 & -180.7203 & -1.442997 & 979788.77 & -976622.3 & -183.7656 \\
\hline 498.57232 & -180.8411 & -1.443346 & 979788.77 & -976622.7 & -184.2385 \\
\hline 498.95472 & -180.9799 & -1.443745 & 979788.76 & -976622.3 & -183.8402 \\
\hline 499.149 & -181.0504 & -1.443947 & 979788.76 & -976622.4 & -183.8623 \\
\hline 499.351 & -181.1237 & -1.444158 & 979788.76 & -976622.4 & -183.902 \\
\hline 499.51907 & -181.1847 & -1.444332 & 979788.75 & -976622.2 & -183.7421 \\
\hline 499.75869 & -181.2716 & -1.444581 & 979788.75 & -976621.9 & -183.3568 \\
\hline 499.91442 & -181.3281 & -1.444742 & 979788.75 & -976622.1 & -183.5696 \\
\hline 500.00231 & -181.36 & -1.444833 & 979788.74 & -976622.4 & -183.9233 \\
\hline 500.06646 & -181.3833 & -1.444899 & 979788.74 & -976622 & -183.4844 \\
\hline 500.08743 & -181.3909 & -1.444921 & 979788.74 & -976621.8 & -183.3043 \\
\hline 500.12875 & -181.4059 & -1.444964 & 979788.74 & -976622.4 & -183.9212 \\
\hline 500.12413 & -181.4042 & -1.444959 & 979788.74 & -976621.9 & -183.367 \\
\hline 500.0754 & -181.3865 & -1.444909 & 979788.73 & -976622.1 & -183.5852 \\
\hline 500.04549 & -181.3757 & -1.444878 & 979788.73 & -976621.9 & -183.4444 \\
\hline 500.00386 & -181.3606 & -1.444835 & 979788.72 & -976621.9 & -183.3985 \\
\hline 499.96438 & -181.3463 & -1.444794 & 979788.72 & -976622.1 & -183.556 \\
\hline 499.91535 & -181.3285 & -1.444743 & 979788.72 & -976621.9 & -183.4316 \\
\hline 499.82499 & -181.2957 & -1.444649 & 979788.71 & -976622.2 & -183.7309 \\
\hline 499.71706 & -181.2565 & -1.444538 & 979788.71 & -976621.6 & -183.0494 \\
\hline 499.51846 & -181.1845 & -1.444332 & 979788.7 & -976621.8 & -183.3407 \\
\hline 499.29704 & -181.1041 & -1.444101 & 979788.69 & -976621.6 & -183.1365 \\
\hline
\end{tabular}




\begin{tabular}{|r|r|l|l|l|l|}
\hline & SAN & FRANCISCO & VOLCANIC & FIELD & \\
\hline & SPIDER & WEB & RANCH & GRAVITY & SURVEY \\
\hline & & LINE\#3000 & & N105 from & base \#2 \\
\hline & & & & & \\
\hline & & & & & \\
\hline & (M) & (M) & (DEGREG) & & \\
\hline base \#1 & & 1598.676 & & & \\
\hline base \#2 & 0 & 1597.346 & 35.6589 & 0.1271557 & 2853.4078 \\
\hline 3050 & 50 & 1596.296 & 35.658783 & 0.1271549 & 2854.3218 \\
\hline 3100 & 100 & 1595.336 & 35.658667 & 0.1271541 & 2854.1825 \\
\hline 3150 & 150 & 1594.379 & 35.65855 & 0.1271532 & 2854.2809 \\
\hline 3200 & 200 & 1594.886 & 35.658434 & 0.1271524 & 2854.1544 \\
\hline 3225 & 225 & 1595.941 & 35.658375 & 0.127152 & 2853.8278 \\
\hline 3250 & 250 & 1597.991 & 35.658317 & 0.1271516 & 2853.5024 \\
\hline 3275 & 275 & 1599.526 & 35.658259 & 0.1271511 & 2852.9785 \\
\hline 3280 & 280 & 1600.201 & 35.658247 & 0.1271511 & 2852.4594 \\
\hline 3285 & 285 & 1600.756 & 35.658236 & 0.127151 & 2852.5577 \\
\hline 3290 & 290 & 1601.291 & 35.658224 & 0.1271509 & 2852.4491 \\
\hline 3295 & 295 & 1602.261 & 35.658212 & 0.1271508 & 2852.3915 \\
\hline 3310 & 310 & 1603.211 & 35.658177 & 0.1271506 & 2852.0439 \\
\hline 3330 & 330 & 1603.011 & 35.658131 & 0.1271502 & 2852.2135 \\
\hline 3345 & 345 & 1602.321 & 35.658096 & 0.12715 & 2852.5247 \\
\hline 3370 & 370 & 1601.056 & 35.658037 & 0.1271496 & 2852.4974 \\
\hline 3420 & 420 & 1599.372 & 35.657921 & 0.1271487 & 2853.2136 \\
\hline 3470 & 470 & 1595.869 & 35.657804 & 0.1271479 & 2853.8319 \\
\hline 3520 & 520 & 1593.881 & 35.657688 & 0.1271471 & 2854.3933 \\
\hline 3570 & 570 & 1592.391 & 35.657571 & 0.1271462 & 2854.5862 \\
\hline & & & & & \\
\hline
\end{tabular}




\begin{tabular}{|r|r|r|r|r|r|}
\hline & & & & & \\
\hline & & & & & \\
\hline & & & & & \\
\hline & & & & & \\
\hline & & & & & \\
\hline 492.78998 & -178.743 & -1.437176 & 979789.08 & -976623.1 & -184.5575 \\
\hline 492.46617 & -178.6255 & -1.436823 & 979789.07 & -976622.3 & -183.8395 \\
\hline 492.17012 & -178.5181 & -1.4365 & 979789.06 & -976622.7 & -184.157 \\
\hline 491.87499 & -178.411 & -1.436177 & 979789.05 & -976622.7 & -184.2364 \\
\hline 492.03134 & -178.4677 & -1.436348 & 979789.04 & -976622.8 & -184.2534 \\
\hline 492.3567 & -178.5858 & -1.436704 & 979789.03 & -976622.9 & -184.3681 \\
\hline 492.9889 & -178.8152 & -1.437393 & 979789.03 & -976622.8 & -184.2864 \\
\hline 493.46228 & -178.987 & -1.437906 & 979789.02 & -976623 & -184.5043 \\
\hline 493.67044 & -179.0625 & -1.438132 & 979789.02 & -976623.4 & -184.89 \\
\hline 493.8416 & -179.1246 & -1.438317 & 979789.02 & -976623.2 & -184.6817 \\
\hline 494.00659 & -179.1845 & -1.438495 & 979789.02 & -976623.2 & -184.6844 \\
\hline 494.30572 & -179.293 & -1.438817 & 979789.02 & -976623.1 & -184.5508 \\
\hline 494.59869 & -179.3993 & -1.439133 & 979789.01 & -976623.2 & -184.709 \\
\hline 494.53702 & -179.3769 & -1.439066 & 979789.01 & -976623.1 & -184.5747 \\
\hline 494.32423 & -179.2997 & -1.438837 & 979789.01 & -976622.9 & -184.3958 \\
\hline 493.93412 & -179.1582 & -1.438417 & 979789 & -976623.2 & -184.6662 \\
\hline 493.41479 & -178.9697 & -1.437855 & 979788.99 & -976622.8 & -184.2704 \\
\hline 492.3345 & -178.5777 & -1.43668 & 979788.98 & -976622.8 & -184.3293 \\
\hline 491.72142 & -178.3553 & -1.436009 & 979788.97 & -976622.7 & -184.1479 \\
\hline 491.26192 & -178.1886 & -1.435504 & 979788.96 & -976622.7 & -184.2372 \\
\hline
\end{tabular}




\begin{tabular}{|r|r|l|l|l|l|}
\hline & SAN & FRANCISCO & VOLCANIC & FIELD & \\
\hline & SPIDER & WEB & RANCH & GRAVITY & SURVEY \\
\hline & & LINE $\# 4000$ & & N90 ${ }^{\circ}$ FROM & base $\# 1$ \\
\hline & & & & & \\
\hline STATION\# & DISTANCE & ELEVATION & LATITUDE & Sigma & Gobs(mgals) \\
\hline & (M) & (M) & (DEGREE) & & \\
\hline base \#1 & & 1598.676 & & & \\
\hline base \#1 & 0 & 1598.676 & 35.6589 & 0.1271557 & 2853.6862 \\
\hline 4050 & 50 & 1598.101 & 35.6589 & 0.1271557 & 2853.9646 \\
\hline 4100 & 100 & 1596.891 & 35.6589 & 0.1271557 & 2854.1992 \\
\hline 4150 & 150 & 1595.636 & 35.6589 & 0.1271557 & 2854.6482 \\
\hline 4200 & 200 & 1594.426 & 35.6589 & 0.1271557 & 2854.7002 \\
\hline 4225 & 225 & 1593.821 & 35.6589 & 0.1271557 & 2854.7789 \\
\hline 4250 & 250 & 1594.251 & 35.6589 & 0.1271557 & 2854.5474 \\
\hline 4270 & 270 & 1594.081 & 35.6589 & 0.1271557 & 2854.7534 \\
\hline 4295 & 295 & 1594.291 & 35.6589 & 0.1271557 & 2854.637 \\
\hline 4310 & 310 & 1594.841 & 35.6589 & 0.1271557 & 2854.5563 \\
\hline 4325 & 325 & 1594.806 & 35.6589 & 0.1271557 & 2854.5909 \\
\hline 4340 & 340 & 1594.601 & 35.6589 & 0.1271557 & 2854.6193 \\
\hline 4355 & 355 & 1594.481 & 35.6589 & 0.1271557 & 2854.7375 \\
\hline 4370 & 370 & 1594.321 & 35.6589 & 0.1271557 & 2854.8607 \\
\hline 4385 & 385 & 1594.026 & 35.6589 & 0.1271557 & 2854.9861 \\
\hline 4400 & 400 & 1593.751 & 35.6589 & 0.1271557 & 2854.7648 \\
\hline 4415 & 415 & 1593.511 & 35.6589 & 0.1271557 & 2855.0933 \\
\hline 4440 & 440 & 1593.536 & 35.6589 & 0.1271557 & 2855.2077 \\
\hline 4465 & 465 & 1593.806 & 35.6589 & 0.1271557 & 2855.3527 \\
\hline 4515 & 515 & 1594.151 & 35.6589 & 0.1271557 & 2854.904 \\
\hline 4565 & 565 & 1592.966 & 35.6589 & 0.1271557 & 2855.0133 \\
\hline 4615 & 615 & 1591.801 & 35.6589 & 0.1271557 & 2855.3355 \\
\hline 4665 & 665 & 1590.846 & 35.6589 & 0.1271557 & 2855.4387 \\
\hline & & & & & \\
\hline
\end{tabular}




\begin{tabular}{|r|r|r|r|r|r|}
\hline & & & & & \\
\hline & & & & & \\
\hline & & & & & \\
\hline & & & & & \\
\hline & BREGUER & Earth Curve & Gtheor & CBG(mgals) & Normalized \\
\hline & & & & & 976438.5 \\
\hline 493.20014 & -178.8918 & -1.437622 & 979789.08 & -976622.5 & -184.0182 \\
\hline 493.02281 & -178.8275 & -1.437429 & 979789.08 & -976622.4 & -183.8526 \\
\hline 492.64966 & -178.6921 & -1.437023 & 979789.08 & -976622.4 & -183.8554 \\
\hline 492.26263 & -178.5517 & -1.436601 & 979789.08 & -976622.2 & -183.6525 \\
\hline 491.88948 & -178.4163 & -1.436193 & 979789.08 & -976622.3 & -183.8378 \\
\hline 491.7029 & -178.3486 & -1.435989 & 979789.08 & -976622.4 & -183.8778 \\
\hline 491.73551 & -178.3967 & -1.436134 & 979789.08 & -976622.5 & -184.0249 \\
\hline 491.84784 & -178.3777 & -174.436077 & 979789.08 & -976622.4 & -183.8523 \\
\hline 492.01746 & -178.4627 & -1.436333 & 979789.08 & -976622.4 & -183.9004 \\
\hline 492.00667 & -178.4588 & -1.436321 & 979789.08 & -976622.4 & -183.8725 \\
\hline 491.94345 & -178.4359 & -1.436252 & 979789.08 & -976622.4 & -183.8844 \\
\hline 491.90644 & -178.4224 & -1.436212 & 979789.08 & -976622.3 & -183.7898 \\
\hline 491.8571 & -178.4045 & -1.436158 & 979789.08 & -976622.2 & -183.6979 \\
\hline 491.76612 & -178.3715 & -1.436058 & 979789.08 & -976622.1 & -183.6304 \\
\hline 491.68131 & -178.3407 & -1.435965 & 979789.08 & -976622.4 & -183.9056 \\
\hline 491.6073 & -178.3139 & -1.435884 & 979789.08 & -976622.1 & -183.6242 \\
\hline 491.61501 & -178.3167 & -1.435892 & 979789.08 & -976622 & -183.5049 \\
\hline 491.69827 & -178.3469 & -1.435984 & 979789.08 & -976621.8 & -183.307 \\
\hline 491.80467 & -178.3855 & -1.4361 & 979789.08 & -976622.2 & -183.6879 \\
\hline 491.43923 & -178.2529 & -1.435699 & 979789.08 & -976622.3 & -183.8111 \\
\hline 491.07995 & -178.1225 & -1.435304 & 979789.08 & -976622.2 & -183.7174 \\
\hline 490.78544 & -178.0157 & -1.43498 & 979789.08 & -976622.3 & -183.8016 \\
\hline
\end{tabular}




\begin{tabular}{|c|c|c|c|c|c|}
\hline & SAN & FRANCISCO & VOLCANIC & FIELD & \\
\hline & SPIDER & WEB & RANCH & GRAVITY & SURVEY \\
\hline & & LINE \#5000 & & N124 $4^{\circ}$ from & base \#1 \\
\hline STATION\# & DISTANCE & FIFV & & & \\
\hline & (M) & (M) & $\begin{array}{l}\text { LATITUDE } \\
\text { (DEGREE) }\end{array}$ & & \\
\hline base \#1 & & 1598.676 & & & \\
\hline base \#1 & 0 & 1598.676 & 35.6589 & 0.1271557 & 2854.241 \\
\hline 5050 & 50 & 1597.067 & 35.658648 & 0.1271539 & 2854.4967 \\
\hline 5100 & 100 & 1595.082 & 35.658396 & 0.1271 & 2854.8165 \\
\hline 5150 & 150 & 1595.785 & 35.658144 & & 2854.6253 \\
\hline 5175 & 175 & 1595.202 & 35.658018 & & \\
\hline 5200 & 200 & 1596.072 & & & \\
\hline 5225 & 225 & 1598.584 & & & \\
\hline 5250 & 250 & 1602.478 & & & 2852.9805 \\
\hline 5270 & 270 & 1609.373 & 35.65754 & 0.127146 & 2851.6722 \\
\hline 5290 & 290 & 1614.408 & 35.657439 & 0.1271453 & 739 \\
\hline 5305 & 305 & .681 & 7364 & 0.1271448 & 874 \\
\hline 5320 & 320 & .458 & 7288 & 0.12 & \\
\hline 5327.5 & 327.5 & 368 & 35.65725 & 0.12 & 002 \\
\hline 5335 & 335 & 013 & 35.657212 & 0.1271437 & 28 \\
\hline 5350 & 350 & 1618.906 & 57137 & 0.1271431 & 9.703 \\
\hline 5365 & 365 & 1618.793 & 35.657061 & 0.1271426 & 2850.0151 \\
\hline 5380 & 380 & .828 & 35.656986 & 0.1271421 & 2849.6302 \\
\hline 5395 & 395 & 1618.496 & 35.65691 & 0.1271415 & 2849.8102 \\
\hline 5420 & 420 & 1617.867 & 35.656784 & 0.1271406 & 2850.1486 \\
\hline 5445 & 445 & 1616.893 & 35.656658 & 0.1271397 & 2850.3636 \\
\hline 5470 & 470 & 1615.268 & 35.656532 & 0.1271388 & 2850.4621 \\
\hline 5495 & 495 & 1607.857 & 35.656406 & 0.1271379 & 2852.126 \\
\hline 5520 & 520 & 1599.445 & 35.65628 & 0.127137 & 2853.6464 \\
\hline 5570 & 570 & 1597.615 & 35.656029 & 0.1271352 & 2854.0225 \\
\hline 5620 & 620 & 1596.683 & 35.655777 & 0.1271334 & 2854.0822 \\
\hline
\end{tabular}




\begin{tabular}{|r|r|r|r|r|r|}
\hline & & & & & \\
\hline & & & & & \\
\hline & & & & & \\
\hline FREE AIR & BOUGUER & Earth Curve & Gtheor & CBG(mgals) & Normalized \\
\hline & & & & & 976438.5 \\
\hline & & & & & \\
\hline 493.20014 & -178.8918 & -1.437622 & 979789.08 & -976622 & -183.4634 \\
\hline 492.70394 & -178.7118 & -1.437083 & 979789.05 & -976622 & -183.5017 \\
\hline 492.09179 & -178.4897 & -1.436414 & 979789.03 & -976622.1 & -183.5497 \\
\hline 492.30859 & -178.5683 & -1.436651 & 979789.01 & -976622.1 & -183.5814 \\
\hline 492.1288 & -178.5031 & -1.436455 & 979789 & -976622 & -183.4906 \\
\hline 492.3971 & -178.6005 & -1.436748 & 979788.99 & -976622.1 & -183.6401 \\
\hline 493.17178 & -178.8816 & -1.437591 & 979788.98 & -976622.3 & -183.7459 \\
\hline 494.37265 & -179.3173 & -1.438889 & 979788.97 & -976622.4 & -183.8702 \\
\hline 496.499 & -180.0888 & -1.441162 & 979788.96 & -976622.3 & -183.8174 \\
\hline 498.05173 & -180.6523 & -1.4428 & 979788.95 & -976622.4 & -183.9194 \\
\hline 498.44431 & -180.7947 & -1.443212 & 979788.94 & -976622.5 & -183.9497 \\
\hline 498.99232 & -180.9936 & -1.443784 & 979788.94 & -976622.5 & -183.9671 \\
\hline 499.27295 & -181.0954 & -1.444076 & 979788.93 & -976622.7 & -184.2001 \\
\hline 499.47186 & -181.1676 & -1.444283 & 979788.93 & -976622.6 & -184.0553 \\
\hline 499.43886 & -181.1556 & -1.444249 & 979788.92 & -976622.4 & -183.8821 \\
\hline 499.40402 & -181.1429 & -1.444213 & 979788.92 & -976622.1 & -183.5856 \\
\hline 499.41481 & -181.1469 & -1.444224 & 979788.91 & -976622.5 & -183.9572 \\
\hline 499.31243 & -181.1097 & -1.444117 & 979788.91 & -976622.3 & -183.8358 \\
\hline 499.11845 & -181.0393 & -1.443916 & 979788.89 & -976622.1 & -183.61 \\
\hline 498.81809 & -180.9303 & -1.443602 & 979788.88 & -976622.1 & -183.5753 \\
\hline 498.31696 & -180.7485 & -1.443078 & 979788.87 & -976622.3 & -183.7849 \\
\hline 496.03149 & -179.9192 & -1.440665 & 979788.86 & -976622.1 & -183.5639 \\
\hline 493.43732 & -178.9779 & -1.437879 & 979788.85 & -976622.2 & -183.6828 \\
\hline 492.87297 & -178.7731 & -1.437266 & 979788.83 & -976622.1 & -183.6441 \\
\hline 492.58555 & -178.6688 & -1.436954 & 979788.81 & -976622.3 & -183.7456 \\
\hline & & & & & \\
\hline
\end{tabular}




\begin{tabular}{|c|c|c|c|c|c|}
\hline & SAN & FRANCISCO & VOLCANIC & FIELD & \\
\hline & SPIDER & WEB & RANCH & GRAVITY & SURVEY \\
\hline & & LINE \#6000 & & $\mathrm{N} 105^{\circ}$ from & $\# 6100$ \\
\hline \multirow{2}{*}{ STATION\# } & DISTANCF & & & & \\
\hline & (M) & $\begin{array}{l}\text { ELEVATION } \\
\text { (M) }\end{array}$ & LATITUDE & Sigma & \\
\hline$\# 6100$ & & 1644.572 & & & \\
\hline 6000 & 0 & 1641.7 & 35.6478 & 0.1270766 & 2844.4046 \\
\hline 6050 & 50 & 1643.018 & 35.647683 & 0.1270757 & 2843.9764 \\
\hline 6100 & 100 & 1644.572 & 35.647567 & 0.1270749 & 2843.6875 \\
\hline 6125 & 125 & 1642.248 & 35.647509 & 0.1270745 & 2843.9249 \\
\hline 6175 & 175 & 1633.018 & 35.647392 & 0.1270737 & 2846.1704 \\
\hline 6225 & 225 & 1625.892 & 35.647275 & 0.1270728 & 2847.4663 \\
\hline 6245 & 245 & 1625.182 & 35.647229 & 0.1270725 & 2847.2978 \\
\hline 6265 & 265 & 1624.452 & 35.647182 & 0.1270722 & 2847.3571 \\
\hline 6285 & 286 & 1623.762 & 35.647133 & 0.1270718 & 2846.9768 \\
\hline 6305 & 305 & 1623.321 & 35.647089 & 0.1270715 & 2847.1365 \\
\hline 6325 & 325 & 1622.949 & 35.647042 & 0.1270 & 47.2845 \\
\hline 6345 & 345 & 1622.522 & 35.646996 & 0.1270708 & 2847.3835 \\
\hline 6365 & 365 & 1621.969 & 35.6 & 0.1270705 & 28 \\
\hline 6385 & 385 & 1621.622 & 35.6 & 0.1270702 & 47.7561 \\
\hline 6405 & 405 & 1621.812 & 35.6 & 0.1270698 & 2848.4442 \\
\hline 6425 & 425 & 1623.022 & 35.646809 & 0.1270695 & 2847.7508 \\
\hline 6475 & 475 & 1626.087 & 35.646692 & 0.1270687 & 2847.7246 \\
\hline 6525 & 525 & 1626.234 & 35.646576 & 0.1270678 & 2847.8666 \\
\hline 6575 & 575 & 1622.078 & 35.646459 & 0.127067 & 2848.5606 \\
\hline 6625 & 625 & 1620.103 & 35.646343 & 0.1270662 & 2848.9183 \\
\hline
\end{tabular}




\begin{tabular}{|r|r|r|r|r|r|}
\hline & & & & & \\
\hline & & & & & \\
\hline & & & & & \\
\hline FREE AIR & BOUGUER & Earth Curve & Gtheor & CBG(mgals) & Normalized \\
\hline & & & & & 976438.5 \\
\hline 506.46832 & -183.7062 & -1.451369 & 979788.13 & -976622.4 & -183.9094 \\
\hline 506.87477 & -183.8537 & -1.45177 & 979788.12 & -976622.6 & -184.0691 \\
\hline 507.354 & -184.0276 & -1.452241 & 979788.11 & -976622.5 & -184.0431 \\
\hline 506.63732 & -183.7676 & -1.451536 & 979788.1 & -976622.8 & -184.2566 \\
\hline 503.79093 & -182.7347 & -1.448701 & 979788.09 & -976622.3 & -183.8119 \\
\hline 501.59337 & -181.9373 & -1.44647 & 979788.08 & -976622.4 & -183.9039 \\
\hline 501.37442 & -181.8579 & -1.446246 & 979788.08 & -976622.7 & -184.2077 \\
\hline 501.1493 & -181.7762 & -1.446015 & 979788.07 & -976622.8 & -184.2877 \\
\hline 500.93651 & -181.699 & -1.445797 & 979788.07 & -976623.3 & -184.7991 \\
\hline 500.80051 & -181.6496 & -1.445657 & 979788.06 & -976623.2 & -184.7221 \\
\hline 500.68579 & -181.608 & -1.445539 & 979788.06 & -976623.1 & -184.6431 \\
\hline 500.55411 & -181.5602 & -1.445403 & 979788.06 & -976623.1 & -184.6239 \\
\hline 500.38357 & -181.4983 & -1.445227 & 979788.05 & -976623.1 & -184.6251 \\
\hline 500.27656 & -181.4595 & -1.445117 & 979788.05 & -976622.9 & -184.4199 \\
\hline 500.33516 & -181.4808 & -1.445177 & 979788.04 & -976622.2 & -183.6904 \\
\hline 500.70831 & -181.6162 & -1.445562 & 979788.04 & -976622.6 & -184.1425 \\
\hline 501.65351 & -181.9591 & -1.446532 & 979788.03 & -976622.1 & -183.5574 \\
\hline 501.69885 & -181.9756 & -1.446578 & 979788.02 & -976621.9 & -183.3766 \\
\hline 500.41719 & -181.5105 & -1.445262 & 979788.01 & -976622 & -183.488 \\
\hline 499.80813 & -181.2895 & -1.444632 & 979788 & -976622 & -183.5077 \\
\hline
\end{tabular}




\begin{tabular}{|c|c|c|c|c|c|}
\hline & SAN & FRANCISCO & VOLCANIC & FIELD & \\
\hline & SPIDER & WEB & RANCH & GRAVITY & SURVEY \\
\hline & & LINE \#7000 & & $\mathrm{N} 120^{\circ}$ from & base \#19 \\
\hline STATION\# & DISTANCE & ELEVATION & LATITUDE & Sigma & GOBS (mgals \\
\hline & (M) & (M) & (DEGREE) & & \\
\hline base \#1 & & 1598.676 & & & \\
\hline 7000 & 0 & 1600.416 & 35.6581 & 0.12715 & 2854.2818 \\
\hline 7050 & 50 & 1599.796 & 35.657875 & 0.1271484 & 2854.2005 \\
\hline 7100 & 100 & 1599.076 & 35.65765 & 0.1271468 & 2854.3596 \\
\hline 7150 & 150 & 1598.276 & 35.657424 & 0.1271452 & 2854.2632 \\
\hline 7200 & 200 & 1597.714 & 35.657199 & 0.1271436 & 2854.3492 \\
\hline 7252 & 252 & 1596.621 & 656965 & 0.1271419 & 2854.8105 \\
\hline 7270 & 270 & 1599.576 & 56884 & & 2854.4188 \\
\hline 7295 & 295 & 7.439 & 56771 & & 2853.0258 \\
\hline 7320 & 320 & 17.776 & 6659 & & 2850.8144 \\
\hline 7345 & 345 & 6.406 & 6546 & 0.1271389 & 2845.07 \\
\hline 7375 & 375 & 1659.651 & 6411 & 0.127138 & 2841 \\
\hline 7400 & 400 & 1653.026 & 35.656298 & 0.1271372 & 9821 \\
\hline 7418 & 418 & 1648.876 & 35.656217 & 0.1271366 & 2844.8397 \\
\hline 7443 & 443 & 1633.666 & 35.656105 & 0.1271358 & 2847.9665 \\
\hline 7468 & 468 & 1629.426 & 5992 & 0.127135 & 2849.8037 \\
\hline 7500 & 500 & 1627.646 & 5848 & 0.127134 & 2849.9026 \\
\hline 7550 & 550 & 1624.878 & 35.655623 & 0.1271323 & 2850.6096 \\
\hline 7600 & 600 & 1609.823 & 35.655397 & 0.1271307 & 2854.0905 \\
\hline 7650 & 650 & 1609.353 & 35.655172 & 0.1271291 & 2854.252 \\
\hline 7700 & 700 & 1611.778 & 35.654947 & 0.1271275 & 2853.4395 \\
\hline 7750 & 750 & 1612.196 & 35.654722 & 0.1271259 & 2853.3798 \\
\hline 7800 & 800 & 1612.091 & 35.654496 & 0.1271243 & 2853.5054 \\
\hline
\end{tabular}




\begin{tabular}{|r|r|r|r|r|r|}
\hline & & & & & \\
\hline & & & & & \\
\hline & & & & & \\
\hline & & & & & \\
\hline & FREE AIR & & & & \\
\hline & & & & & 976438.5 \\
\hline 493.73675 & -179.0866 & -1.438203 & 979789.01 & -976621.5 & -183.0128 \\
\hline 493.54555 & -179.0172 & -1.437996 & 979788.99 & -976621.7 & -183.1964 \\
\hline 493.32351 & -178.9366 & -1.437756 & 979788.97 & -976621.7 & -183.1592 \\
\hline 493.0768 & -178.8471 & -1.437488 & 979788.95 & -976621.9 & -183.3932 \\
\hline 492.90349 & -178.7842 & -1.4373 & 979788.93 & -976621.9 & -183.3982 \\
\hline 492.56642 & -178.6619 & -1.436933 & 979788.91 & -976621.6 & -183.1312 \\
\hline 493.47771 & -178.9926 & -1.437923 & 979788.9 & -976621.4 & -182.9364 \\
\hline 495.90258 & -179.8724 & -1.440528 & 979788.89 & -976621.3 & -182.7773 \\
\hline 499.09039 & -181.0291 & -1.443886 & 979788.88 & -976621.5 & -182.9514 \\
\hline 507.91947 & -184.2328 & -1.452794 & 979788.87 & -976621.6 & -183.0696 \\
\hline 512.004 & -185.715 & -1.456719 & 979788.86 & -976622.5 & -183.9987 \\
\hline 509.96097 & -184.9736 & -1.454771 & 979788.85 & -976621.3 & -182.8376 \\
\hline 508.68118 & -184.5092 & -1.453535 & 979788.85 & -976621.3 & -182.7872 \\
\hline 503.99066 & -182.8072 & -1.448902 & 979788.84 & -976621.1 & -182.6347 \\
\hline 502.6831 & -182.3328 & -1.447581 & 979788.83 & -976620.1 & -181.6196 \\
\hline 502.13418 & -182.1336 & -1.447022 & 979788.81 & -976620.4 & -181.8576 \\
\hline 501.28057 & -181.8239 & -1.44615 & 979788.79 & -976620.2 & -181.6742 \\
\hline 496.6378 & -180.1392 & -1.441309 & 979788.78 & -976619.6 & -181.1274 \\
\hline 496.49286 & -180.0866 & -1.441156 & 979788.76 & -976619.5 & -181.0388 \\
\hline 497.2407 & -180.358 & -1.441947 & 979788.74 & -976619.9 & -181.3563 \\
\hline 497.36961 & -180.4047 & -1.442083 & 979788.72 & -976619.8 & -181.3147 \\
\hline 497.33723 & -180.393 & -1.442049 & 979788.7 & -976619.7 & -181.1905 \\
\hline & & & & & \\
\hline
\end{tabular}




\begin{tabular}{|r|r|r|r|l|r|}
\hline & SAN & FRANCISCO & VOLCANIC & FIELD & \\
\hline & SPIDER & WEB & RANCH & GRAVITY & SURVEY \\
\hline & & LINE \#8000 & & N105 $5^{\circ}$ from & $\# 8187$ \\
\hline & & & & & \\
\hline STATION\# & DISTANCE & ELEVATION & LATITUDE & Sigma & GOBS(mgals) \\
\hline & (M) & (M) & (DEGREE) & & \\
\hline$\# 6100$ & & 1644.572 & & & \\
\hline 6000 & -187 & 1641.7 & 35.6478 & 0.1270766 & 2845.3694 \\
\hline 8050 & -137 & 1641.78 & 35.64803 & 0.1270782 & 2845.0252 \\
\hline 8100 & -87 & 1642.515 & 35.64825 & 0.1270798 & 2844.7234 \\
\hline 8150 & -37 & 1642.702 & 35.64845 & 0.1270812 & 2844.4929 \\
\hline 8187 & 0 & 1642.412 & 35.6486 & 0.1270823 & 2844.5328 \\
\hline 8237 & 50 & 1636.234 & 35.648483 & 0.1270814 & 2845.8933 \\
\hline 8290 & 103 & 1627.487 & 35.64836 & 0.1270806 & 2847.5312 \\
\hline 8340 & 153 & 1624.99 & 35.648243 & 0.1270797 & 2847.7321 \\
\hline 8365 & 178 & 1624.497 & 35.648185 & 0.1270793 & 2847.7882 \\
\hline 8390 & 203 & 1623.624 & 35.648127 & 0.1270789 & 2848.0045 \\
\hline 8410 & 223 & 1623.227 & 35.64808 & 0.1270786 & 2848.1264 \\
\hline 8430 & 243 & 1623.436 & 35.648033 & 0.1270782 & 2848.4049 \\
\hline 8450 & 263 & 1623.86 & 35.647987 & 0.1270779 & 2848.4294 \\
\hline 8470 & 283 & 1623.183 & 35.64794 & 0.1270776 & 2847.9164 \\
\hline 8490 & 303 & 1621.152 & 35.647894 & 0.1270772 & 2849.5472 \\
\hline 8510 & 323 & 1619.136 & 35.647847 & 0.1270769 & 2849.97 \\
\hline 8530 & 343 & 1618.682 & 35.6478 & 0.1270766 & 2850.2321 \\
\hline 8550 & 363 & 1618.483 & 35.647754 & 0.1270762 & 2850.1072 \\
\hline 8570 & 383 & 1617.989 & 35.647707 & 0.1270759 & 2850.3245 \\
\hline 8620 & 433 & 1617.538 & 35.64759 & 0.1270751 & 2850.4306 \\
\hline 8670 & 483 & 1616.329 & 35.647474 & 0.1270742 & 2850.6897 \\
\hline 8720 & 533 & 1615.14 & 35.647357 & 0.1270734 & 2850.782 \\
\hline 8770 & 583 & 1613.62 & 35.647241 & 0.1270726 & 2851.2486 \\
\hline & & & & & \\
\hline
\end{tabular}




\begin{tabular}{|r|r|r|r|r|r|}
\hline & & & & & \\
\hline & & & & & \\
\hline & & & & & \\
\hline & & & & & \\
\hline & & & & & \\
\hline 506.46832 & -183.7062 & -1.451369 & 979788.13 & -976621.4 & -182.9446 \\
\hline 506.49299 & -183.7152 & -1.451394 & 979788.14 & -976621.8 & -183.2928 \\
\hline 506.71965 & -183.7974 & -1.451617 & 979788.16 & -976622 & -183.4693 \\
\hline 506.77731 & -183.8184 & -1.451674 & 979788.18 & -976622.2 & -183.6802 \\
\hline 506.68788 & -183.7859 & -1.451586 & 979788.19 & -976622.2 & -183.7101 \\
\hline 504.78268 & -183.0946 & -1.449695 & 979788.18 & -976622.1 & -183.5516 \\
\hline 502.08523 & -182.1158 & -1.446973 & 979788.17 & -976622.1 & -183.619 \\
\hline 501.31519 & -181.8364 & -1.446185 & 979788.16 & -976622.4 & -183.8979 \\
\hline 501.16316 & -181.7812 & -1.446029 & 979788.16 & -976622.4 & -183.9335 \\
\hline 500.89394 & -181.6835 & -1.445753 & 979788.15 & -976622.4 & -183.8835 \\
\hline 500.77151 & -181.6391 & -1.445627 & 979788.15 & -976622.3 & -183.8355 \\
\hline 500.83596 & -181.6625 & -1.445693 & 979788.15 & -976622 & -183.5121 \\
\hline 500.96672 & -181.7099 & -1.445828 & 979788.14 & -976621.9 & -183.4004 \\
\hline 500.75794 & -181.6342 & -1.445613 & 979788.14 & -976622.5 & -184.0421 \\
\hline 500.13161 & -181.4069 & -1.444967 & 979788.13 & -976621.3 & -182.8058 \\
\hline 499.5099 & -181.1813 & -1.444323 & 979788.13 & -976621.3 & -182.7745 \\
\hline 499.36989 & -181.1305 & -1.444177 & 979788.13 & -976621.1 & -182.5974 \\
\hline 499.30853 & -181.1083 & -1.444113 & 979788.12 & -976621.3 & -182.7574 \\
\hline 499.15618 & -181.053 & -1.443955 & 979788.12 & -976621.1 & -182.633 \\
\hline 499.0171 & -181.0025 & -1.44381 & 979788.11 & -976621.1 & -182.6054 \\
\hline 498.64426 & -180.8672 & -1.443421 & 979788.1 & -976621.1 & -182.5735 \\
\hline 498.27759 & -180.7342 & -1.443037 & 979788.09 & -976621.2 & -182.7044 \\
\hline 497.80884 & -180.5641 & -1.442545 & 979788.08 & -976621 & -182.526 \\
\hline
\end{tabular}




\begin{tabular}{|r|l|l|l|l|l|}
\hline & SAN & FRANCISCO & VOLCANIC & FIELD & \\
\hline & SPIDER & WEB & RANCH & \multicolumn{1}{l|}{ GRAVITY } & SURVEY \\
\hline & & LINE \#9000 & & N120 from & base \#27 \\
\hline & & & & & \\
\hline STATION\# & DISTANCE & ELEVATION & LATITUDE & Sigma & GOBS(mgals \\
\hline & (M) & (M) & (DEGREE) & & \\
\hline base \#1 & & 1598.676 & & & \\
\hline base \#26 & & 1605.236 & & & \\
\hline base \#27 & 0 & 1607.306 & 35.6544 & 0.1271236 & 2853.2476 \\
\hline 9050 & 50 & 1605.186 & 35.654175 & 0.127122 & 2853.3016 \\
\hline 9100 & 100 & 1604.681 & 35.65395 & 0.1271204 & 2853.5682 \\
\hline 9150 & 150 & 1603.994 & 35.653724 & 0.1271188 & 2854.0964 \\
\hline 9178 & 178 & 1602.062 & 35.653598 & 0.1271179 & 2854.2906 \\
\hline 9200 & 200 & 1604.151 & 35.653499 & 0.1271172 & 2854.0911 \\
\hline 9225 & 225 & 1606.26 & 35.653387 & 0.1271164 & 2854.2573 \\
\hline 9250 & 250 & 1607.998 & 35.653274 & 0.1271156 & 2853.7193 \\
\hline 9275 & 275 & 1609.16 & 35.653161 & 0.1271148 & 2853.3128 \\
\hline 9300 & 300 & 1611.232 & 35.653049 & 0.127114 & 2852.8481 \\
\hline 9320 & 320 & 1614.019 & 35.652959 & 0.1271134 & 2852.5166 \\
\hline 9340 & 340 & 1616.173 & 35.652869 & 0.1271127 & 2852.1825 \\
\hline 9360 & 360 & 1618.823 & 35.652778 & 0.1271121 & 2851.3023 \\
\hline 9380 & 380 & 1622.261 & 35.652688 & 0.1271114 & 2850.8056 \\
\hline 9400 & 400 & 1625.21 & 35.652598 & 0.1271108 & 2850.3981 \\
\hline 9420 & 420 & 1626.988 & 35.652508 & 0.1271101 & 2849.7346 \\
\hline 9440 & 440 & 1629.443 & 35.652418 & 0.1271095 & 2849.3113 \\
\hline 9460 & 460 & 1632.263 & 35.652328 & 0.1271089 & 2848.6616 \\
\hline
\end{tabular}




\begin{tabular}{|r|r|r|r|r|r|}
\hline & & & & & \\
\hline & & & & & \\
\hline & & & & & \\
\hline & & & & & \\
\hline & & & & & \\
\hline & & & & & 976438.5 \\
\hline 495.86159 & -179.8575 & -1.440484 & 979788.69 & -976620.9 & -182.3786 \\
\hline 495.20781 & -179.6203 & -1.439786 & 979788.67 & -976621.2 & -182.7212 \\
\hline 495.05208 & -179.5638 & -1.439619 & 979788.65 & -976621 & -182.5344 \\
\hline 494.84021 & -179.4869 & -1.439392 & 979788.63 & -976620.6 & -182.1216 \\
\hline 494.24441 & -179.2707 & -1.438751 & 979788.62 & -976620.8 & -182.2956 \\
\hline 494.88863 & -179.5045 & -1.439444 & 979788.61 & -976620.6 & -182.0768 \\
\hline 495.53903 & -179.7405 & -1.44014 & 979788.6 & -976620 & -181.4873 \\
\hline 496.07501 & -179.935 & -1.440712 & 979788.59 & -976620.2 & -181.6748 \\
\hline 496.43336 & -180.065 & -1.441092 & 979788.58 & -976620.3 & -181.8437 \\
\hline 497.07234 & -180.2969 & -1.441769 & 979788.57 & -976620.4 & -181.8922 \\
\hline 497.93182 & -180.6087 & -1.442674 & 979788.57 & -976620.2 & -181.6693 \\
\hline 498.59609 & -180.8498 & -1.44337 & 979788.56 & -976620.1 & -181.5731 \\
\hline 499.41332 & -181.1463 & -1.444222 & 979788.55 & -976620.4 & -181.9258 \\
\hline 500.47355 & -181.531 & -1.44532 & 979788.54 & -976620.2 & -181.7404 \\
\hline 501.38299 & -181.861 & -1.446255 & 979788.54 & -976620.1 & -181.5617 \\
\hline 501.9313 & -182.06 & -1.446816 & 979788.53 & -976620.4 & -181.8686 \\
\hline 502.68839 & -182.3347 & -1.447586 & 979788.52 & -976620.3 & -181.8026 \\
\hline 503.55804 & -182.6502 & -1.448466 & 979788.51 & -976620.4 & -181.8914 \\
\hline
\end{tabular}




\begin{tabular}{|r|r|l|l|l|l|}
\hline & SAN & FRANCISCO & VOLCANIC & FIELD & \\
\hline & SPIDER & WEB & RANCH & GRAVITY & SURVEY \\
\hline & & LINE\# 10000 & & N90 from & $\# 10000$ \\
\hline & & & & & \\
\hline STATION\# & DISTANCE & ELEVATION & LATITUDE & Sigma & Gobs(mgals) \\
\hline & $(M)$ & (M) & (DEGREE) & & \\
\hline base \#1 & & 1598.676 & & & \\
\hline 10000 & 0 & 1597.649 & 35.6598 & 0.1271621 & 2854.5989 \\
\hline 10090 & 90 & 1595.437 & 35.6598 & 0.1271621 & 2855.1119 \\
\hline 10140 & 140 & 1594.344 & 35.6598 & 0.1271621 & 2855.3609 \\
\hline 10190 & 190 & 1592.384 & 35.6598 & 0.1271621 & 2855.5885 \\
\hline 10240 & 240 & 1592.349 & 35.6598 & 0.1271621 & 2855.5682 \\
\hline 10270 & 270 & 1592.479 & 35.6598 & 0.1271621 & 2855.7244 \\
\hline 10290 & 290 & 1592.429 & 35.6598 & 0.1271621 & 2855.5899 \\
\hline 10310 & 310 & 1592.394 & 35.6598 & 0.1271621 & 2855.5802 \\
\hline 10330 & 330 & 1592.019 & 35.6598 & 0.1271621 & 2855.8693 \\
\hline 10350 & 350 & 1591.999 & 35.6598 & 0.1271621 & 2855.7637 \\
\hline 10370 & 370 & 1591.789 & 35.6598 & 0.1271621 & 2855.6887 \\
\hline 10390 & 390 & 1591.719 & 35.6598 & 0.1271621 & 2855.8013 \\
\hline 10415 & 415 & 1591.514 & 35.6598 & 0.1271621 & 2855.8521 \\
\hline 10440 & 440 & 1591.336 & 35.6598 & 0.1271621 & 2855.8018 \\
\hline 10465 & 465 & 1591.224 & 35.6598 & 0.1271621 & 2855.8781 \\
\hline 10490 & 490 & 1591.484 & 35.6598 & 0.1271621 & 2855.7857 \\
\hline 10540 & 540 & 1592.634 & 35.6598 & 0.1271621 & 2855.7763 \\
\hline 10590 & 590 & 1592.579 & 35.6598 & 0.1271621 & 2855.8713 \\
\hline 10640 & 640 & 1591.733 & 35.6598 & 0.1271621 & 2856.0533 \\
\hline 10690 & 690 & 1591.444 & 35.6598 & 0.1271621 & 2855.9752 \\
\hline & & & & & \\
\hline
\end{tabular}




\begin{tabular}{|r|r|r|r|r|r|}
\hline & & & & & \\
\hline & & & & & \\
\hline & & & & & \\
\hline & & & & & \\
\hline & & & & & \\
\hline 492.88341 & -178.7769 & -1.437278 & 979789.15 & -976621.9 & -183.384 \\
\hline 492.20125 & -178.5294 & -1.436534 & 979789.15 & -976621.8 & -183.3049 \\
\hline 491.86418 & -178.4071 & -1.436165 & 979789.15 & -976621.8 & -183.2703 \\
\hline 491.25973 & -178.1878 & -1.435502 & 979789.15 & -976621.9 & -183.4271 \\
\hline 491.24894 & -178.1839 & -1.43549 & 979789.15 & -976622 & -183.4543 \\
\hline 491.28903 & -178.1984 & -1.435534 & 979789.15 & -976621.8 & -183.2726 \\
\hline 491.27361 & -178.1928 & -1.435517 & 979789.15 & -976621.9 & -183.4169 \\
\hline 491.26282 & -178.1889 & -1.435505 & 979789.15 & -976621.9 & -183.4335 \\
\hline 491.14717 & -178.1469 & -1.435378 & 979789.15 & -976621.7 & -183.2179 \\
\hline 491.141 & -178.1447 & -1.435371 & 979789.15 & -976621.8 & -183.3275 \\
\hline 491.07624 & -178.1212 & -1.4353 & 979789.15 & -976621.9 & -183.4437 \\
\hline 491.05465 & -178.1134 & -1.435276 & 979789.15 & -976621.8 & -183.3448 \\
\hline 490.99143 & -178.0904 & -1.435207 & 979789.15 & -976621.8 & -183.3342 \\
\hline 490.93654 & -178.0705 & -1.435146 & 979789.15 & -976621.9 & -183.4194 \\
\hline 490.902 & -178.058 & -1.435108 & 979789.15 & -976621.9 & -183.3651 \\
\hline 490.98218 & -178.0871 & -1.435196 & 979789.15 & -976621.9 & -183.4065 \\
\hline 491.33683 & -178.2157 & -1.435587 & 979789.15 & -976621.7 & -183.1903 \\
\hline 491.31987 & -178.2096 & -1.435568 & 979789.15 & -976621.6 & -183.1061 \\
\hline 491.05897 & -178.1149 & -1.435281 & 979789.15 & -976621.6 & -183.09 \\
\hline 490.96984 & -178.0826 & -1.435183 & 979789.15 & -976621.7 & -183.2248 \\
\hline
\end{tabular}




\begin{tabular}{|l|l|l|l|l|l|}
\hline & SAN & FRANCISCO & VOLCANIC & FIELD & \\
\hline & SPIDER & WEB & RANCH & GRAVITY & SURVEY \\
\hline & & LINE base\# & & N12.5 from & base \#1 \\
\hline & & & & & \\
\hline STATION\# & DISTANCE & ELEVATION & LATITUDE & Sigma & GOBS(mgals \\
\hline & (M) & (M) & (DEGREE) & & \\
\hline base \#1 & & 1598.676 & & & \\
\hline base \#1 & 0 & 1598.676 & 35.6589 & 0.1271557 & 2854.3807 \\
\hline$\# 18$ & 100 & 1598.106 & 35.658021 & 0.1271494 & 2854.5287 \\
\hline$\# 19$ & 150 & 1599.076 & 35.657581 & 0.1271463 & 2854.3982 \\
\hline$\# 20$ & 200 & 1599.451 & 35.657141 & 0.1271432 & 2853.9965 \\
\hline$\# 21$ & 230 & 1600.001 & 35.656877 & 0.1271413 & 2853.7967 \\
\hline$\# 22$ & 280 & 1600.441 & 35.656437 & 0.1271382 & 2853.8396 \\
\hline$\# 23$ & 330 & 1600.971 & 35.655998 & 0.127135 & 2853.7877 \\
\hline$\# 24$ & 362 & 1601.996 & 35.655716 & 0.127133 & 2853.4982 \\
\hline$\# 25$ & 386.4 & 1602.936 & 35.655501 & 0.1271315 & 2853.3169 \\
\hline$\# 26$ & 436.4 & 1605.236 & 35.655062 & 0.1271283 & 2852.6838 \\
\hline
\end{tabular}




\begin{tabular}{|l|r|r|r|r|r|}
\hline & & & & & \\
\hline & & & & & \\
\hline & & & & & \\
\hline & & & & & \\
\hline & & & & & \\
\hline 493.20014 & -178.8918 & -1.437622 & 979789.08 & -976621.8 & -183.3237 \\
\hline 493.02436 & -178.8281 & -1.437431 & 979789 & -976621.7 & -183.2122 \\
\hline 493.32351 & -178.9366 & -1.437756 & 979788.96 & -976621.6 & -183.1147 \\
\hline 493.43916 & -178.9786 & -1.437881 & 979788.92 & -976621.9 & -183.4052 \\
\hline 493.60878 & -179.0401 & -1.438065 & 979788.9 & -976622 & -183.4746 \\
\hline 493.74447 & -179.0894 & -1.438212 & 979788.86 & -976621.8 & -183.3077 \\
\hline 493.90793 & -179.1487 & -1.438388 & 979788.83 & -976621.7 & -183.218 \\
\hline 494.22403 & -179.2634 & -1.438729 & 979788.8 & -976621.8 & -183.2823 \\
\hline 494.51392 & -179.3685 & -1.439041 & 979788.78 & -976621.8 & -183.2609 \\
\hline 495.22322 & -179.6259 & -1.439803 & 979788.75 & -976621.9 & -183.4051 \\
\hline
\end{tabular}




\begin{tabular}{|c|c|c|c|c|}
\hline SAN & FRANCISCO & VOLCANIC & FIELD & \\
\hline SPIDER & WEB & RANCH & MAGNETIC & SURVEY \\
\hline & LINE \#5000 & & N124 from & base \#1 \\
\hline station\# & distance & reading & time & drift corr. \\
\hline & (M) & $(\mathrm{nT})$ & $(\min )$. & (nT) \\
\hline base \#1 & 0 & 51321.7 & 0 & 51321.7 \\
\hline 5050 & 50 & 51320.6 & 2 & 51320.8779 \\
\hline 5100 & 100 & 51355.8 & 5 & 51356.4947 \\
\hline 5150 & 150 & 51342.9 & 7 & 51343.8726 \\
\hline 5175 & 175 & 51356.9 & 9 & 51358.1505 \\
\hline 5200 & 200 & 51326.3 & 12 & 51327.9674 \\
\hline 5225 & 225 & 51298.3 & 15 & 51300.3842 \\
\hline 5250 & 250 & 51314.1 & 17 & 51316.4621 \\
\hline 5270 & 270 & 51279.7 & 22 & 51282.7568 \\
\hline 5290 & 290 & 51362.6 & 26 & 51366.2126 \\
\hline 5305 & 305 & 51331.6 & 29 & 51335.6295 \\
\hline 5320 & 320 & 51381 & 32 & 51385.4463 \\
\hline 5327.5 & 327.5 & 52785.7 & 36 & 52790.7021 \\
\hline 5335 & 335 & 52099.3 & 39 & 52104.7189 \\
\hline 5342 & 342 & 52167 & 43 & 52172.9747 \\
\hline 5350 & 350 & 51026.3 & 45 & 51032.5526 \\
\hline 5365 & 365 & 52366.1 & 47 & 52372.6305 \\
\hline 5395 & 395 & 51589.6 & 52 & 51596.8253 \\
\hline 5420 & 420 & 52172 & 55 & 52179.6421 \\
\hline 5445 & 445 & 50343 & 58 & 50351.0589 \\
\hline 5470 & 470 & 50744 & 60 & 50752.3368 \\
\hline 5495 & 495 & 51308.2 & 62 & 51316.8147 \\
\hline 5520 & 520 & 51300.3 & 65 & 51309.3316 \\
\hline 5570 & 570 & 51291.5 & 68 & 51300.9484 \\
\hline 5620 & 620 & 51286.7 & 70 & 51296.4263 \\
\hline 5670 & 670 & 51281.7 & 73 & 51291.8432 \\
\hline base $\# 1$ & 0 & 51308.5 & 95 & 51321.7 \\
\hline
\end{tabular}




\begin{tabular}{|c|c|c|c|c|}
\hline \multirow{3}{*}{$\begin{array}{l}\text { SAN } \\
\text { SPIDER }\end{array}$} & FRANCISCO & VOLCANIC & FIELD & \\
\hline & WEB & RANCH & MAGNETIC & SURVEY \\
\hline & LINE\#6000 & & $\mathrm{N} 124^{\circ}$ from & $\# 6000$ \\
\hline \multirow{2}{*}{ station\# } & distance & reading & time & drift corr. \\
\hline & (M) & (nT) & (min.) & $(n T)$ \\
\hline & & & & \\
\hline 6000 & 0 & 51387 & 0 & 51387 \\
\hline 6050 & 50 & 51408 & 15 & 51407.5673 \\
\hline 6100 & 100 & 51645 & 20 & 51644.4231 \\
\hline 6125 & 125 & 50940 & 25 & 50939.2788 \\
\hline 6175 & 175 & 51525 & 29 & 51524.1635 \\
\hline 6225 & 225 & 51269 & 33 & 51268.0481 \\
\hline 6245 & 245 & 51352 & 37 & 51350.9327 \\
\hline 6265 & 265 & 51387 & 40 & 51385.8462 \\
\hline 6285 & 285 & 51398 & 43 & 51396.7596 \\
\hline 6305 & 305 & 51390 & 46 & 51388.6731 \\
\hline 6325 & 325 & 51407 & 48 & 51405.6154 \\
\hline 6345 & 345 & 51458 & 50 & 51456.5577 \\
\hline 6365 & 365 & 51465 & 52 & 51463.5 \\
\hline 6385 & 385 & 51497 & 54 & 51495.4423 \\
\hline 6405 & 405 & 51385 & 56 & 51383.3846 \\
\hline 6410 & 410 & 51372 & 0 & 51372 \\
\hline 6415 & 415 & 51426 & 0 & 51426 \\
\hline 6420 & 420 & 51559 & 0 & 51559 \\
\hline 6422.5 & 422.5 & 52060 & 0 & 52060 \\
\hline 6425 & 425 & 52913 & 60 & 52911.2692 \\
\hline 6427.5 & 427.5 & 52089 & 0 & 52089 \\
\hline 6430 & 430 & 50630 & 0 & 50630 \\
\hline 6435 & 435 & 50930 & 0 & 50930 \\
\hline 6440 & 440 & 51085 & 0 & 51085 \\
\hline 6445 & 445 & 51130 & 0 & 51130 \\
\hline 6450 & 450 & 51162 & 63 & 51160.1827 \\
\hline 6475 & 475 & 51210 & 66 & 51208.0962 \\
\hline 6525 & 525 & 51210 & 70 & 51207.9808 \\
\hline 6575 & 575 & 51282 & 75 & 51279.8365 \\
\hline 6625 & 625 & 51302 & 78 & 51299.75 \\
\hline 6000 & 0 & 51390 & 104 & 51387 \\
\hline
\end{tabular}




\begin{tabular}{|c|c|c|c|c|}
\hline \multirow{3}{*}{$\begin{array}{l}\text { SAN } \\
\text { SPIDER }\end{array}$} & FRANCISCO & \multirow{2}{*}{$\begin{array}{l}\text { VOLCANIC } \\
\text { RANCH }\end{array}$} & FIELD & \multirow{2}{*}{ SURVEY } \\
\hline & WEB & & MAGNETIC & \\
\hline & LINE $\# 7000$ & & $\mathrm{~N}_{124^{\circ}}$ from & base \#1 \\
\hline station\# & distance & reading & time & drift corr. \\
\hline & (M) & $(n T)$ & $(\min )$. & (nT) \\
\hline & & & & \\
\hline 7000 & 0 & 51294 & 0 & 51294 \\
\hline 7050 & 50 & 51288 & 2 & 51288.2824 \\
\hline 7100 & 100 & 51283 & 4 & 51283.5647 \\
\hline 7150 & 150 & 51255 & 7 & 51255.9882 \\
\hline 7200 & 200 & 51286 & 9 & 51287.2706 \\
\hline 7252 & 252 & 51349 & 11 & 51350.5529 \\
\hline 7270 & 270 & 51256 & 13 & 51257.8353 \\
\hline 7295 & 295 & 51127 & 16 & 51129.2588 \\
\hline 7320 & 320 & 50882 & 21 & 50884.9647 \\
\hline 7345 & 345 & 51427 & 28 & 51430.9529 \\
\hline 7400 & 400 & 49832 & 36 & 49837.0824 \\
\hline 7418 & 418 & 52781 & 40 & 52786.6471 \\
\hline 7445 & 445 & 50887 & 45 & 50893.3529 \\
\hline 7468 & 468 & 51138 & 48 & 51144.7765 \\
\hline 7500 & 500 & 51040 & 50 & 51047.0588 \\
\hline 7550 & 550 & 52611 & 53 & 52618.4824 \\
\hline 7600 & 600 & 51229 & 57 & 51237.0471 \\
\hline 7700 & 700 & 51240 & 62 & 51248.7529 \\
\hline 7750 & 750 & 51282 & 63 & 51290.8941 \\
\hline 7800 & 800 & 51278 & 65 & 51287.1765 \\
\hline 7000 & 0 & 51282 & 85 & 51294 \\
\hline
\end{tabular}




\begin{tabular}{|c|c|c|c|c|}
\hline \multirow{3}{*}{$\begin{array}{l}\text { SAN } \\
\text { SPIDER }\end{array}$} & FRANCISCO & VOLCANIC & FIELD & \\
\hline & WEB & RANCH & MAGNETIC & SURVEY \\
\hline & LINE \#8000 & & $\mathrm{N} 124^{\circ}$ from & $\# 8187$ \\
\hline \multirow[t]{2}{*}{ station\# } & distance & reading & time & drift corr. \\
\hline & $(\mathrm{M})$ & $(n T)$ & $(\min )$. & $(n T)$ \\
\hline 6000 & -187 & 51352 & 0 & 51352 \\
\hline 8050 & -137 & 51108 & 3 & 51110.04 \\
\hline 8100 & .87 & 51515 & 6 & 51519.08 \\
\hline 8150 & -37 & 50637 & 9 & 50643.12 \\
\hline 8187 & 0 & 50548 & 11 & 50555.48 \\
\hline 8237 & 50 & 51165 & 14 & 51174.52 \\
\hline 8290 & 103 & 51326 & 17 & 51337.56 \\
\hline 8340 & 153 & 51275 & 19 & 51287.92 \\
\hline 8365 & 178 & 51291 & 21 & 51305.28 \\
\hline 8377 & 190 & 51308 & 23 & 51323.64 \\
\hline 8390 & 203 & 51323 & 26 & 51340.68 \\
\hline 8400 & 213 & 51333 & 27 & 51351.36 \\
\hline 8410 & 223 & 51413 & 30 & 51433.4 \\
\hline 8420 & 233 & 51368 & 32 & 51389.76 \\
\hline 8430 & 243 & 51412 & 33 & 51434.44 \\
\hline 8435 & 248 & 51901 & 39 & 51927.52 \\
\hline 8440 & 253 & 52963 & 36 & 52987.48 \\
\hline 8445 & 258 & 52126 & 40 & 52153.2 \\
\hline 8450 & 263 & 51823 & 42 & 51851.56 \\
\hline 8455 & 268 & 50978 & 45 & 51008.6 \\
\hline 8460 & 273 & 50498 & 47 & 50529.96 \\
\hline 8470 & 283 & 51036 & 50 & 51070 \\
\hline 8480 & 293 & 51122 & 52 & 51157.36 \\
\hline 8490 & 303 & 51138 & 54 & 51174.72 \\
\hline 8500 & 313 & 51108 & 57 & 51146.76 \\
\hline 8510 & 323 & 51131 & 59 & 51171.12 \\
\hline 8520 & 333 & 51120 & 61 & 51161.48 \\
\hline 8530 & 343 & 51153 & 62 & 51195.16 \\
\hline 8550 & 363 & 51177 & 63 & 51219.84 \\
\hline 8570 & 383 & 51190 & 65 & 51234.2 \\
\hline 8595 & 408 & 51200 & 67 & 51245.56 \\
\hline 8620 & 433 & 51190 & 69 & 51236.92 \\
\hline 8645 & 458 & 51160 & 71 & 51208.28 \\
\hline 8670 & 483 & 51216 & 72 & 51264.96 \\
\hline 8695 & 508 & 51229 & 74 & 51279.32 \\
\hline 8720 & 533 & 51238 & 75 & 51289 \\
\hline 8770 & 583 & 51222 & 77 & 51274.36 \\
\hline 8820 & 633 & 51236 & 80 & 51290.4 \\
\hline 6000 & & 51284 & 100 & 51352 \\
\hline
\end{tabular}




\begin{tabular}{|c|c|c|c|c|}
\hline \multirow{3}{*}{$\begin{array}{l}\text { SAN } \\
\text { SPIDER }\end{array}$} & FRANCISCO & VOLCANIC & FIELD & \\
\hline & WEB & RANCH & MAGNETIC & SURVEY \\
\hline & LINE \#10000 & & N90 from & $\# 10000$ \\
\hline station\# & distance $(m)$ & reading & time & \\
\hline & & $(n T)$ & $(\min )$. & (nT) \\
\hline & & & & \\
\hline 4050 & & 51310 & 0 & 51310 \\
\hline 10000 & 0 & 51320 & 4 & 51319.8532 \\
\hline 10090 & 90 & 51275 & 8 & 51274.7064 \\
\hline 10140 & 140 & 51282 & 11 & 51281.5963 \\
\hline 10190 & 190 & 51284 & 13 & 51283.5229 \\
\hline 10240 & 240 & 51293 & 16 & 51292.4128 \\
\hline 10250 & 250 & 51273 & 18 & 51272.3394 \\
\hline 10270 & 270 & 51320 & 20 & 51319.2661 \\
\hline 19275 & 275 & 51327 & 26 & 51326.0459 \\
\hline 10280 & 280 & 51466 & 21 & 51465.2294 \\
\hline 10282.5 & 282.5 & 51140 & 29 & 51138.9358 \\
\hline 10285 & 285 & 51105 & 23 & 51104.156 \\
\hline 10287.5 & 287.5 & 51204 & 30 & 51202.8991 \\
\hline 10290 & 290 & 51238 & 24 & 51237.1193 \\
\hline 10295 & 295 & 51298 & 31 & 51296.8624 \\
\hline 10300 & 300 & 51260 & 33 & 51258.789 \\
\hline 10310 & 310 & 51290 & 35 & 51288.7156 \\
\hline 10320 & 320 & 51293 & 36 & 51291.6789 \\
\hline 10330 & 330 & 51292 & 39 & 51290.5688 \\
\hline 10340 & 340 & 51292 & 40 & 51290.5321 \\
\hline 10350 & 350 & 51284 & 42 & 51282.4587 \\
\hline 10360 & 360 & 51328 & 46 & 51326.3119 \\
\hline 10370 & 370 & 51296 & 44 & 51294.3853 \\
\hline 10390 & 390 & 51371 & 48 & 51369.2385 \\
\hline 10400 & 400 & 51288 & 50 & 51286.1651 \\
\hline 10415 & 415 & 51239 & 51 & 51237.1284 \\
\hline 10440 & 440 & 51307 & 53 & 51305.055 \\
\hline 10465 & 465 & 51309 & 55 & 51306.9817 \\
\hline 10490 & 490 & 51295 & 56 & 51292.945 \\
\hline 10540 & 540 & 51271 & 59 & 51268.8349 \\
\hline 10590 & 590 & 51282 & 64 & 51279.6514 \\
\hline 10640 & 640 & 51276 & 66 & 51273.578 \\
\hline 10690 & 690 & 51305 & 68 & 51302.5046 \\
\hline 4050 & & 51314 & 109 & 51310 \\
\hline
\end{tabular}

